\title{
Appendix
}

for

\section{State Estimates for the Annual Cost of Foodborne Illness}

as published in

\author{
Journal of Food Protection \\ by Robert L. Scharff \\ (Scharff.8@osu.edu)
}

The Ohio State University

This appendix provides state specific estimates for the health costs associated with 30 identified foodborne illnesses, as well as costs associated with unspecified illnesses. For detailed descriptions of what these measures represent and how they were measured, please refer to the main article, "State Estimates for the Annual Cost of Foodborne Illness," in Journal of Food Protection. 
TABLE A1. Alabama Cost per Case of Foodborne Illness (by pathogen, \$2013)

\begin{tabular}{|c|c|c|c|c|c|c|c|}
\hline \multirow[b]{2}{*}{ Disease or Agent } & \multirow{2}{*}{$\begin{array}{l}\text { Illness } \\
\text { Incidence }^{1}\end{array}$} & \multicolumn{2}{|c|}{$\begin{array}{l}\text { Total Cost } \\
\text { (\$million) }\end{array}$} & \multicolumn{2}{|c|}{$\begin{array}{l}\text { Cost per } \\
\text { Resident }\end{array}$} & \multicolumn{2}{|c|}{$\begin{array}{c}\text { Cost } \\
\text { per Case }\end{array}$} \\
\hline & & Basic & Enhanced & Basic & Enhanced & Basic & Enhanced \\
\hline \multicolumn{8}{|l|}{ Bacterial } \\
\hline$\overline{\text { Bacillus cereus }}$ & 2.01 & 0.14 & 0.23 & 0.03 & 0.05 & 147 & 239 \\
\hline Brucella spp. & 0.01 & 0.11 & 0.15 & 0.02 & 0.03 & 15,973 & 21,605 \\
\hline Campylobacter spp. & 26.73 & 21.83 & 113.03 & 4.52 & 23.38 & 1,690 & 8,748 \\
\hline Clostridium botulinum & $<0.01$ & 1.07 & 1.37 & 0.22 & 0.28 & $1,267,196$ & $1,615,578$ \\
\hline Clostridium perfringens & 30.56 & 5.28 & 7.00 & 1.09 & 1.45 & 358 & 474 \\
\hline STEC O157:H7 & 1.37 & 6.34 & 6.74 & 1.31 & 1.39 & 9,540 & 10,142 \\
\hline STEC non-0157 & 2.45 & 0.91 & 1.66 & 0.19 & 0.34 & 770 & 1,402 \\
\hline ETEC & 0.57 & 0.20 & 0.37 & 0.04 & 0.08 & 727 & 1,359 \\
\hline Other diarrheogenic E. coli, & 0.38 & 0.13 & 0.25 & 0.03 & 0.05 & 726 & 1,360 \\
\hline Listeria monocytogenes & 0.03 & 19.42 & 19.65 & 4.02 & 4.06 & $1,198,500$ & $1,212,412$ \\
\hline Salmonella, Nontyphoidal & 42.15 & 81.42 & 237.10 & 16.84 & 49.05 & 3,996 & 11,637 \\
\hline S. enterica serotype Typhi & 0.02 & 0.03 & 0.09 & 0.01 & 0.02 & 3,994 & 12,196 \\
\hline Shigella, spp & 5.97 & 5.05 & 29.69 & 1.05 & 6.14 & 1,752 & 10,297 \\
\hline Staphylococcus aureus & 7.63 & 1.82 & 2.60 & 0.38 & 0.54 & 495 & 705 \\
\hline Streptococcus spp. Group A & 0.36 & 0.19 & 0.37 & 0.04 & 0.08 & 1,124 & 2,154 \\
\hline Vibrio cholerae, toxigenic & $<0.01$ & $<0.01$ & $<0.01$ & $<0.01$ & $<0.01$ & 1,323 & 2,299 \\
\hline Vibrio vulnificus & $<0.01$ & 4.58 & 4.58 & 0.95 & 0.95 & $2,613,528$ & $2,615,295$ \\
\hline Vibrio parahaemolyticus & 1.31 & 1.10 & 1.60 & 0.23 & 0.33 & 1,733 & 2,532 \\
\hline Vibrio spp., other & 0.66 & 1.29 & 1.55 & 0.27 & 0.32 & 4,035 & 4,833 \\
\hline Yersinia enterocolitica & 3.09 & 5.54 & 17.70 & 1.15 & 3.66 & 3,710 & 11,857 \\
\hline \multicolumn{8}{|l|}{ Parasitic } \\
\hline$\overline{\text { Cryptosporidium spp. }}$ & 1.46 & 1.25 & 2.07 & 0.26 & 0.43 & 1,779 & 2,933 \\
\hline Cyclospora cayetanensis & $<0.01$ & $<0.01$ & $<0.01$ & $<0.01$ & $<0.01$ & 805 & 1,510 \\
\hline Giardia intestinalis & 1.56 & 1.53 & 2.80 & 0.32 & 0.58 & 2,025 & 3,722 \\
\hline Toxoplasma gondii & 2.74 & 44.97 & 51.99 & 9.30 & 10.76 & 33,929 & 39,224 \\
\hline Trichinella spp. & $<0.01$ & 0.02 & 0.04 & $<0.01$ & 0.01 & 8,015 & 15,426 \\
\hline \multicolumn{8}{|l|}{ Viral } \\
\hline$\overline{\text { Astrovirus }}$ & 0.49 & 0.17 & 0.30 & 0.03 & 0.06 & 716 & 1,281 \\
\hline Hepatitis A virus & 0.02 & 0.26 & 0.28 & 0.05 & 0.06 & 33,649 & 35,199 \\
\hline Norovirus & 172.77 & 40.57 & 56.64 & 8.39 & 11.72 & 486 & 678 \\
\hline Rotavirus & 0.49 & 0.18 & 0.29 & 0.04 & 0.06 & 747 & 1,220 \\
\hline Sapovirus & 0.49 & 0.14 & 0.25 & 0.03 & 0.05 & 597 & 1,078 \\
\hline Known & & 245.55 & 560.39 & 50.80 & 115.93 & 1,664 & 3,797 \\
\hline Unknown & $1,214.46$ & 466.59 & 692.87 & 96.53 & 143.34 & 795 & 1,180 \\
\hline Total & & 712.14 & $1,253.26$ & 147.33 & 259.27 & 969 & 1,706 \\
\hline
\end{tabular}

${ }^{1}$ Incidence per 10,000 residents. 
TABLE A2. Alaska Cost per Case of Foodborne Illness (by pathogen, \$2013)

\begin{tabular}{|c|c|c|c|c|c|c|c|}
\hline \multirow[b]{2}{*}{ Disease or Agent } & \multirow{2}{*}{$\begin{array}{c}\text { Illness } \\
\text { Incidence }^{1} \\
\end{array}$} & \multicolumn{2}{|c|}{$\begin{array}{l}\text { Total Cost } \\
\text { (\$million) }\end{array}$} & \multicolumn{2}{|c|}{$\begin{array}{l}\text { Cost per } \\
\text { Resident }\end{array}$} & \multicolumn{2}{|c|}{$\begin{array}{c}\text { Cost } \\
\text { per Case }\end{array}$} \\
\hline & & Basic & Enhanced & Basic & Enhanced & Basic 1 & Enhanced \\
\hline \multicolumn{8}{|l|}{ Bacterial } \\
\hline$\overline{\text { Bacillus cereus }}$ & 2.01 & 0.03 & 0.05 & 0.04 & 0.07 & 208 & 339 \\
\hline Brucella spp. & 0.03 & 0.05 & 0.06 & 0.06 & 0.08 & 22,063 & 30,116 \\
\hline Campylobacter spp. & 26.73 & 4.67 & 24.66 & 6.35 & 33.54 & 2,377 & 12,547 \\
\hline Clostridium botulinum & $<0.01$ & 0.23 & 0.29 & 0.31 & 0.40 & $1,784,957$ & $2,287,041$ \\
\hline Clostridium perfringens & 30.56 & 1.15 & 1.52 & 1.57 & 2.07 & 512 & 679 \\
\hline STEC O157:H7 & 0.63 & 0.62 & 0.66 & 0.85 & 0.90 & 13,469 & 14,326 \\
\hline STEC non-0157 & 1.12 & 0.09 & 0.17 & 0.12 & 0.23 & 1,105 & 2,007 \\
\hline ETEC & 0.57 & 0.04 & 0.08 & 0.06 & 0.11 & 1,058 & 1,960 \\
\hline Other diarrheogenic E. coli, & 0.38 & 0.03 & 0.05 & 0.04 & 0.07 & 1,058 & 1,962 \\
\hline Listeria monocytogenes & 0.02 & 2.65 & 2.68 & 3.61 & 3.65 & $1,703,437$ & $1,722,528$ \\
\hline Salmonella, spp., Nontyphoidal & 21.14 & 8.75 & 25.85 & 11.90 & 35.17 & 5,632 & 16,638 \\
\hline S. enterica serotype Typhi & 0.01 & $<0.01$ & 0.01 & 0.01 & 0.02 & 4,896 & 16,705 \\
\hline Shigella, spp & 0.63 & 0.12 & 0.69 & 0.16 & 0.93 & 2,488 & 14,799 \\
\hline Staphylococcus aureus & 7.63 & 0.39 & 0.56 & 0.53 & 0.76 & 695 & 994 \\
\hline Streptococcus spp. Group A & 0.36 & 0.04 & 0.08 & 0.06 & 0.11 & 1,651 & 3,119 \\
\hline Vibrio cholerae, toxigenic & $<0.01$ & $<0.01$ & $<0.01$ & $<0.01$ & $<0.01$ & 1,852 & 3,243 \\
\hline Vibrio vulnificus & $<0.01$ & 0.43 & 0.43 & 0.58 & 0.58 & $3,751,798$ & $3,754,325$ \\
\hline Vibrio parahaemolyticus & 0.56 & 0.10 & 0.15 & 0.14 & 0.20 & 2,501 & 3,640 \\
\hline Vibrio spp., other & 0.28 & 0.12 & 0.15 & 0.17 & 0.20 & 5,822 & 6,960 \\
\hline Yersinia enterocolitica & 3.09 & 1.22 & 3.88 & 1.66 & 5.28 & 5,365 & 17,093 \\
\hline \multicolumn{8}{|l|}{ Parasitic } \\
\hline$\overline{\text { Cryptosporidium spp. }}$ & 0.51 & 0.10 & 0.16 & 0.13 & 0.21 & 2,577 & 4,223 \\
\hline Cyclospora cayetanensis & 0.09 & 0.01 & 0.01 & 0.01 & 0.02 & 1,173 & 2,178 \\
\hline Giardia intestinalis & 4.87 & 1.06 & 1.92 & 1.44 & 2.62 & 2,957 & 5,377 \\
\hline Toxoplasma gondii & 2.74 & 9.62 & 11.14 & 13.08 & 15.16 & 47,709 & 55,280 \\
\hline Trichinella spp. & $<0.01$ & $<0.01$ & 0.01 & 0.01 & 0.01 & 11,520 & 22,100 \\
\hline \multicolumn{8}{|l|}{ Viral } \\
\hline$\overline{\text { Astrovirus }}$ & 0.49 & 0.04 & 0.07 & 0.05 & 0.09 & 1,017 & 1,823 \\
\hline Hepatitis A virus & 0.03 & 0.10 & 0.10 & 0.13 & 0.14 & 48,073 & 50,284 \\
\hline Norovirus & 172.77 & 8.67 & 12.15 & 11.79 & 16.53 & 682 & 957 \\
\hline Rotavirus & 0.49 & 0.04 & 0.06 & 0.05 & 0.08 & 1,016 & 1,691 \\
\hline Sapovirus & 0.49 & 0.03 & 0.06 & 0.04 & 0.08 & 854 & 1,540 \\
\hline Known & & 40.39 & 87.72 & 54.95 & 119.32 & 1,975 & 4,289 \\
\hline Unknown & $1,214.46$ & 101.37 & 150.46 & 137.89 & 204.67 & 1,135 & 1,685 \\
\hline Total & & 141.77 & 238.18 & 192.84 & 323.99 & 1,292 & 2,171 \\
\hline
\end{tabular}

${ }^{1}$ Incidence per 10,000 residents. 
TABLE A3. Arizona Cost per Case of Foodborne Illness (by pathogen, \$2013)

\begin{tabular}{|c|c|c|c|c|c|c|c|}
\hline \multirow[b]{2}{*}{ Disease or Agent } & \multirow{2}{*}{$\begin{array}{l}\text { Illness } \\
\text { Incidence }^{1}\end{array}$} & \multicolumn{2}{|c|}{$\begin{array}{l}\text { Total Cost } \\
\text { (\$million) }\end{array}$} & \multicolumn{2}{|c|}{$\begin{array}{l}\text { Cost per } \\
\text { Resident }\end{array}$} & \multicolumn{2}{|c|}{$\begin{array}{c}\text { Cost } \\
\text { per Case }\end{array}$} \\
\hline & & Basic & Enhanced & Basic & Enhanced & Basic 1 & Enhanced \\
\hline \multicolumn{8}{|l|}{ Bacterial } \\
\hline$\overline{\text { Bacillus cereus }}$ & 2.01 & 0.21 & 0.34 & 0.03 & 0.05 & 161 & 258 \\
\hline Brucella spp. & 0.05 & 0.54 & 0.73 & 0.08 & 0.11 & 17,581 & 23,574 \\
\hline Campylobacter spp. & 26.73 & 32.94 & 167.52 & 4.97 & 25.28 & 1,860 & 9,457 \\
\hline Clostridium botulinum & $<0.01$ & 1.60 & 2.03 & 0.24 & 0.31 & $1,375,347$ & $1,750,482$ \\
\hline Clostridium perfringens & 30.56 & 7.89 & 10.39 & 1.19 & 1.57 & 390 & 513 \\
\hline STEC O157:H7 & 1.77 & 12.15 & 12.90 & 1.83 & 1.95 & 10,363 & 11,000 \\
\hline STEC non-0157 & 3.16 & 1.79 & 3.20 & 0.27 & 0.48 & 857 & 1,527 \\
\hline ETEC & 0.57 & 0.30 & 0.55 & 0.05 & 0.08 & 808 & 1,478 \\
\hline Other diarrheogenic E. coli, & 0.38 & 0.20 & 0.37 & 0.03 & 0.06 & 807 & 1,479 \\
\hline Listeria monocytogenes & 0.03 & 28.36 & 28.67 & 4.28 & 4.33 & $1,298,210$ & $1,312,116$ \\
\hline Salmonella, spp., Nontyphoidal & 29.36 & 85.04 & 245.00 & 12.83 & 36.97 & 4,371 & 12,593 \\
\hline S. enterica serotype Typhi & 0.03 & 0.08 & 0.25 & 0.01 & 0.04 & 4,510 & 13,329 \\
\hline Shigella, spp & 6.39 & 8.20 & 47.15 & 1.24 & 7.12 & 1,936 & 11,133 \\
\hline Staphylococcus aureus & 7.63 & 2.75 & 3.87 & 0.41 & 0.58 & 544 & 766 \\
\hline Streptococcus spp. Group A & 0.36 & 0.29 & 0.55 & 0.04 & 0.08 & 1,250 & 2,342 \\
\hline Vibrio cholerae, toxigenic & $<0.01$ & $<0.01$ & $<0.01$ & $<0.01$ & $<0.01$ & 1,477 & 2,511 \\
\hline Vibrio vulnificus & $<0.01$ & 6.28 & 6.29 & 0.95 & 0.95 & $2,821,931$ & $2,823,812$ \\
\hline Vibrio parahaemolyticus & 1.21 & 1.53 & 2.21 & 0.23 & 0.33 & 1,902 & 2,748 \\
\hline Vibrio spp., other & 0.61 & 1.79 & 2.13 & 0.27 & 0.32 & 4,385 & 5,231 \\
\hline Yersinia enterocolitica & 3.09 & 8.31 & 26.24 & 1.25 & 3.96 & 4,061 & 12,820 \\
\hline \multicolumn{8}{|l|}{ Parasitic } \\
\hline$\overline{\text { Cryptosporidium spp. }}$ & 0.45 & 0.58 & 0.95 & 0.09 & 0.14 & 1,966 & 3,189 \\
\hline Cyclospora cayetanensis & 0.01 & 0.01 & 0.01 & $<0.01$ & $<0.01$ & 895 & 1,642 \\
\hline Giardia intestinalis & 0.96 & 1.43 & 2.57 & 0.22 & 0.39 & 2,250 & 4,049 \\
\hline Toxoplasma gondii & 2.74 & 67.20 & 77.44 & 10.14 & 11.69 & 36,981 & 42,615 \\
\hline Trichinella spp. & $<0.01$ & 0.03 & 0.05 & $<0.01$ & 0.01 & 8,947 & 16,814 \\
\hline \multicolumn{8}{|l|}{ Viral } \\
\hline$\overline{\text { Astrovirus }}$ & 0.49 & 0.26 & 0.45 & 0.04 & 0.07 & 797 & 1,396 \\
\hline Hepatitis A virus & 0.10 & 2.42 & 2.52 & 0.36 & 0.38 & 36,428 & 38,072 \\
\hline Norovirus & 172.77 & 61.10 & 84.47 & 9.22 & 12.75 & 534 & 738 \\
\hline Rotavirus & 0.49 & 0.27 & 0.43 & 0.04 & 0.07 & 835 & 1,337 \\
\hline Sapovirus & 0.49 & 0.21 & 0.38 & 0.03 & 0.06 & 664 & 1,174 \\
\hline Known & & 333.79 & 729.68 & 50.37 & 110.11 & 1,722 & 3,765 \\
\hline Unknown & $1,214.46$ & 703.39 & 1032.31 & 106.15 & 155.78 & 874 & 1,283 \\
\hline Total & & $1,037.18$ & $1,761.98$ & 156.52 & 265.89 & 1,039 & 1,765 \\
\hline
\end{tabular}

${ }^{1}$ Incidence per 10,000 residents. 
TABLE A4. Arkansas Cost per Case of Foodborne Illness (by pathogen, \$2013)

\begin{tabular}{|c|c|c|c|c|c|c|c|}
\hline \multirow[b]{2}{*}{ Disease or Agent } & \multirow{2}{*}{$\begin{array}{l}\text { Illness } \\
\text { Incidence }^{1}\end{array}$} & \multicolumn{2}{|c|}{$\begin{array}{l}\text { Total Cost } \\
\text { (\$million) }\end{array}$} & \multicolumn{2}{|c|}{$\begin{array}{l}\text { Cost per } \\
\text { Resident }\end{array}$} & \multicolumn{2}{|c|}{$\begin{array}{c}\text { Cost } \\
\text { per Case }\end{array}$} \\
\hline & & Basic & Enhanced & Basic & Enhanced & Basic 1 & Enhanced \\
\hline \multicolumn{8}{|l|}{ Bacterial } \\
\hline$\overline{\text { Bacillus cereus }}$ & 2.01 & 0.08 & 0.13 & 0.03 & 0.04 & 139 & 221 \\
\hline Brucella spp. & 0.02 & 0.08 & 0.11 & 0.03 & 0.04 & 14,461 & 19,484 \\
\hline Campylobacter spp. & 26.73 & 12.20 & 62.51 & 4.12 & 21.12 & 1,543 & 7,902 \\
\hline Clostridium botulinum & $<0.01$ & 0.59 & 0.75 & 0.20 & 0.25 & $1,141,198$ & $1,455,166$ \\
\hline Clostridium perfringens & 30.56 & 2.98 & 3.92 & 1.01 & 1.32 & 330 & 434 \\
\hline STEC O157:H7 & 1.89 & 4.81 & 5.10 & 1.62 & 1.72 & 8,612 & 9,146 \\
\hline STEC non-0157 & 3.37 & 0.71 & 1.27 & 0.24 & 0.43 & 715 & 1,277 \\
\hline ETEC & 0.57 & 0.11 & 0.21 & 0.04 & 0.07 & 677 & 1,239 \\
\hline Other diarrheogenic E. coli, & 0.38 & 0.08 & 0.14 & 0.03 & 0.05 & 677 & 1,240 \\
\hline Listeria monocytogenes & 0.03 & 8.46 & 8.55 & 2.86 & 2.89 & $1,080,509$ & $1,092,260$ \\
\hline Salmonella, spp., Nontyphoidal & 62.09 & 66.63 & 193.09 & 22.51 & 65.25 & 3,626 & 10,507 \\
\hline S. enterica serotype Typhi & 0.01 & 0.02 & 0.05 & 0.01 & 0.02 & 3,586 & 10,968 \\
\hline Shigella, spp & 4.25 & 2.02 & 11.71 & 0.68 & 3.96 & 1,607 & 9,305 \\
\hline Staphylococcus aureus & 7.63 & 1.03 & 1.45 & 0.35 & 0.49 & 455 & 642 \\
\hline Streptococcus spp. Group A & 0.36 & 0.11 & 0.21 & 0.04 & 0.07 & 1,047 & 1,962 \\
\hline Vibrio cholerae, toxigenic & $<0.01$ & $<0.01$ & $<0.01$ & $<0.01$ & $<0.01$ & 1,222 & 2,089 \\
\hline Vibrio vulnificus & $<0.01$ & 1.99 & 1.99 & 0.67 & 0.67 & $2,357,282$ & $2,358,859$ \\
\hline Vibrio parahaemolyticus & 1.03 & 0.48 & 0.70 & 0.16 & 0.24 & 1,589 & 2,299 \\
\hline Vibrio spp., other & 0.52 & 0.57 & 0.68 & 0.19 & 0.23 & 3,666 & 4,376 \\
\hline Yersinia enterocolitica & 3.09 & 3.10 & 9.80 & 1.05 & 3.31 & 3,390 & 10,721 \\
\hline \multicolumn{8}{|l|}{ Parasitic } \\
\hline$\overline{\text { Cryptosporidium spp. }}$ & 1.05 & 0.51 & 0.83 & 0.17 & 0.28 & 1,638 & 2,664 \\
\hline Cyclospora cayetanensis & 0.04 & 0.01 & 0.02 & $<0.01$ & 0.01 & 750 & 1,376 \\
\hline Giardia intestinalis & 1.63 & 0.91 & 1.63 & 0.31 & 0.55 & 1,876 & 3,384 \\
\hline Toxoplasma gondii & 2.74 & 24.86 & 28.70 & 8.40 & 9.70 & 30,639 & 35,361 \\
\hline Trichinella spp. & $<0.01$ & 0.01 & 0.02 & $<0.01$ & 0.01 & 7,410 & 14,007 \\
\hline \multicolumn{8}{|l|}{ Viral } \\
\hline$\overline{\text { Astrovirus }}$ & 0.49 & 0.10 & 0.17 & 0.03 & 0.06 & 663 & 1,166 \\
\hline Hepatitis A virus & 0.04 & 0.32 & 0.34 & 0.11 & 0.11 & 30,385 & 31,764 \\
\hline Norovirus & 172.77 & 22.80 & 31.55 & 7.71 & 10.66 & 446 & 617 \\
\hline Rotavirus & 0.49 & 0.10 & 0.16 & 0.03 & 0.05 & 686 & 1,107 \\
\hline Sapovirus & 0.49 & 0.08 & 0.14 & 0.03 & 0.05 & 554 & 982 \\
\hline Known & & 155.75 & 365.92 & 52.63 & 123.65 & 1,623 & 3,813 \\
\hline Unknown & $1,214.46$ & 262.43 & 385.60 & 88.68 & 130.30 & 730 & 1,073 \\
\hline Total & & 418.18 & 751.53 & 141.31 & 253.95 & 918 & 1,650 \\
\hline
\end{tabular}

${ }^{1}$ Incidence per 10,000 residents. 
TABLE A5. California Cost per Case of Foodborne Illness (by pathogen, \$2013)

\begin{tabular}{|c|c|c|c|c|c|c|c|}
\hline \multirow[b]{2}{*}{ Disease or Agent } & \multirow{2}{*}{$\begin{array}{c}\text { Illness } \\
\text { Incidence }^{1} \\
\end{array}$} & \multicolumn{2}{|c|}{$\begin{array}{l}\text { Total Cost } \\
\text { (\$million) }\end{array}$} & \multicolumn{2}{|c|}{$\begin{array}{l}\text { Cost per } \\
\text { Resident }\end{array}$} & \multicolumn{2}{|c|}{$\begin{array}{c}\text { Cost } \\
\text { per Case }\end{array}$} \\
\hline & & Basic & Enhanced & Basic & Enhanced & Basic 1 & Enhanced \\
\hline \multicolumn{8}{|l|}{ Bacterial } \\
\hline$\overline{\text { Bacillus cereus }}$ & 2.01 & 1.49 & 2.37 & 0.04 & 0.06 & 194 & 308 \\
\hline Brucella spp. & 0.05 & 4.26 & 5.66 & 0.11 & 0.15 & 21,454 & 28,514 \\
\hline Campylobacter spp. & 26.73 & 233.28 & $1,167.00$ & 6.09 & 30.44 & 2,277 & 11,389 \\
\hline Clostridium botulinum & $<0.01$ & 11.12 & 14.14 & 0.29 & 0.37 & $1,657,092$ & $2,107,239$ \\
\hline Clostridium perfringens & 30.56 & 55.07 & 72.01 & 1.44 & 1.88 & 470 & 615 \\
\hline STEC 0157:H7 & 1.33 & 63.93 & 67.74 & 1.67 & 1.77 & 12,501 & 13,246 \\
\hline STEC non-0157 & 2.38 & 9.75 & 16.92 & 0.25 & 0.44 & 1,068 & 1,853 \\
\hline ETEC & 0.57 & 2.19 & 3.89 & 0.06 & 0.10 & 1,009 & 1,794 \\
\hline Other diarrheogenic E. coli, & 0.38 & 1.47 & 2.61 & 0.04 & 0.07 & 1,009 & 1,796 \\
\hline Listeria monocytogenes & 0.06 & 330.57 & 333.68 & 8.62 & 8.70 & $1,563,922$ & $1,578,639$ \\
\hline Salmonella, spp., Nontyphoidal & 25.59 & 521.63 & $1,488.29$ & 13.61 & 38.83 & 5,318 & 15,173 \\
\hline S. enterica serotype Typhi & 0.10 & 2.06 & 6.00 & 0.05 & 0.16 & 5,516 & 16,074 \\
\hline Shigella, spp & 3.17 & 29.02 & 163.01 & 0.76 & 4.25 & 2,388 & 13,416 \\
\hline Staphylococcus aureus & 7.63 & 19.37 & 26.99 & 0.51 & 0.70 & 662 & 923 \\
\hline Streptococcus spp. Group A & 0.36 & 2.13 & 3.87 & 0.06 & 0.10 & 1,569 & 2,847 \\
\hline Vibrio cholerae, toxigenic & $<0.01$ & 0.02 & 0.04 & $<0.01$ & $<0.01$ & 1,836 & 3,047 \\
\hline Vibrio vulnificus & $<0.01$ & 47.29 & 47.32 & 1.23 & 1.23 & $3,394,739$ & $3,396,956$ \\
\hline Vibrio parahaemolyticus & 1.31 & 11.75 & 16.74 & 0.31 & 0.44 & 2,337 & 3,328 \\
\hline Vibrio spp., other & 0.66 & 13.56 & 16.09 & 0.35 & 0.42 & 5,323 & 6,314 \\
\hline Yersinia enterocolitica & 3.09 & 59.00 & 183.13 & 1.54 & 4.78 & 4,983 & 15,465 \\
\hline \multicolumn{8}{|l|}{ Parasitic } \\
\hline$\overline{\text { Cryptosporidium spp. }}$ & 0.68 & 6.40 & 10.16 & 0.17 & 0.27 & 2,440 & 3,873 \\
\hline Cyclospora cayetanensis & $<0.01$ & 0.01 & 0.02 & $<0.01$ & $<0.01$ & 1,118 & 1,993 \\
\hline Giardia intestinalis & 1.84 & 19.90 & 34.77 & 0.52 & 0.91 & 2,819 & 4,926 \\
\hline Toxoplasma gondii & 2.74 & 470.71 & 540.45 & 12.28 & 14.10 & 44,781 & 51,417 \\
\hline Trichinella spp. & $<0.01$ & 0.21 & 0.39 & 0.01 & 0.01 & 11,230 & 20,462 \\
\hline \multicolumn{8}{|l|}{ Viral } \\
\hline$\overline{\text { Astrovirus }}$ & 0.49 & 1.86 & 3.17 & 0.05 & 0.08 & 992 & 1,694 \\
\hline Hepatitis A virus & 0.07 & 12.00 & 12.53 & 0.31 & 0.33 & 43,904 & 45,832 \\
\hline Norovirus & 172.77 & 430.36 & 588.58 & 11.23 & 15.35 & 650 & 889 \\
\hline Rotavirus & 0.49 & 1.93 & 3.03 & 0.05 & 0.08 & 1,032 & 1,619 \\
\hline Sapovirus & 0.49 & 1.55 & 2.66 & 0.04 & 0.07 & 826 & 1,424 \\
\hline Known & & $2,363.87$ & $4,833.26$ & 61.67 & 126.09 & 2,160 & 4,416 \\
\hline Unknown & $1,214.46$ & $4,991.31$ & $7,220.06$ & 130.21 & 188.35 & 1,072 & 1,551 \\
\hline Total & & $7,355.18$ & $12,053.32$ & 191.88 & 314.44 & 1,279 & 2,096 \\
\hline
\end{tabular}

${ }^{1}$ Incidence per 10,000 residents. 
TABLE A6. Colorado Cost per Case of Foodborne Illness (by pathogen, \$2013)

\begin{tabular}{|c|c|c|c|c|c|c|c|}
\hline \multirow[b]{2}{*}{ Disease or Agent } & \multirow{2}{*}{$\begin{array}{c}\text { Illness } \\
\text { Incidence }^{1} \\
\end{array}$} & \multicolumn{2}{|c|}{$\begin{array}{l}\text { Total Cost } \\
\text { (\$million) }\end{array}$} & \multicolumn{2}{|c|}{$\begin{array}{l}\text { Cost per } \\
\text { Resident }\end{array}$} & \multicolumn{2}{|c|}{$\begin{array}{l}\text { Cost per } \\
\text { Case }\end{array}$} \\
\hline & & Basic & Enhanced & Basic & Enhanced & Basic 1 & Enhanced \\
\hline \multicolumn{8}{|l|}{ Bacterial } \\
\hline$\overline{\text { Bacillus cereus }}$ & 2.01 & 0.20 & 0.32 & 0.04 & 0.06 & 192 & 305 \\
\hline Brucella spp. & 0.02 & 0.24 & 0.32 & 0.05 & 0.06 & 20,652 & 27,694 \\
\hline Campylobacter spp. & 26.73 & 31.39 & 160.12 & 5.96 & 30.39 & 2,229 & 11,370 \\
\hline Clostridium botulinum & $<0.01$ & 1.50 & 1.92 & 0.28 & 0.36 & $1,625,814$ & $2,077,408$ \\
\hline Clostridium perfringens & 30.56 & 7.56 & 9.88 & 1.43 & 1.87 & 470 & 614 \\
\hline STEC 0157:H7 & 3.47 & 22.46 & 23.82 & 4.26 & 4.52 & 12,291 & 13,032 \\
\hline STEC non-0157 & 6.19 & 3.47 & 6.02 & 0.66 & 1.14 & 1,064 & 1,845 \\
\hline ETEC & 0.57 & 0.30 & 0.54 & 0.06 & 0.10 & 1,018 & 1,799 \\
\hline Other diarrheogenic E. coli, & 0.38 & 0.20 & 0.36 & 0.04 & 0.07 & 1,018 & 1,801 \\
\hline Listeria monocytogenes & 0.05 & 40.85 & 41.23 & 7.75 & 7.83 & $1,547,582$ & $1,561,729$ \\
\hline Salmonella, spp., Nontyphoidal & 23.51 & 64.61 & 187.02 & 12.26 & 35.50 & 5,217 & 15,100 \\
\hline S. enterica serotype Typhi & 0.05 & 0.12 & 0.38 & 0.02 & 0.07 & 4,775 & 15,360 \\
\hline Shigella, spp & 2.29 & 2.85 & 16.22 & 0.54 & 3.08 & 2,357 & 13,418 \\
\hline Staphylococcus aureus & 7.63 & 2.61 & 3.65 & 0.49 & 0.69 & 648 & 908 \\
\hline Streptococcus spp. Group A & 0.36 & 0.30 & 0.54 & 0.06 & 0.10 & 1,593 & 2,866 \\
\hline Vibrio cholerae, toxigenic & $<0.01$ & $<0.01$ & $<0.01$ & $<0.01$ & $<0.01$ & 1,787 & 2,992 \\
\hline Vibrio vulnificus & $<0.01$ & 3.23 & 3.23 & 0.61 & 0.61 & $3,391,898$ & $3,394,109$ \\
\hline Vibrio parahaemolyticus & 0.65 & 0.80 & 1.14 & 0.15 & 0.22 & 2,342 & 3,329 \\
\hline Vibrio spp., other & 0.33 & 0.93 & 1.10 & 0.18 & 0.21 & 5,340 & 6,326 \\
\hline Yersinia enterocolitica & 3.09 & 8.14 & 25.24 & 1.55 & 4.79 & 5,003 & 15,511 \\
\hline \multicolumn{8}{|l|}{ Parasitic } \\
\hline$\overline{\text { Cryptosporidium spp. }}$ & 1.62 & 2.09 & 3.30 & 0.40 & 0.63 & 2,451 & 3,877 \\
\hline Cyclospora cayetanensis & 0.07 & 0.04 & 0.08 & 0.01 & 0.01 & 1,128 & 1,999 \\
\hline Giardia intestinalis & 3.50 & 5.25 & 9.12 & 1.00 & 1.73 & 2,849 & 4,947 \\
\hline Toxoplasma gondii & 2.74 & 63.35 & 72.91 & 12.02 & 13.84 & 43,849 & 50,466 \\
\hline Trichinella spp. & $<0.01$ & 0.03 & 0.05 & 0.01 & 0.01 & 11,186 & 20,383 \\
\hline \multicolumn{8}{|l|}{ Viral } \\
\hline Astrovirus & 0.49 & 0.25 & 0.43 & 0.05 & 0.08 & 980 & 1,679 \\
\hline Hepatitis A virus & 0.03 & 0.77 & 0.80 & 0.15 & 0.15 & 43,659 & 45,579 \\
\hline Norovirus & 172.77 & 57.91 & 79.55 & 10.99 & 15.10 & 636 & 874 \\
\hline Rotavirus & 0.49 & 0.25 & 0.40 & 0.05 & 0.08 & 980 & 1,564 \\
\hline Sapovirus & 0.49 & 0.21 & 0.36 & 0.04 & 0.07 & 821 & 1,416 \\
\hline Known & & 321.93 & 650.05 & 61.11 & 123.39 & 2,107 & 4,254 \\
\hline Unknown & $1,214.46$ & 681.41 & 986.37 & 129.34 & 187.22 & 1,065 & 1,542 \\
\hline Total & & $1,003.34$ & $1,636.42$ & 190.45 & 310.61 & 1,266 & 2,064 \\
\hline
\end{tabular}

${ }^{1}$ Incidence per 10,000 residents. 
TABLE A7. Connecticut Cost per Case of Foodborne Illness (by pathogen, \$2013)

\begin{tabular}{|c|c|c|c|c|c|c|c|}
\hline \multirow[b]{2}{*}{ Disease or Agent } & \multirow{2}{*}{$\begin{array}{c}\text { Illness } \\
\text { Incidence }^{1}\end{array}$} & \multicolumn{2}{|c|}{$\begin{array}{l}\text { Total Cost } \\
\text { (\$million) }\end{array}$} & \multicolumn{2}{|c|}{$\begin{array}{l}\text { Cost per } \\
\text { Resident }\end{array}$} & \multicolumn{2}{|c|}{$\begin{array}{c}\text { Cost } \\
\text { per Case }\end{array}$} \\
\hline & & Basic & Enhanced & Basic & Enhanced & Basic 1 & Enhanced \\
\hline \multicolumn{8}{|l|}{ Bacterial } \\
\hline$\overline{\text { Bacillus cereus }}$ & 2.01 & 0.15 & 0.24 & 0.04 & 0.07 & 206 & 335 \\
\hline Brucella spp. & $<0.01$ & $<0.01$ & $<0.01$ & $<0.01$ & $<0.01$ & 22,293 & 30,261 \\
\hline Campylobacter spp. & 26.73 & 23.24 & 121.62 & 6.46 & 33.82 & 2,418 & 12,652 \\
\hline Clostridium botulinum & $<0.01$ & 1.13 & 1.45 & 0.31 & 0.40 & $1,792,615$ & $2,298,104$ \\
\hline Clostridium perfringens & 30.56 & 5.67 & 7.46 & 1.58 & 2.08 & 516 & 679 \\
\hline STEC 0157:H7 & 2.26 & 10.99 & 11.68 & 3.06 & 3.25 & 13,544 & 14,386 \\
\hline STEC non-0157 & 4.03 & 1.66 & 2.95 & 0.46 & 0.82 & 1,146 & 2,034 \\
\hline ETEC & 0.57 & 0.22 & 0.41 & 0.06 & 0.11 & 1,103 & 1,990 \\
\hline Other diarrheogenic E. coli, & 0.38 & 0.15 & 0.27 & 0.04 & 0.08 & 1,103 & 1,993 \\
\hline Listeria monocytogenes & 0.11 & 64.92 & 65.57 & 18.05 & 18.23 & $1,714,485$ & $1,731,610$ \\
\hline Salmonella, spp., Nontyphoidal & 27.28 & 55.93 & 164.50 & 15.55 & 45.74 & 5,702 & 16,772 \\
\hline S. enterica serotype Typhi & 0.08 & 0.13 & 0.47 & 0.04 & 0.13 & 4,796 & 16,659 \\
\hline Shigella, spp & 1.22 & 1.12 & 6.53 & 0.31 & 1.82 & 2,554 & 14,940 \\
\hline Staphylococcus aureus & 7.63 & 1.92 & 2.73 & 0.54 & 0.76 & 702 & 996 \\
\hline Streptococcus spp. Group A & 0.36 & 0.22 & 0.41 & 0.06 & 0.11 & 1,732 & 3,177 \\
\hline Vibrio cholerae, toxigenic & 0.01 & $<0.01$ & 0.01 & $<0.01$ & $<0.01$ & 1,906 & 3,274 \\
\hline Vibrio vulnificus & 0.01 & 9.93 & 9.94 & 2.76 & 2.76 & $3,781,409$ & $3,783,911$ \\
\hline Vibrio parahaemolyticus & 2.64 & 2.43 & 3.50 & 0.68 & 0.97 & 2,568 & 3,688 \\
\hline Vibrio spp., other & 1.34 & 2.84 & 3.38 & 0.79 & 0.94 & 5,919 & 7,039 \\
\hline Yersinia enterocolitica & 3.09 & 6.12 & 19.20 & 1.70 & 5.34 & 5,506 & 17,285 \\
\hline \multicolumn{8}{|l|}{ Parasitic } \\
\hline$\overline{\text { Cryptosporidium spp. }}$ & 1.06 & 1.02 & 1.64 & 0.28 & 0.46 & 2,673 & 4,293 \\
\hline Cyclospora cayetanensis & 1.81 & 0.80 & 1.44 & 0.22 & 0.40 & 1,223 & 2,212 \\
\hline Giardia intestinalis & 3.18 & 3.54 & 6.27 & 0.98 & 1.74 & 3,097 & 5,479 \\
\hline Toxoplasma gondii & 2.74 & 47.43 & 54.82 & 13.19 & 15.24 & 48,099 & 55,588 \\
\hline Trichinella spp. & $<0.01$ & 0.02 & 0.04 & 0.01 & 0.01 & 12,049 & 22,480 \\
\hline \multicolumn{8}{|l|}{ Viral } \\
\hline$\overline{\text { Astrovirus }}$ & 0.49 & 0.18 & 0.32 & 0.05 & 0.09 & 1,052 & 1,845 \\
\hline Hepatitis A virus & 0.05 & 0.88 & 0.92 & 0.24 & 0.25 & 48,459 & 50,637 \\
\hline Norovirus & 172.77 & 42.82 & 59.60 & 11.91 & 16.57 & 689 & 959 \\
\hline Rotavirus & 0.49 & 0.18 & 0.30 & 0.05 & 0.08 & 1,033 & 1,696 \\
\hline Sapovirus & 0.49 & 0.16 & 0.27 & 0.04 & 0.08 & 884 & 1,559 \\
\hline Known & & 285.82 & 547.92 & 79.48 & 152.36 & 2,710 & 5,194 \\
\hline Unknown & $1,214.46$ & 506.82 & 743.17 & 140.94 & 206.66 & 1,160 & 1,702 \\
\hline Total & & 792.64 & $1,291.08$ & 220.42 & 359.02 & 1,462 & 2,381 \\
\hline
\end{tabular}

${ }^{1}$ Incidence per 10,000 residents. 
TABLE A8. Delaware Cost per Case of Foodborne Illness (by pathogen, \$2013)

\begin{tabular}{|c|c|c|c|c|c|c|c|}
\hline \multirow[b]{2}{*}{ Disease or Agent } & \multirow{2}{*}{$\begin{array}{l}\text { Illness } \\
\text { Incidence }^{1}\end{array}$} & \multicolumn{2}{|c|}{$\begin{array}{l}\text { Total Cost } \\
\text { (\$million) }\end{array}$} & \multicolumn{2}{|c|}{$\begin{array}{c}\text { Cost } \\
\text { per Resident }\end{array}$} & \multicolumn{2}{|c|}{$\begin{array}{c}\text { Cost } \\
\text { per Case }\end{array}$} \\
\hline & & Basic & Enhanced & Basic & Enhanced & Basic 1 & Enhanced \\
\hline \multicolumn{8}{|l|}{ Bacterial } \\
\hline$\overline{\text { Bacillus cereus }}$ & 2.01 & 0.03 & 0.05 & 0.04 & 0.06 & 181 & 275 \\
\hline Brucella spp. & 0.03 & 0.05 & 0.07 & 0.05 & 0.07 & 18,240 & 24,103 \\
\hline Campylobacter spp. & 26.73 & 4.93 & 24.31 & 5.32 & 26.26 & 1,992 & 9,822 \\
\hline Clostridium botulinum & $<0.01$ & 0.23 & 0.29 & 0.25 & 0.31 & $1,404,035$ & $1,791,188$ \\
\hline Clostridium perfringens & 30.56 & 1.19 & 1.53 & 1.29 & 1.65 & 422 & 541 \\
\hline STEC O157:H7 & 1.98 & 1.96 & 2.07 & 2.11 & 2.23 & 10,663 & 11,272 \\
\hline STEC non-0157 & 3.54 & 0.32 & 0.53 & 0.35 & 0.58 & 982 & 1,626 \\
\hline ETEC & 0.57 & 0.05 & 0.08 & 0.05 & 0.09 & 941 & 1,586 \\
\hline Other diarrheogenic E. coli, & 0.38 & 0.03 & 0.06 & 0.04 & 0.06 & 941 & 1,587 \\
\hline Listeria monocytogenes & 0.06 & 6.84 & 6.89 & 7.38 & 7.44 & $1,335,791$ & $1,345,314$ \\
\hline Salmonella, spp., Nontyphoidal & 32.08 & 13.64 & 38.76 & 14.73 & 41.86 & 4,593 & 13,052 \\
\hline S. enterica serotype Typhi & 0.05 & 0.02 & 0.06 & 0.02 & 0.06 & 4,298 & 13,339 \\
\hline Shigella, spp & 6.23 & 1.23 & 6.68 & 1.32 & 7.22 & 2,127 & 11,599 \\
\hline Staphylococcus aureus & 7.63 & 0.41 & 0.56 & 0.45 & 0.61 & 586 & 800 \\
\hline Streptococcus spp. Group A & 0.36 & 0.05 & 0.08 & 0.05 & 0.09 & 1,472 & 2,522 \\
\hline Vibrio cholerae, toxigenic & 0.01 & $<0.01$ & $<0.01$ & $<0.01$ & $<0.01$ & 1,643 & 2,636 \\
\hline Vibrio vulnificus & 0.01 & 1.83 & 1.83 & 1.98 & 1.98 & $2,919,751$ & $2,921,594$ \\
\hline Vibrio parahaemolyticus & 2.45 & 0.48 & 0.66 & 0.51 & 0.71 & 2,096 & 2,910 \\
\hline Vibrio spp., other & 1.24 & 0.54 & 0.63 & 0.58 & 0.68 & 4,676 & 5,489 \\
\hline Yersinia enterocolitica & 3.09 & 1.27 & 3.84 & 1.37 & 4.15 & 4,448 & 13,421 \\
\hline \multicolumn{8}{|l|}{ Parasitic } \\
\hline$\overline{\text { Cryptosporidium spp. }}$ & 0.86 & 0.18 & 0.27 & 0.19 & 0.29 & 2,220 & 3,397 \\
\hline Cyclospora cayetanensis & 0.18 & 0.02 & 0.03 & 0.02 & 0.03 & 1,044 & 1,762 \\
\hline Giardia intestinalis & 1.60 & 0.39 & 0.64 & 0.42 & 0.69 & 2,611 & 4,341 \\
\hline Toxoplasma gondii & 2.74 & 9.69 & 11.09 & 10.47 & 11.98 & 38,189 & 43,696 \\
\hline Trichinella spp. & $<0.01$ & $<0.01$ & 0.01 & 0.01 & 0.01 & 10,278 & 17,886 \\
\hline \multicolumn{8}{|l|}{ Viral } \\
\hline$\overline{\text { Astrovirus }}$ & 0.49 & 0.04 & 0.07 & 0.04 & 0.07 & 903 & 1,479 \\
\hline Hepatitis A virus & 0.03 & 0.12 & 0.13 & 0.13 & 0.14 & 37,753 & 39,340 \\
\hline Norovirus & 172.77 & 9.16 & 12.30 & 9.90 & 13.28 & 573 & 769 \\
\hline Rotavirus & 0.49 & 0.04 & 0.06 & 0.04 & 0.07 & 898 & 1,380 \\
\hline Sapovirus & 0.49 & 0.03 & 0.06 & 0.04 & 0.06 & 758 & 1,249 \\
\hline Known & & 54.78 & 113.63 & 59.17 & 122.75 & 1,981 & 4,110 \\
\hline Unknown & $1,214.46$ & 107.82 & 152.02 & 116.46 & 164.21 & 959 & 1,352 \\
\hline Total & & 162.59 & 265.65 & 175.63 & 286.96 & 1,161 & 1,897 \\
\hline
\end{tabular}

${ }^{1}$ Incidence per 10,000 residents. 
TABLE A9. District of Columbia Cost per Case of Foodborne Illness (by pathogen, \$2013)

\begin{tabular}{|c|c|c|c|c|c|c|c|}
\hline \multirow[b]{2}{*}{ Disease or Agent } & \multirow{2}{*}{$\begin{array}{l}\text { Illness } \\
\text { Incidence }^{1}\end{array}$} & \multicolumn{2}{|c|}{$\begin{array}{l}\text { Total Cost } \\
\text { (\$million) }\end{array}$} & \multicolumn{2}{|c|}{$\begin{array}{l}\text { Cost per } \\
\text { Resident }\end{array}$} & \multicolumn{2}{|c|}{$\begin{array}{c}\text { Cost } \\
\text { per Case }\end{array}$} \\
\hline & & Basic & Enhanced & Basic & Enhanced & Basic 1 & Enhanced \\
\hline \multicolumn{8}{|l|}{ Bacterial } \\
\hline$\overline{\text { Bacillus cereus }}$ & 2.01 & 0.04 & 0.05 & 0.06 & 0.08 & 294 & 385 \\
\hline Brucella spp. & 0.04 & 0.07 & 0.09 & 0.12 & 0.14 & 27,112 & 33,274 \\
\hline Campylobacter spp. & 26.73 & 5.35 & 22.70 & 8.27 & 35.11 & 3,093 & 13,136 \\
\hline Clostridium botulinum & $<0.01$ & 0.21 & 0.27 & 0.33 & 0.41 & $1,869,475$ & $2,368,359$ \\
\hline Clostridium perfringens & 30.56 & 1.24 & 1.47 & 1.92 & 2.28 & 630 & 745 \\
\hline STEC O157:H7 & 0.82 & 0.77 & 0.80 & 1.18 & 1.23 & 14,467 & 15,040 \\
\hline STEC non-0157 & 1.46 & 0.16 & 0.22 & 0.25 & 0.35 & 1,741 & 2,366 \\
\hline ETEC & 0.57 & 0.06 & 0.08 & 0.10 & 0.13 & 1,689 & 2,315 \\
\hline Other diarrheogenic E. coli, & 0.38 & 0.04 & 0.06 & 0.06 & 0.09 & 1,689 & 2,317 \\
\hline Listeria monocytogenes & 0.06 & 6.73 & 6.70 & 10.42 & 10.37 & $1,780,069$ & $1,771,440$ \\
\hline Salmonella, spp., Nontyphoidal & 24.31 & 10.55 & 27.50 & 16.33 & 42.54 & 6,717 & 17,504 \\
\hline S. enterica serotype Typhi & 0.05 & 0.02 & 0.06 & 0.04 & 0.10 & 6,553 & 17,947 \\
\hline Shigella, spp & 4.01 & 0.90 & 4.04 & 1.39 & 6.25 & 3,481 & 15,603 \\
\hline Staphylococcus aureus & 7.63 & 0.45 & 0.55 & 0.70 & 0.85 & 912 & 1,119 \\
\hline Streptococcus spp. Group A & 0.36 & 0.06 & 0.08 & 0.10 & 0.13 & 2,676 & 3,697 \\
\hline Vibrio cholerae, toxigenic & $<0.01$ & $<0.01$ & $<0.01$ & $<0.01$ & $<0.01$ & 2,854 & 3,816 \\
\hline Vibrio vulnificus & $<0.01$ & 1.17 & 1.17 & 1.81 & 1.81 & $3,848,301$ & $3,850,254$ \\
\hline Vibrio parahaemolyticus & 1.70 & 0.37 & 0.45 & 0.57 & 0.70 & 3,329 & 4,120 \\
\hline Vibrio spp., other & 0.86 & 0.37 & 0.42 & 0.58 & 0.65 & 6,731 & 7,521 \\
\hline Yersinia enterocolitica & 3.09 & 1.38 & 3.64 & 2.14 & 5.62 & 6,928 & 18,207 \\
\hline \multicolumn{8}{|l|}{ Parasitic } \\
\hline$\overline{\text { Cryptosporidium spp. }}$ & 1.49 & 0.36 & 0.47 & 0.56 & 0.73 & 3,752 & 4,897 \\
\hline Cyclospora cayetanensis & 4.13 & 0.50 & 0.69 & 0.77 & 1.06 & 1,874 & 2,572 \\
\hline Giardia intestinalis & 3.54 & 1.07 & 1.45 & 1.65 & 2.25 & 4,661 & 6,345 \\
\hline Toxoplasma gondii & 2.74 & 9.44 & 10.46 & 14.60 & 16.18 & 53,236 & 59,004 \\
\hline Trichinella spp. & $<0.01$ & 0.01 & 0.01 & 0.01 & 0.01 & 18,513 & 26,105 \\
\hline \multicolumn{8}{|l|}{ Viral } \\
\hline$\overline{\text { Astrovirus }}$ & 0.49 & 0.05 & 0.07 & 0.08 & 0.10 & 1,589 & 2,148 \\
\hline Hepatitis A virus & 0.10 & 0.34 & 0.35 & 0.53 & 0.54 & 50,749 & 52,318 \\
\hline Norovirus & 172.77 & 9.87 & 11.99 & 15.27 & 18.55 & 884 & 1,074 \\
\hline Rotavirus & 0.49 & 0.05 & 0.06 & 0.07 & 0.10 & 1,514 & 1,978 \\
\hline Sapovirus & 0.49 & 0.04 & 0.06 & 0.07 & 0.09 & 1,338 & 1,814 \\
\hline Known & & 51.69 & 95.97 & 79.96 & 148.46 & 2,749 & 5,104 \\
\hline Unknown & $1,214.46$ & 120.14 & 150.19 & 185.84 & 232.34 & 1,530 & 1,913 \\
\hline Total & & 171.83 & 246.17 & 265.81 & 380.80 & 1,766 & 2,530 \\
\hline
\end{tabular}

${ }^{1}$ Incidence per 10,000 residents. 
TABLE A10. Florida Cost per Case of Foodborne Illness (by pathogen, \$2013)

\begin{tabular}{|c|c|c|c|c|c|c|c|}
\hline \multirow[b]{2}{*}{ Disease or Agent } & \multirow{2}{*}{$\begin{array}{c}\text { Illness } \\
\text { Incidence }^{1} \\
\end{array}$} & \multicolumn{2}{|c|}{$\begin{array}{l}\text { Total Cost } \\
\text { (\$million) }\end{array}$} & \multicolumn{2}{|c|}{$\begin{array}{l}\text { Cost per } \\
\text { Resident }\end{array}$} & \multicolumn{2}{|c|}{$\begin{array}{c}\text { Cost } \\
\text { per Case }\end{array}$} \\
\hline & & Basic & Enhanced & Basic & Enhanced & Basic 1 & Enhanced \\
\hline \multicolumn{8}{|l|}{ Bacterial } \\
\hline$\overline{\text { Bacillus cereus }}$ & 2.01 & 0.64 & 1.01 & 0.03 & 0.05 & 162 & 257 \\
\hline Brucella spp. & 0.03 & 1.13 & 1.50 & 0.06 & 0.08 & 17,614 & 23,458 \\
\hline Campylobacter spp. & 26.73 & 97.03 & 486.01 & 4.96 & 24.86 & 1,857 & 9,299 \\
\hline Clostridium botulinum & $<0.01$ & 4.66 & 5.92 & 0.24 & 0.30 & $1,361,039$ & $1,728,533$ \\
\hline Clostridium perfringens & 30.56 & 23.08 & 30.27 & 1.18 & 1.55 & 386 & 507 \\
\hline STEC 0157:H7 & 0.89 & 17.92 & 19.00 & 0.92 & 0.97 & 10,258 & 10,878 \\
\hline STEC non-0157 & 1.60 & 2.68 & 4.71 & 0.14 & 0.24 & 858 & 1,510 \\
\hline ETEC & 0.57 & 0.89 & 1.61 & 0.05 & 0.08 & 804 & 1,457 \\
\hline Other diarrheogenic E. coli, & 0.38 & 0.60 & 1.08 & 0.03 & 0.06 & 804 & 1,459 \\
\hline Listeria monocytogenes & 0.04 & 100.94 & 101.98 & 5.16 & 5.22 & $1,280,458$ & $1,293,687$ \\
\hline Salmonella, spp., Nontyphoidal & 59.55 & 505.97 & $1,443.51$ & 25.88 & 73.83 & 4,346 & 12,397 \\
\hline S. enterica serotype Typhi & 0.04 & 0.34 & 0.96 & 0.02 & 0.05 & 4,700 & 13,334 \\
\hline Shigella, spp & 6.32 & 23.86 & 135.12 & 1.22 & 6.91 & 1,932 & 10,940 \\
\hline Staphylococcus aureus & 7.63 & 8.12 & 11.35 & 0.42 & 0.58 & 544 & 761 \\
\hline Streptococcus spp. Group A & 0.36 & 0.86 & 1.60 & 0.04 & 0.08 & 1,242 & 2,305 \\
\hline Vibrio cholerae, toxigenic & 0.01 & 0.02 & 0.03 & $<0.01$ & $<0.01$ & 1,488 & 2,495 \\
\hline Vibrio vulnificus & 0.01 & 38.76 & 38.79 & 1.98 & 1.98 & $2,771,410$ & $2,773,244$ \\
\hline Vibrio parahaemolyticus & 2.58 & 9.51 & 13.67 & 0.49 & 0.70 & 1,884 & 2,708 \\
\hline Vibrio spp., other & 1.31 & 11.05 & 13.15 & 0.56 & 0.67 & 4,317 & 5,141 \\
\hline Yersinia enterocolitica & 3.09 & 24.24 & 76.03 & 1.24 & 3.89 & 4,013 & 12,587 \\
\hline \multicolumn{8}{|l|}{ Parasitic } \\
\hline$\overline{\text { Cryptosporidium spp. }}$ & 1.64 & 6.25 & 10.06 & 0.32 & 0.51 & 1,951 & 3,143 \\
\hline Cyclospora cayetanensis & 2.10 & 3.66 & 6.65 & 0.19 & 0.34 & 891 & 1,618 \\
\hline Giardia intestinalis & 2.43 & 10.60 & 18.91 & 0.54 & 0.97 & 2,235 & 3,987 \\
\hline Toxoplasma gondii & 2.74 & 196.76 & 226.22 & 10.06 & 11.57 & 36,697 & 42,191 \\
\hline Trichinella spp. & $<0.01$ & 0.09 & 0.16 & $<0.01$ & 0.01 & 8,944 & 16,609 \\
\hline \multicolumn{8}{|l|}{ Viral } \\
\hline$\overline{\text { Astrovirus }}$ & 0.49 & 0.76 & 1.32 & 0.04 & 0.07 & 800 & 1,383 \\
\hline Hepatitis A virus & 0.06 & 3.96 & 4.14 & 0.20 & 0.21 & 35,879 & 37,480 \\
\hline Norovirus & 172.77 & 180.26 & 247.39 & 9.22 & 12.65 & 534 & 732 \\
\hline Rotavirus & 0.49 & 0.81 & 1.28 & 0.04 & 0.07 & 848 & 1,336 \\
\hline Sapovirus & 0.49 & 0.63 & 1.11 & 0.03 & 0.06 & 665 & 1,161 \\
\hline Known & & $1,276.07$ & $2,904.52$ & 65.26 & 148.55 & 1,997 & 4,544 \\
\hline Unknown & $1,214.46$ & $2,064.87$ & $3,010.06$ & 105.60 & 153.94 & 870 & 1,268 \\
\hline Total & & $3,340.94$ & $5,914.58$ & 170.87 & 302.49 & 1,109 & 1,963 \\
\hline
\end{tabular}

${ }^{1}$ Incidence per 10,000 residents. 
TABLE A11. Georgia Cost per Case of Foodborne Illness (by pathogen, \$2013)

\begin{tabular}{|c|c|c|c|c|c|c|c|}
\hline \multirow[b]{2}{*}{ Disease or Agent } & \multirow{2}{*}{$\begin{array}{l}\text { Illness } \\
\text { Incidence }^{1}\end{array}$} & \multicolumn{2}{|c|}{$\begin{array}{l}\text { Total Cost } \\
\text { (\$million) }\end{array}$} & \multicolumn{2}{|c|}{$\begin{array}{l}\text { Cost per } \\
\text { Resident }\end{array}$} & \multicolumn{2}{|c|}{$\begin{array}{c}\text { Cost } \\
\text { per Case }\end{array}$} \\
\hline & & Basic & Enhanced & Basic & Enhanced & Basic 1 & Enhanced \\
\hline \multicolumn{8}{|l|}{ Bacterial } \\
\hline$\overline{\text { Bacillus cereus }}$ & 2.01 & 0.33 & 0.53 & 0.03 & 0.05 & 164 & 262 \\
\hline Brucella spp. & 0.03 & 0.47 & 0.63 & 0.05 & 0.06 & 17,324 & 23,404 \\
\hline Campylobacter spp. & 26.73 & 49.73 & 256.90 & 4.98 & 25.71 & 1,862 & 9,618 \\
\hline Clostridium botulinum & $<0.01$ & 2.41 & 3.08 & 0.24 & 0.31 & $1,377,303$ & $1,760,328$ \\
\hline Clostridium perfringens & 30.56 & 12.13 & 15.95 & 1.21 & 1.60 & 397 & 522 \\
\hline STEC O157:H7 & 1.07 & 11.15 & 11.85 & 1.12 & 1.19 & 10,400 & 11,044 \\
\hline STEC non-0157 & 1.92 & 1.67 & 2.97 & 0.17 & 0.30 & 873 & 1,552 \\
\hline ETEC & 0.57 & 0.47 & 0.85 & 0.05 & 0.09 & 833 & 1,511 \\
\hline Other diarrheogenic E. coli, & 0.38 & 0.32 & 0.57 & 0.03 & 0.06 & 832 & 1,513 \\
\hline Listeria monocytogenes & 0.04 & 57.47 & 58.07 & 5.75 & 5.81 & $1,309,923$ & $1,323,534$ \\
\hline Salmonella, spp., Nontyphoidal & 45.69 & 200.00 & 583.06 & 20.02 & 58.35 & 4,381 & 12,772 \\
\hline S. enterica serotype Typhi & 0.05 & 0.19 & 0.61 & 0.02 & 0.06 & 4,047 & 13,044 \\
\hline Shigella, spp & 7.56 & 14.75 & 85.63 & 1.48 & 8.57 & 1,953 & 11,341 \\
\hline Staphylococcus aureus & 7.63 & 4.15 & 5.87 & 0.42 & 0.59 & 545 & 770 \\
\hline Streptococcus spp. Group A & 0.36 & 0.46 & 0.85 & 0.05 & 0.09 & 1,297 & 2,402 \\
\hline Vibrio cholerae, toxigenic & $<0.01$ & $<0.01$ & 0.01 & $<0.01$ & $<0.01$ & 1,473 & 2,520 \\
\hline Vibrio vulnificus & $<0.01$ & 8.25 & 8.26 & 0.83 & 0.83 & $2,871,532$ & $2,873,440$ \\
\hline Vibrio parahaemolyticus & 1.04 & 2.02 & 2.91 & 0.20 & 0.29 & 1,945 & 2,802 \\
\hline Vibrio spp., other & 0.53 & 2.36 & 2.81 & 0.24 & 0.28 & 4,482 & 5,338 \\
\hline Yersinia enterocolitica & 3.09 & 12.83 & 40.41 & 1.28 & 4.04 & 4,158 & 13,093 \\
\hline \multicolumn{8}{|l|}{ Parasitic } \\
\hline$\overline{\text { Cryptosporidium spp. }}$ & 1.91 & 3.86 & 6.23 & 0.39 & 0.62 & 2,015 & 3,254 \\
\hline Cyclospora cayetanensis & 0.52 & 0.48 & 0.87 & 0.05 & 0.09 & 923 & 1,679 \\
\hline Giardia intestinalis & 2.61 & 6.06 & 10.82 & 0.61 & 1.08 & 2,321 & 4,143 \\
\hline Toxoplasma gondii & 2.74 & 101.33 & 116.98 & 10.14 & 11.71 & 36,980 & 42,696 \\
\hline Trichinella spp. & $<0.01$ & 0.04 & 0.08 & $<0.01$ & 0.01 & 9,109 & 17,079 \\
\hline \multicolumn{8}{|l|}{ Viral } \\
\hline$\overline{\text { Astrovirus }}$ & 0.49 & 0.39 & 0.69 & 0.04 & 0.07 & 806 & 1,412 \\
\hline Hepatitis A virus & 0.08 & 2.85 & 2.98 & 0.29 & 0.30 & 36,922 & 38,587 \\
\hline Norovirus & 172.77 & 92.32 & 127.98 & 9.24 & 12.81 & 535 & 741 \\
\hline Rotavirus & 0.49 & 0.40 & 0.64 & 0.04 & 0.06 & 814 & 1,322 \\
\hline Sapovirus & 0.49 & 0.33 & 0.58 & 0.03 & 0.06 & 675 & 1,191 \\
\hline Known & & 589.22 & $1,349.68$ & 58.97 & 135.07 & 1,894 & 4,339 \\
\hline Unknown & $1,214.46$ & $1,076.31$ & $1,578.48$ & 107.72 & 157.97 & 887 & 1,301 \\
\hline Total & & $1,665.54$ & $2,928.16$ & 166.68 & 293.05 & 1,092 & 1,921 \\
\hline
\end{tabular}

${ }^{1}$ Incidence per 10,000 residents. 
TABLE A12. Hawaii Cost per Case of Foodborne Illness (by pathogen, \$2013)

\begin{tabular}{|c|c|c|c|c|c|c|c|}
\hline \multirow[b]{2}{*}{ Disease or Agent } & \multirow{2}{*}{$\begin{array}{l}\text { Illness } \\
\text { Incidence }^{1}\end{array}$} & \multicolumn{2}{|c|}{$\begin{array}{l}\text { Total Cost } \\
\text { (\$million) }\end{array}$} & \multicolumn{2}{|c|}{$\begin{array}{l}\text { Cost per } \\
\text { Resident }\end{array}$} & \multicolumn{2}{|c|}{$\begin{array}{c}\text { Cost } \\
\text { per Case }\end{array}$} \\
\hline & & Basic & Enhanced & Basic & Enhanced & Basic 1 & Enhanced \\
\hline \multicolumn{8}{|l|}{ Bacterial } \\
\hline$\overline{\text { Bacillus cereus }}$ & 2.01 & 0.05 & 0.08 & 0.03 & 0.06 & 173 & 294 \\
\hline Brucella spp. & 0.11 & 0.31 & 0.42 & 0.22 & 0.30 & 20,205 & 27,599 \\
\hline Campylobacter spp. & 26.73 & 7.91 & 41.96 & 5.63 & 29.88 & 2,108 & 11,180 \\
\hline Clostridium botulinum & $<0.01$ & 0.40 & 0.51 & 0.28 & 0.36 & $1,625,413$ & $2,072,931$ \\
\hline Clostridium perfringens & 30.56 & 1.89 & 2.55 & 1.35 & 1.82 & 441 & 595 \\
\hline STEC O157:H7 & 1.62 & 2.77 & 2.95 & 1.97 & 2.10 & 12,187 & 12,984 \\
\hline STEC non-0157 & 2.89 & 0.38 & 0.72 & 0.27 & 0.51 & 928 & 1,763 \\
\hline ETEC & 0.57 & 0.07 & 0.14 & 0.05 & 0.10 & 871 & 1,706 \\
\hline Other diarrheogenic E. coli, & 0.38 & 0.05 & 0.09 & 0.03 & 0.06 & 870 & 1,708 \\
\hline Listeria monocytogenes & 0.08 & 17.89 & 18.13 & 12.74 & 12.91 & $1,535,453$ & $1,555,716$ \\
\hline Salmonella, spp., Nontyphoidal & 46.42 & 32.90 & 96.96 & 23.43 & 69.05 & 5,047 & 14,875 \\
\hline S. enterica serotype Typhi & 0.18 & 0.13 & 0.40 & 0.09 & 0.28 & 5,086 & 15,651 \\
\hline Shigella, spp & 2.59 & 0.79 & 4.78 & 0.56 & 3.40 & 2,163 & 13,149 \\
\hline Staphylococcus aureus & 7.63 & 0.65 & 0.95 & 0.47 & 0.68 & 610 & 888 \\
\hline Streptococcus spp. Group A & 0.36 & 0.07 & 0.13 & 0.05 & 0.10 & 1,346 & 2,706 \\
\hline Vibrio cholerae, toxigenic & 0.02 & $<0.01$ & 0.01 & $<0.01$ & 0.01 & 1,611 & 2,900 \\
\hline Vibrio vulnificus & 0.02 & 11.28 & 11.29 & 8.03 & 8.04 & $3,349,313$ & $3,351,631$ \\
\hline Vibrio parahaemolyticus & 8.66 & 2.61 & 3.89 & 1.86 & 2.77 & 2,148 & 3,203 \\
\hline Vibrio spp., other & 4.39 & 3.14 & 3.79 & 2.24 & 2.70 & 5,096 & 6,150 \\
\hline Yersinia enterocolitica & 3.09 & 2.01 & 6.56 & 1.43 & 4.67 & 4,624 & 15,122 \\
\hline \multicolumn{8}{|l|}{ Parasitic } \\
\hline 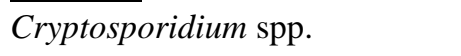 & 0.11 & 0.03 & 0.06 & 0.02 & 0.04 & 2,180 & 3,705 \\
\hline Cyclospora cayetanensis & $<0.01$ & $<0.01$ & $<0.01$ & $<0.01$ & $<0.01$ & 964 & 1,895 \\
\hline Giardia intestinalis & 1.49 & 0.51 & 0.98 & 0.37 & 0.70 & 2,449 & 4,691 \\
\hline Toxoplasma gondii & 2.74 & 16.65 & 19.33 & 11.86 & 13.77 & 43,252 & 50,207 \\
\hline Trichinella spp. & $<0.01$ & 0.01 & 0.01 & $<0.01$ & 0.01 & 9,705 & 19,479 \\
\hline \multicolumn{8}{|l|}{ Viral } \\
\hline$\overline{\text { Astrovirus }}$ & 0.49 & 0.06 & 0.11 & 0.04 & 0.08 & 865 & 1,612 \\
\hline Hepatitis A virus & 0.04 & 0.25 & 0.27 & 0.18 & 0.19 & 43,005 & 45,049 \\
\hline Norovirus & 172.77 & 14.59 & 20.76 & 10.39 & 14.79 & 601 & 856 \\
\hline Rotavirus & 0.49 & 0.06 & 0.11 & 0.04 & 0.08 & 917 & 1,543 \\
\hline Sapovirus & 0.49 & 0.05 & 0.09 & 0.04 & 0.07 & 719 & 1,355 \\
\hline Known & & 117.51 & 238.02 & 83.69 & 169.52 & 2,641 & 5,349 \\
\hline Unknown & $1,214.46$ & 167.31 & 254.16 & 119.16 & 181.02 & 981 & 1,491 \\
\hline Total & & 284.82 & 492.18 & 202.85 & 350.54 & 1,325 & 2,289 \\
\hline
\end{tabular}

${ }^{1}$ Incidence per 10,000 residents. 
TABLE A13. Idaho Cost per Case of Foodborne Illness (by pathogen, \$2013)

\begin{tabular}{|c|c|c|c|c|c|c|c|}
\hline \multirow[b]{2}{*}{ Disease or Agent } & \multirow{2}{*}{$\begin{array}{l}\text { Illness } \\
\text { Incidence }^{1}\end{array}$} & \multicolumn{2}{|c|}{$\begin{array}{l}\text { Total Cost } \\
\text { (\$million) }\end{array}$} & \multicolumn{2}{|c|}{$\begin{array}{l}\text { Cost per } \\
\text { Resident }\end{array}$} & \multicolumn{2}{|c|}{$\begin{array}{c}\text { Cost } \\
\text { per Case }\end{array}$} \\
\hline & & Basic & Enhanced & Basic & Enhanced & Basic I & Enhanced \\
\hline \multicolumn{8}{|l|}{ Bacterial } \\
\hline$\overline{\text { Bacillus cereus }}$ & 2.01 & 0.05 & 0.08 & 0.03 & 0.05 & 151 & 254 \\
\hline Brucella spp. & 0.02 & 0.06 & 0.08 & 0.03 & 0.05 & 16,075 & 22,362 \\
\hline Campylobacter spp. & 26.73 & 7.46 & 40.94 & 4.63 & 25.39 & 1,732 & 9,499 \\
\hline Clostridium botulinum & $<0.01$ & 0.38 & 0.49 & 0.23 & 0.30 & $1,340,613$ & $1,723,829$ \\
\hline Clostridium perfringens & 30.56 & 1.87 & 2.52 & 1.16 & 1.56 & 381 & 511 \\
\hline STEC 0157:H7 & 8.83 & 14.37 & 15.33 & 8.91 & 9.51 & 10,094 & 10,770 \\
\hline STEC non-0157 & 15.76 & 2.00 & 3.80 & 1.24 & 2.36 & 786 & 1,495 \\
\hline ETEC & 0.57 & 0.07 & 0.13 & 0.04 & 0.08 & 756 & 1,465 \\
\hline Other diarrheogenic E. coli, & 0.38 & 0.05 & 0.09 & 0.03 & 0.06 & 756 & 1,467 \\
\hline Listeria monocytogenes & 0.02 & 3.74 & 3.79 & 2.32 & 2.35 & $1,284,766$ & $1,301,449$ \\
\hline Salmonella, spp., Nontyphoidal & 22.04 & 14.78 & 44.66 & 9.17 & 27.71 & 4,160 & 12,572 \\
\hline S. enterica serotype Typhi & 0.01 & $<0.01$ & 0.01 & $<0.01$ & 0.01 & 3,311 & 12,350 \\
\hline Shigella, spp & 0.82 & 0.24 & 1.48 & 0.15 & 0.92 & 1,799 & 11,204 \\
\hline Staphylococcus aureus & 7.63 & 0.62 & 0.91 & 0.39 & 0.57 & 506 & 741 \\
\hline Streptococcus spp. Group A & 0.36 & 0.07 & 0.13 & 0.04 & 0.08 & 1,180 & 2,334 \\
\hline Vibrio cholerae, toxigenic & $<0.01$ & $<0.01$ & $<0.01$ & $<0.01$ & $<0.01$ & 1,307 & 2,401 \\
\hline Vibrio vulnificus & $<0.01$ & 1.30 & 1.30 & 0.81 & 0.81 & $2,848,235$ & $2,850,206$ \\
\hline Vibrio parahaemolyticus & 1.02 & 0.30 & 0.45 & 0.19 & 0.28 & 1,837 & 2,732 \\
\hline Vibrio spp., other & 0.52 & 0.36 & 0.44 & 0.23 & 0.27 & 4,364 & 5,258 \\
\hline Yersinia enterocolitica & 3.09 & 1.97 & 6.44 & 1.22 & 4.00 & 3,961 & 12,941 \\
\hline \multicolumn{8}{|l|}{ Parasitic } \\
\hline$\overline{\text { Cryptosporidium spp. }}$ & 5.94 & 1.79 & 3.03 & 1.11 & 1.88 & 1,868 & 3,161 \\
\hline Cyclospora cayetanensis & 0.10 & 0.01 & 0.03 & 0.01 & 0.02 & 838 & 1,628 \\
\hline Giardia intestinalis & 4.13 & 1.41 & 2.68 & 0.88 & 1.66 & 2,119 & 4,021 \\
\hline Toxoplasma gondii & 2.74 & 15.70 & 18.32 & 9.74 & 11.36 & 35,518 & 41,431 \\
\hline Trichinella spp. & $<0.01$ & 0.01 & 0.01 & $<0.01$ & 0.01 & 8,164 & 16,463 \\
\hline \multicolumn{8}{|l|}{ Viral } \\
\hline$\overline{\text { Astrovirus }}$ & 0.49 & 0.06 & 0.11 & 0.04 & 0.07 & 722 & 1,356 \\
\hline Hepatitis A virus & 0.04 & 0.20 & 0.21 & 0.13 & 0.13 & 36,295 & 38,030 \\
\hline Norovirus & 172.77 & 13.87 & 19.88 & 8.60 & 12.33 & 498 & 714 \\
\hline Rotavirus & 0.49 & 0.06 & 0.10 & 0.03 & 0.06 & 712 & 1,243 \\
\hline Sapovirus & 0.49 & 0.05 & 0.09 & 0.03 & 0.06 & 608 & 1,147 \\
\hline Known & & 82.84 & 167.52 & 51.39 & 103.91 & 1,671 & 3,379 \\
\hline Unknown & $1,214.46$ & 162.29 & 246.90 & 100.67 & 153.15 & 829 & 1,261 \\
\hline Total & & 245.13 & 414.42 & 152.05 & 257.06 & 999 & 1,689 \\
\hline
\end{tabular}

${ }^{1}$ Incidence per 10,000 residents. 
TABLE A14. Illinois Cost per Case of Foodborne Illness (by pathogen, \$2013)

\begin{tabular}{|c|c|c|c|c|c|c|c|}
\hline \multirow[b]{2}{*}{ Disease or Agent } & \multirow{2}{*}{$\begin{array}{l}\text { Illness } \\
\text { Incidence }^{1}\end{array}$} & \multicolumn{2}{|c|}{$\begin{array}{l}\text { Total Cost } \\
\text { (\$million) }\end{array}$} & \multicolumn{2}{|c|}{$\begin{array}{l}\text { Cost per } \\
\text { Resident }\end{array}$} & \multicolumn{2}{|c|}{$\begin{array}{c}\text { Cost } \\
\text { per Case }\end{array}$} \\
\hline & & Basic & Enhanced & Basic & Enhanced & Basic 1 & Enhanced \\
\hline \multicolumn{8}{|l|}{ Bacterial } \\
\hline$\overline{\text { Bacillus cereus }}$ & 2.01 & 0.47 & 0.74 & 0.04 & 0.06 & 183 & 285 \\
\hline Brucella spp. & 0.03 & 0.82 & 1.09 & 0.06 & 0.08 & 19,277 & 25,611 \\
\hline Campylobacter spp. & 26.73 & 71.45 & 356.63 & 5.55 & 27.68 & 2,075 & 10,357 \\
\hline Clostridium botulinum & $<0.01$ & 3.36 & 4.29 & 0.26 & 0.33 & $1,492,277$ & $1,901,516$ \\
\hline Clostridium perfringens & 30.56 & 17.14 & 22.23 & 1.33 & 1.73 & 436 & 565 \\
\hline STEC O157:H7 & 1.58 & 22.95 & 24.30 & 1.78 & 1.89 & 11,292 & 11,956 \\
\hline STEC non-0157 & 2.82 & 3.61 & 6.16 & 0.28 & 0.48 & 995 & 1,696 \\
\hline ETEC & 0.57 & 0.69 & 1.20 & 0.05 & 0.09 & 947 & 1,648 \\
\hline Other diarrheogenic E. coli, & 0.38 & 0.46 & 0.81 & 0.04 & 0.06 & 947 & 1,650 \\
\hline Listeria monocytogenes & 0.05 & 83.19 & 83.90 & 6.46 & 6.51 & $1,414,655$ & $1,426,764$ \\
\hline Salmonella, spp., Nontyphoidal & 29.28 & 181.92 & 519.55 & 14.12 & 40.33 & 4,824 & 13,776 \\
\hline S. enterica serotype Typhi & 0.07 & 0.43 & 1.31 & 0.03 & 0.10 & 4,722 & 14,305 \\
\hline Shigella, spp & 3.87 & 10.94 & 60.92 & 0.85 & 4.73 & 2,194 & 12,214 \\
\hline Staphylococcus aureus & 7.63 & 5.97 & 8.26 & 0.46 & 0.64 & 607 & 840 \\
\hline Streptococcus spp. Group A & 0.36 & 0.68 & 1.20 & 0.05 & 0.09 & 1,477 & 2,619 \\
\hline Vibrio cholerae, toxigenic & $<0.01$ & $<0.01$ & $<0.01$ & $<0.01$ & $<0.01$ & 1,686 & 2,767 \\
\hline Vibrio vulnificus & $<0.01$ & 5.28 & 5.28 & 0.41 & 0.41 & $3,083,872$ & $3,085,862$ \\
\hline Vibrio parahaemolyticus & 0.48 & 1.33 & 1.88 & 0.10 & 0.15 & 2,158 & 3,043 \\
\hline Vibrio spp., other & 0.24 & 1.53 & 1.81 & 0.12 & 0.14 & 4,877 & 5,762 \\
\hline Yersinia enterocolitica & 3.09 & 18.28 & 56.13 & 1.42 & 4.36 & 4,592 & 14,105 \\
\hline \multicolumn{8}{|l|}{ Parasitic } \\
\hline 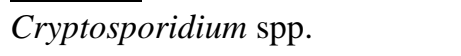 & 1.18 & 3.44 & 5.39 & 0.27 & 0.42 & 2,265 & 3,545 \\
\hline Cyclospora cayetanensis & 0.24 & 0.33 & 0.57 & 0.03 & 0.04 & 1,050 & 1,831 \\
\hline Giardia intestinalis & 1.95 & 6.61 & 11.33 & 0.51 & 0.88 & 2,637 & 4,519 \\
\hline Toxoplasma gondii & 2.74 & 142.73 & 163.75 & 11.08 & 12.71 & 40,406 & 46,357 \\
\hline Trichinella spp. & $<0.01$ & 0.07 & 0.12 & 0.01 & 0.01 & 10,428 & 18,687 \\
\hline \multicolumn{8}{|l|}{ Viral } \\
\hline$\overline{\text { Astrovirus }}$ & 0.49 & 0.58 & 0.97 & 0.04 & 0.08 & 920 & 1,546 \\
\hline Hepatitis A virus & 0.04 & 2.03 & 2.11 & 0.16 & 0.16 & 39,851 & 41,574 \\
\hline Norovirus & 172.77 & 132.40 & 179.89 & 10.28 & 13.96 & 595 & 808 \\
\hline Rotavirus & 0.49 & 0.59 & 0.92 & 0.05 & 0.07 & 934 & 1,459 \\
\hline Sapovirus & 0.49 & 0.48 & 0.82 & 0.04 & 0.06 & 769 & 1,303 \\
\hline Known & & 719.78 & $1,523.57$ & 55.87 & 118.27 & 1,926 & 4,077 \\
\hline Unknown & $1,214.46$ & $1,546.05$ & $2,215.21$ & 120.02 & 171.96 & 988 & 1,416 \\
\hline Total & & $2,265.83$ & $3,738.78$ & 175.89 & 290.23 & 1,169 & 1,929 \\
\hline
\end{tabular}

${ }^{1}$ Incidence per 10,000 residents. 
TABLE A15. Indiana Cost per Case of Foodborne Illness (by pathogen, \$2013)

\begin{tabular}{|c|c|c|c|c|c|c|c|}
\hline \multirow[b]{2}{*}{ Disease or Agent } & \multirow{2}{*}{$\begin{array}{c}\text { Illness } \\
\text { Incidence }^{1}\end{array}$} & \multicolumn{2}{|c|}{$\begin{array}{l}\text { Total Cost } \\
\text { (\$million) }\end{array}$} & \multicolumn{2}{|c|}{$\begin{array}{l}\text { Cost per } \\
\text { Resident }\end{array}$} & \multicolumn{2}{|c|}{$\begin{array}{c}\text { Cost } \\
\text { per Case }\end{array}$} \\
\hline & & Basic & Enhanced & Basic & Enhanced & Basic 1 & Enhanced \\
\hline \multicolumn{8}{|l|}{ Bacterial } \\
\hline$\overline{\text { Bacillus cereus }}$ & 2.01 & 0.21 & 0.33 & 0.03 & 0.05 & 156 & 252 \\
\hline Brucella spp. & 0.01 & 0.10 & 0.14 & 0.02 & 0.02 & 16,460 & 22,341 \\
\hline Campylobacter spp. & 26.73 & 31.10 & 162.13 & 4.73 & 24.67 & 1,771 & 9,231 \\
\hline Clostridium botulinum & $<0.01$ & 1.52 & 1.94 & 0.23 & 0.30 & $1,318,608$ & $1,686,954$ \\
\hline Clostridium perfringens & 30.56 & 7.64 & 10.07 & 1.16 & 1.53 & 380 & 502 \\
\hline STEC O157:H7 & 2.16 & 14.11 & 15.00 & 2.15 & 2.28 & 9,954 & 10,579 \\
\hline STEC non-0157 & 3.85 & 2.09 & 3.76 & 0.32 & 0.57 & 826 & 1,484 \\
\hline ETEC & 0.57 & 0.29 & 0.54 & 0.04 & 0.08 & 789 & 1,446 \\
\hline Other diarrheogenic E. coli, & 0.38 & 0.20 & 0.36 & 0.03 & 0.05 & 789 & 1,448 \\
\hline Listeria monocytogenes & 0.04 & 32.69 & 33.04 & 4.97 & 5.03 & $1,255,622$ & $1,269,220$ \\
\hline Salmonella, spp., Nontyphoidal & 21.98 & 60.35 & 176.95 & 9.19 & 26.93 & 4,178 & 12,251 \\
\hline S. enterica serotype Typhi & 0.02 & 0.04 & 0.13 & 0.01 & 0.02 & 3,777 & 12,436 \\
\hline Shigella, spp & 2.32 & 2.82 & 16.58 & 0.43 & 2.52 & 1,854 & 10,884 \\
\hline Staphylococcus aureus & 7.63 & 2.60 & 3.69 & 0.40 & 0.56 & 519 & 737 \\
\hline Streptococcus spp. Group A & 0.36 & 0.29 & 0.54 & 0.04 & 0.08 & 1,229 & 2,299 \\
\hline Vibrio cholerae, toxigenic & $<0.01$ & $<0.01$ & $<0.01$ & $<0.01$ & $<0.01$ & 1,391 & 2,405 \\
\hline Vibrio vulnificus & $<0.01$ & 1.31 & 1.31 & 0.20 & 0.20 & $2,757,503$ & $2,759,349$ \\
\hline Vibrio parahaemolyticus & 0.26 & 0.32 & 0.46 & 0.05 & 0.07 & 1,853 & 2,683 \\
\hline Vibrio spp., other & 0.13 & 0.37 & 0.45 & 0.06 & 0.07 & 4,291 & 5,121 \\
\hline Yersinia enterocolitica & 3.09 & 8.05 & 25.51 & 1.23 & 3.88 & 3,967 & 12,566 \\
\hline \multicolumn{8}{|l|}{ Parasitic } \\
\hline$\overline{\text { Cryptosporidium spp. }}$ & 2.12 & 2.67 & 4.34 & 0.41 & 0.66 & 1,914 & 3,115 \\
\hline Cyclospora cayetanensis & 0.06 & 0.03 & 0.06 & 0.01 & 0.01 & 875 & 1,607 \\
\hline Giardia intestinalis & 1.68 & 2.43 & 4.39 & 0.37 & 0.67 & 2,199 & 3,964 \\
\hline Toxoplasma gondii & 2.74 & 63.65 & 73.62 & 9.69 & 11.20 & 35,328 & 40,856 \\
\hline Trichinella spp. & $<0.01$ & 0.03 & 0.05 & $<0.01$ & 0.01 & 8,605 & 16,324 \\
\hline \multicolumn{8}{|l|}{ Viral } \\
\hline$\overline{\text { Astrovirus }}$ & 0.49 & 0.24 & 0.43 & 0.04 & 0.07 & 762 & 1,350 \\
\hline Hepatitis A virus & 0.02 & 0.46 & 0.48 & 0.07 & 0.07 & 35,406 & 37,019 \\
\hline Norovirus & 172.77 & 57.80 & 80.53 & 8.80 & 12.26 & 509 & 709 \\
\hline Rotavirus & 0.49 & 0.25 & 0.40 & 0.04 & 0.06 & 768 & 1,260 \\
\hline Sapovirus & 0.49 & 0.20 & 0.37 & 0.03 & 0.06 & 639 & 1,139 \\
\hline Known & & 293.87 & 617.59 & 44.72 & 93.99 & 1,581 & 3,322 \\
\hline Unknown & $1,214.46$ & 673.74 & 993.72 & 102.53 & 151.23 & 844 & 1,245 \\
\hline Total & & 967.61 & $1,611.31$ & 147.26 & 245.22 & 983 & 1,638 \\
\hline
\end{tabular}

${ }^{1}$ Incidence per 10,000 residents. 
TABLE A16. Iowa Cost per Case of Foodborne Illness (by pathogen, \$2013)

\begin{tabular}{|c|c|c|c|c|c|c|c|}
\hline \multirow[b]{2}{*}{ Disease or Agent } & \multirow{2}{*}{$\begin{array}{l}\text { Illness } \\
\text { Incidence }^{1}\end{array}$} & \multicolumn{2}{|c|}{$\begin{array}{l}\text { Total Cost } \\
\text { (\$million) }\end{array}$} & \multicolumn{2}{|c|}{$\begin{array}{l}\text { Cost per } \\
\text { Resident }\end{array}$} & \multicolumn{2}{|c|}{$\begin{array}{c}\text { Cost } \\
\text { per Case }\end{array}$} \\
\hline & & Basic & Enhanced & Basic & Enhanced & Basic 1 & Enhanced \\
\hline \multicolumn{8}{|l|}{ Bacterial } \\
\hline$\overline{\text { Bacillus cereus }}$ & 2.01 & 0.10 & 0.17 & 0.03 & 0.06 & 169 & 280 \\
\hline Brucella spp. & 0.02 & 0.10 & 0.14 & 0.03 & 0.04 & 18,149 & 24,951 \\
\hline Campylobacter spp. & 26.73 & 16.26 & 87.24 & 5.26 & 28.23 & 1,969 & 10,561 \\
\hline Clostridium botulinum & $<0.01$ & 0.81 & 1.03 & 0.26 & 0.33 & $1,488,933$ & $1,913,103$ \\
\hline Clostridium perfringens & 30.56 & 4.03 & 5.35 & 1.30 & 1.73 & 427 & 567 \\
\hline STEC O157:H7 & 6.73 & 23.36 & 24.87 & 7.56 & 8.05 & 11,236 & 11,960 \\
\hline STEC non-0157 & 12.01 & 3.41 & 6.24 & 1.10 & 2.02 & 919 & 1,680 \\
\hline ETEC & 0.57 & 0.16 & 0.29 & 0.05 & 0.09 & 886 & 1,648 \\
\hline Other diarrheogenic E. coli, & 0.38 & 0.10 & 0.19 & 0.03 & 0.06 & 886 & 1,650 \\
\hline Listeria monocytogenes & 0.03 & 11.44 & 11.57 & 3.70 & 3.74 & $1,427,606$ & $1,443,716$ \\
\hline Salmonella, spp., Nontyphoidal & 32.42 & 46.93 & 140.10 & 15.18 & 45.33 & 4,683 & 13,981 \\
\hline S. enterica serotype Typhi & 0.03 & 0.03 & 0.11 & 0.01 & 0.04 & 3,734 & 13,710 \\
\hline Shigella, spp & 2.31 & 1.48 & 8.91 & 0.48 & 2.88 & 2,068 & 12,469 \\
\hline Staphylococcus aureus & 7.63 & 1.35 & 1.95 & 0.44 & 0.63 & 573 & 825 \\
\hline Streptococcus spp. Group A & 0.36 & 0.15 & 0.29 & 0.05 & 0.09 & 1,390 & 2,630 \\
\hline Vibrio cholerae, toxigenic & $<0.01$ & $<0.01$ & $<0.01$ & $<0.01$ & $<0.01$ & 1,521 & 2,696 \\
\hline Vibrio vulnificus & $<0.01$ & 2.77 & 2.77 & 0.90 & 0.90 & $3,161,565$ & $3,163,699$ \\
\hline Vibrio parahaemolyticus & 1.02 & 0.66 & 0.97 & 0.22 & 0.31 & 2,099 & 3,061 \\
\hline Vibrio spp., other & 0.52 & 0.79 & 0.94 & 0.25 & 0.30 & 4,904 & 5,866 \\
\hline Yersinia enterocolitica & 3.09 & 4.31 & 13.77 & 1.39 & 4.46 & 4,514 & 14,422 \\
\hline \multicolumn{8}{|l|}{ Parasitic } \\
\hline$\overline{\text { Cryptosporidium spp. }}$ & 6.79 & 4.54 & 7.46 & 1.47 & 2.41 & 2,164 & 3,554 \\
\hline Cyclospora cayetanensis & 0.04 & 0.01 & 0.02 & $<0.01$ & 0.01 & 983 & 1,831 \\
\hline Giardia intestinalis & 3.30 & 2.54 & 4.63 & 0.82 & 1.50 & 2,488 & 4,532 \\
\hline Toxoplasma gondii & 2.74 & 33.65 & 39.07 & 10.89 & 12.64 & 39,709 & 46,104 \\
\hline Trichinella spp. & $<0.01$ & 0.01 & 0.03 & $<0.01$ & 0.01 & 9,613 & 18,549 \\
\hline \multicolumn{8}{|l|}{ Viral } \\
\hline$\overline{\text { Astrovirus }}$ & 0.49 & 0.13 & 0.23 & 0.04 & 0.07 & 842 & 1,523 \\
\hline Hepatitis A virus & 0.05 & 0.61 & 0.64 & 0.20 & 0.21 & 40,376 & 42,244 \\
\hline Norovirus & 172.77 & 30.06 & 42.44 & 9.73 & 13.73 & 563 & 795 \\
\hline Rotavirus & 0.49 & 0.12 & 0.21 & 0.04 & 0.07 & 822 & 1,392 \\
\hline Sapovirus & 0.49 & 0.11 & 0.19 & 0.03 & 0.06 & 709 & 1,289 \\
\hline Known & & 190.03 & 401.82 & 61.49 & 130.02 & 1,961 & 4,147 \\
\hline Unknown & $1,214.46$ & 355.14 & 529.45 & 114.92 & 171.32 & 946 & 1,411 \\
\hline Total & & 545.18 & 931.27 & 176.41 & 301.34 & 1,154 & 1,972 \\
\hline
\end{tabular}

${ }^{1}$ Incidence per 10,000 residents. 
TABLE A17. Kansas Cost per Case of Foodborne Illness (by pathogen, \$2013)

\begin{tabular}{|c|c|c|c|c|c|c|c|}
\hline \multirow[b]{2}{*}{ Disease or Agent } & \multirow{2}{*}{$\begin{array}{l}\text { Illness } \\
\text { Incidence }^{1}\end{array}$} & \multicolumn{2}{|c|}{$\begin{array}{l}\text { Total Cost } \\
\text { (\$million) }\end{array}$} & \multicolumn{2}{|c|}{$\begin{array}{l}\text { Cost per } \\
\text { Resident }\end{array}$} & \multicolumn{2}{|c|}{$\begin{array}{c}\text { Cost } \\
\text { per Case }\end{array}$} \\
\hline & & Basic & Enhanced & Basic & Enhanced & Basic 1 & Enhanced \\
\hline \multicolumn{8}{|l|}{ Bacterial } \\
\hline$\overline{\text { Bacillus cereus }}$ & 2.01 & 0.10 & 0.16 & 0.03 & 0.05 & 167 & 269 \\
\hline Brucella spp. & 0.02 & 0.12 & 0.17 & 0.04 & 0.06 & 17,953 & 24,263 \\
\hline Campylobacter spp. & 26.73 & 14.90 & 77.15 & 5.15 & 26.66 & 1,927 & 9,974 \\
\hline Clostridium botulinum & $<0.01$ & 0.72 & 0.92 & 0.25 & 0.32 & $1,428,476$ & $1,825,864$ \\
\hline Clostridium perfringens & 30.56 & 3.62 & 4.77 & 1.25 & 1.65 & 409 & 539 \\
\hline STEC O157:H7 & 2.81 & 8.75 & 9.30 & 3.03 & 3.21 & 10,780 & 11,449 \\
\hline STEC non-0157 & 5.01 & 1.31 & 2.33 & 0.45 & 0.80 & 902 & 1,606 \\
\hline ETEC & 0.57 & 0.14 & 0.26 & 0.05 & 0.09 & 860 & 1,564 \\
\hline Other diarrheogenic E. coli, & 0.38 & 0.09 & 0.17 & 0.03 & 0.06 & 860 & 1,566 \\
\hline Listeria monocytogenes & 0.03 & 11.87 & 12.00 & 4.10 & 4.15 & $1,358,690$ & $1,372,845$ \\
\hline Salmonella, spp., Nontyphoidal & 29.79 & 39.14 & 114.20 & 13.52 & 39.46 & 4,539 & 13,245 \\
\hline S. enterica serotype Typhi & 0.02 & 0.02 & 0.08 & 0.01 & 0.03 & 4,181 & 13,516 \\
\hline Shigella, spp & 3.53 & 2.06 & 12.01 & 0.71 & 4.15 & 2,021 & 11,761 \\
\hline Staphylococcus aureus & 7.63 & 1.24 & 1.76 & 0.43 & 0.61 & 562 & 796 \\
\hline Streptococcus spp. Group A & 0.36 & 0.14 & 0.26 & 0.05 & 0.09 & 1,341 & 2,488 \\
\hline Vibrio cholerae, toxigenic & $<0.01$ & $<0.01$ & $<0.01$ & $<0.01$ & $<0.01$ & 1,522 & 2,608 \\
\hline Vibrio vulnificus & $<0.01$ & 2.45 & 2.45 & 0.84 & 0.85 & $2,978,905$ & $2,980,886$ \\
\hline Vibrio parahaemolyticus & 1.02 & 0.60 & 0.86 & 0.21 & 0.30 & 2,013 & 2,903 \\
\hline Vibrio spp., other & 0.52 & 0.70 & 0.83 & 0.24 & 0.29 & 4,645 & 5,534 \\
\hline Yersinia enterocolitica & 3.09 & 3.85 & 12.14 & 1.33 & 4.19 & 4,309 & 13,579 \\
\hline \multicolumn{8}{|l|}{ Parasitic } \\
\hline$\overline{\text { Cryptosporidium spp. }}$ & 2.48 & 1.50 & 2.43 & 0.52 & 0.84 & 2,087 & 3,373 \\
\hline Cyclospora cayetanensis & 0.02 & 0.01 & 0.01 & $<0.01$ & $<0.01$ & 953 & 1,738 \\
\hline Giardia intestinalis & 2.26 & 1.57 & 2.80 & 0.54 & 0.97 & 2,404 & 4,295 \\
\hline Toxoplasma gondii & 2.74 & 30.43 & 35.14 & 10.51 & 12.14 & 38,345 & 44,277 \\
\hline Trichinella spp. & $<0.01$ & 0.01 & 0.03 & $<0.01$ & 0.01 & 9,434 & 17,707 \\
\hline \multicolumn{8}{|l|}{ Viral } \\
\hline$\overline{\text { Astrovirus }}$ & 0.49 & 0.12 & 0.21 & 0.04 & 0.07 & 832 & 1,462 \\
\hline Hepatitis A virus & 0.03 & 0.33 & 0.35 & 0.11 & 0.12 & 38,287 & 40,016 \\
\hline Norovirus & 172.77 & 27.58 & 38.30 & 9.53 & 13.24 & 552 & 766 \\
\hline Rotavirus & 0.49 & 0.12 & 0.19 & 0.04 & 0.07 & 840 & 1,367 \\
\hline Sapovirus & 0.49 & 0.10 & 0.17 & 0.03 & 0.06 & 697 & 1,233 \\
\hline Known & & 153.60 & 331.42 & 53.07 & 114.52 & 1,794 & 3,871 \\
\hline Unknown & $1,214.46$ & 322.22 & 473.19 & 111.34 & 163.51 & 917 & 1,346 \\
\hline Total & & 475.82 & 804.60 & 164.42 & 278.03 & 1,089 & 1,841 \\
\hline
\end{tabular}

${ }^{1}$ Incidence per 10,000 residents. 
TABLE A18. Kentucky Cost per Case of Foodborne Illness (by pathogen, \$2013)

\begin{tabular}{|c|c|c|c|c|c|c|c|}
\hline \multirow[b]{2}{*}{ Disease or Agent } & \multirow{2}{*}{$\begin{array}{c}\text { Illness } \\
\text { Incidence }^{1} \\
\end{array}$} & \multicolumn{2}{|c|}{$\begin{array}{l}\text { Total Cost } \\
\text { (\$million) }\end{array}$} & \multicolumn{2}{|c|}{$\begin{array}{l}\text { Cost per } \\
\text { Resident }\end{array}$} & \multicolumn{2}{|c|}{$\begin{array}{c}\text { Cost } \\
\text { per Case }\end{array}$} \\
\hline & & Basic & Enhanced & Basic & Enhanced & Basic 1 & Enhanced \\
\hline \multicolumn{8}{|l|}{ Bacterial } \\
\hline$\overline{\text { Bacillus cereus }}$ & 2.01 & 0.13 & 0.20 & 0.03 & 0.05 & 149 & 232 \\
\hline Brucella spp. & 0.01 & 0.06 & 0.08 & 0.01 & 0.02 & 15,248 & 20,416 \\
\hline Campylobacter spp. & 26.73 & 19.28 & 97.52 & 4.39 & 22.19 & 1,641 & 8,300 \\
\hline Clostridium botulinum & $<0.01$ & 0.92 & 1.17 & 0.21 & 0.27 & $1,193,932$ & $1,522,887$ \\
\hline Clostridium perfringens & 30.56 & 4.71 & 6.13 & 1.07 & 1.39 & 350 & 456 \\
\hline STEC O157:H7 & 2.36 & 9.36 & 9.93 & 2.13 & 2.26 & 9,030 & 9,576 \\
\hline STEC non-0157 & 4.21 & 1.44 & 2.50 & 0.33 & 0.57 & 778 & 1,353 \\
\hline ETEC & 0.57 & 0.18 & 0.33 & 0.04 & 0.07 & 740 & 1,315 \\
\hline Other diarrheogenic E. coli, & 0.38 & 0.12 & 0.22 & 0.03 & 0.05 & 740 & 1,316 \\
\hline Listeria monocytogenes & 0.03 & 13.40 & 13.53 & 3.05 & 3.08 & $1,132,572$ & $1,143,457$ \\
\hline Salmonella, spp., Nontyphoidal & 24.63 & 41.48 & 119.46 & 9.44 & 27.18 & 3,831 & 11,034 \\
\hline S. enterica serotype Typhi & 0.01 & 0.02 & 0.07 & 0.01 & 0.02 & 3,705 & 11,422 \\
\hline Shigella, spp & 4.42 & 3.35 & 18.99 & 0.76 & 4.32 & 1,724 & 9,784 \\
\hline Staphylococcus aureus & 7.63 & 1.62 & 2.26 & 0.37 & 0.51 & 484 & 675 \\
\hline Streptococcus spp. Group A & 0.36 & 0.18 & 0.33 & 0.04 & 0.07 & 1,149 & 2,086 \\
\hline Vibrio cholerae, toxigenic & $<0.01$ & $<0.01$ & $<0.01$ & $<0.01$ & $<0.01$ & 1,318 & 2,205 \\
\hline Vibrio vulnificus & $<0.01$ & 0.56 & 0.57 & 0.13 & 0.13 & $2,473,186$ & $2,474,809$ \\
\hline Vibrio parahaemolyticus & 0.19 & 0.14 & 0.20 & 0.03 & 0.05 & 1,704 & 2,430 \\
\hline Vibrio spp., other & 0.10 & 0.16 & 0.19 & 0.04 & 0.04 & 3,886 & 4,611 \\
\hline Yersinia enterocolitica & 3.09 & 4.93 & 15.33 & 1.12 & 3.49 & 3,628 & 11,290 \\
\hline \multicolumn{8}{|l|}{ Parasitic } \\
\hline$\overline{\text { Cryptosporidium spp. }}$ & 1.65 & 1.29 & 2.05 & 0.29 & 0.47 & 1,774 & 2,823 \\
\hline Cyclospora cayetanensis & $<0.01$ & $<0.01$ & $<0.01$ & $<0.01$ & $<0.01$ & 820 & 1,461 \\
\hline Giardia intestinalis & 2.12 & 1.91 & 3.34 & 0.43 & 0.76 & 2,051 & 3,594 \\
\hline Toxoplasma gondii & 2.74 & 38.80 & 44.65 & 8.83 & 10.16 & 32,193 & 37,050 \\
\hline Trichinella spp. & $<0.01$ & 0.02 & 0.03 & $<0.01$ & 0.01 & 8,087 & 14,847 \\
\hline \multicolumn{8}{|l|}{ Viral } \\
\hline$\overline{\text { Astrovirus }}$ & 0.49 & 0.15 & 0.26 & 0.04 & 0.06 & 719 & 1,233 \\
\hline Hepatitis A virus & 0.02 & 0.35 & 0.36 & 0.08 & 0.08 & 31,909 & 33,321 \\
\hline Norovirus & 172.77 & 35.98 & 49.26 & 8.18 & 11.21 & 474 & 649 \\
\hline Rotavirus & 0.49 & 0.16 & 0.25 & 0.04 & 0.06 & 733 & 1,163 \\
\hline Sapovirus & 0.49 & 0.13 & 0.22 & 0.03 & 0.05 & 602 & 1,040 \\
\hline Known & & 180.83 & 389.47 & 41.14 & 88.61 & 1,428 & 3,076 \\
\hline Unknown & $1,214.46$ & 417.30 & 604.46 & 94.94 & 137.52 & 782 & 1,132 \\
\hline Total & & 598.13 & 993.93 & 136.08 & 226.13 & 906 & 1,505 \\
\hline
\end{tabular}

${ }^{1}$ Incidence per 10,000 residents. 
TABLE A19. Louisiana Cost per Case of Foodborne Illness (by pathogen, \$2013)

\begin{tabular}{|c|c|c|c|c|c|c|c|}
\hline \multirow[b]{2}{*}{ Disease or Agent } & \multirow{2}{*}{$\begin{array}{l}\text { Illness } \\
\text { Incidence }^{1}\end{array}$} & \multicolumn{2}{|c|}{$\begin{array}{l}\text { Total Cost } \\
\text { (\$million) }\end{array}$} & \multicolumn{2}{|c|}{$\begin{array}{l}\text { Cost per } \\
\text { Resident }\end{array}$} & \multicolumn{2}{|c|}{$\begin{array}{c}\text { Cost } \\
\text { per Case }\end{array}$} \\
\hline & & Basic & Enhanced & Basic & Enhanced & Basic 1 & Enhanced \\
\hline \multicolumn{8}{|l|}{ Bacterial } \\
\hline$\overline{\text { Bacillus cereus }}$ & 2.01 & 0.14 & 0.21 & 0.03 & 0.05 & 149 & 227 \\
\hline Brucella spp. & 0.01 & 0.10 & 0.13 & 0.02 & 0.03 & 15,432 & 20,283 \\
\hline Campylobacter spp. & 26.73 & 20.31 & 98.66 & 4.39 & 21.33 & 1,643 & 7,980 \\
\hline Clostridium botulinum & $<0.01$ & 0.95 & 1.20 & 0.20 & 0.26 & $1,168,451$ & $1,481,592$ \\
\hline Clostridium perfringens & 30.56 & 4.84 & 6.24 & 1.05 & 1.35 & 343 & 442 \\
\hline STEC O157:H7 & 0.54 & 2.22 & 2.35 & 0.48 & 0.51 & 8,840 & 9,348 \\
\hline STEC non-0157 & 0.97 & 0.35 & 0.59 & 0.08 & 0.13 & 782 & 1,319 \\
\hline ETEC & 0.57 & 0.19 & 0.33 & 0.04 & 0.07 & 736 & 1,273 \\
\hline Other diarrheogenic E. coli, & 0.38 & 0.13 & 0.22 & 0.03 & 0.05 & 735 & 1,274 \\
\hline Listeria monocytogenes & 0.04 & 18.80 & 18.96 & 4.06 & 4.10 & $1,098,460$ & $1,107,790$ \\
\hline Salmonella, spp., Nontyphoidal & 51.75 & 90.84 & 254.82 & 19.64 & 55.09 & 3,795 & 10,645 \\
\hline S. enterica serotype Typhi & 0.01 & 0.01 & 0.03 & $<0.01$ & 0.01 & 4,175 & 11,508 \\
\hline Shigella, spp & 5.78 & 4.61 & 25.11 & 1.00 & 5.43 & 1,725 & 9,393 \\
\hline Staphylococcus aureus & 7.63 & 1.71 & 2.34 & 0.37 & 0.51 & 485 & 664 \\
\hline Streptococcus spp. Group A & 0.36 & 0.19 & 0.33 & 0.04 & 0.07 & 1,136 & 2,011 \\
\hline Vibrio cholerae, toxigenic & 0.01 & $<0.01$ & 0.01 & $<0.01$ & $<0.01$ & 1,351 & 2,179 \\
\hline Vibrio vulnificus & 0.01 & 7.94 & 7.95 & 1.72 & 1.72 & $2,370,828$ & $2,372,352$ \\
\hline Vibrio parahaemolyticus & 2.61 & 2.02 & 2.84 & 0.44 & 0.61 & 1,670 & 2,349 \\
\hline Vibrio spp., other & 1.32 & 2.30 & 2.71 & 0.50 & 0.59 & 3,751 & 4,429 \\
\hline Yersinia enterocolitica & 3.09 & 5.05 & 15.46 & 1.09 & 3.34 & 3,537 & 10,817 \\
\hline \multicolumn{8}{|l|}{ Parasitic } \\
\hline$\overline{\text { Cryptosporidium spp. }}$ & 1.13 & 0.91 & 1.42 & 0.20 & 0.31 & 1,751 & 2,732 \\
\hline Cyclospora cayetanensis & 0.04 & 0.01 & 0.02 & $<0.01$ & 0.01 & 815 & 1,414 \\
\hline Giardia intestinalis & 0.94 & 0.89 & 1.52 & 0.19 & 0.33 & 2,030 & 3,472 \\
\hline Toxoplasma gondii & 2.74 & 40.27 & 46.05 & 8.71 & 9.96 & 31,747 & 36,305 \\
\hline Trichinella spp. & $<0.01$ & 0.02 & 0.03 & $<0.01$ & 0.01 & 8,138 & 14,464 \\
\hline \multicolumn{8}{|l|}{ Viral } \\
\hline$\overline{\text { Astrovirus }}$ & 0.49 & 0.16 & 0.27 & 0.04 & 0.06 & 728 & 1,208 \\
\hline Hepatitis A virus & 0.03 & 0.41 & 0.43 & 0.09 & 0.09 & 30,822 & 32,142 \\
\hline Norovirus & 172.77 & 37.92 & 50.99 & 8.20 & 11.02 & 475 & 638 \\
\hline Rotavirus & 0.49 & 0.17 & 0.26 & 0.04 & 0.06 & 766 & 1,168 \\
\hline Sapovirus & 0.49 & 0.14 & 0.23 & 0.03 & 0.05 & 606 & 1,015 \\
\hline Known & & 243.61 & 541.72 & 52.67 & 117.12 & 1,680 & 3,736 \\
\hline Unknown & $1,214.46$ & 435.12 & 619.18 & 94.07 & 133.86 & 775 & 1,102 \\
\hline Total & & 678.73 & $1,160.90$ & 146.74 & 250.98 & 960 & 1,643 \\
\hline
\end{tabular}

${ }^{1}$ Incidence per 10,000 residents. 
TABLE A20. Maine Cost per Case of Foodborne Illness (by pathogen, \$2013)

\begin{tabular}{|c|c|c|c|c|c|c|c|}
\hline \multirow[b]{2}{*}{ Disease or Agent } & \multirow{2}{*}{$\begin{array}{c}\text { Illness } \\
\text { Incidence }^{1} \\
\end{array}$} & \multicolumn{2}{|c|}{$\begin{array}{l}\text { Total Cost } \\
\text { (\$million) }\end{array}$} & \multicolumn{2}{|c|}{$\begin{array}{l}\text { Cost per } \\
\text { Resident }\end{array}$} & \multicolumn{2}{|c|}{$\begin{array}{c}\text { Cost } \\
\text { per Case }\end{array}$} \\
\hline & & Basic & Enhanced & Basic & Enhanced & Basic 1 & Enhanced \\
\hline \multicolumn{8}{|l|}{ Bacterial } \\
\hline$\overline{\text { Bacillus cereus }}$ & 2.01 & 0.05 & 0.07 & 0.03 & 0.05 & 171 & 269 \\
\hline Brucella spp. & 0.01 & 0.02 & 0.03 & 0.02 & 0.02 & 17,701 & 23,776 \\
\hline Campylobacter spp. & 26.73 & 6.83 & 34.85 & 5.14 & 26.24 & 1,922 & 9,815 \\
\hline Clostridium botulinum & $<0.01$ & 0.33 & 0.42 & 0.24 & 0.31 & $1,398,028$ & $1,787,999$ \\
\hline Clostridium perfringens & 30.56 & 1.67 & 2.17 & 1.25 & 1.63 & 411 & 535 \\
\hline STEC O157:H7 & 2.86 & 4.02 & 4.26 & 3.03 & 3.21 & 10,583 & 11,222 \\
\hline STEC non-0157 & 5.11 & 0.63 & 1.08 & 0.47 & 0.82 & 923 & 1,597 \\
\hline ETEC & 0.57 & 0.07 & 0.12 & 0.05 & 0.09 & 885 & 1,559 \\
\hline Other diarrheogenic E. coli, & 0.38 & 0.04 & 0.08 & 0.03 & 0.06 & 885 & 1,561 \\
\hline Listeria monocytogenes & 0.07 & 12.86 & 12.98 & 9.68 & 9.77 & $1,332,976$ & $1,345,109$ \\
\hline Salmonella, spp., Nontyphoidal & 22.97 & 13.71 & 39.74 & 10.32 & 29.92 & 4,493 & 13,027 \\
\hline S. enterica serotype Typhi & 0.01 & 0.01 & 0.02 & 0.01 & 0.02 & 4,015 & 13,154 \\
\hline Shigella, spp & 0.71 & 0.19 & 1.10 & 0.15 & 0.83 & 2,035 & 11,586 \\
\hline Staphylococcus aureus & 7.63 & 0.57 & 0.80 & 0.43 & 0.60 & 563 & 787 \\
\hline Streptococcus spp. Group A & 0.36 & 0.07 & 0.12 & 0.05 & 0.09 & 1,384 & 2,482 \\
\hline Vibrio cholerae, toxigenic & $<0.01$ & $<0.01$ & $<0.01$ & $<0.01$ & $<0.01$ & 1,542 & 2,582 \\
\hline Vibrio vulnificus & $<0.01$ & 1.45 & 1.45 & 1.09 & 1.09 & $2,926,770$ & $2,928,678$ \\
\hline Vibrio parahaemolyticus & 1.34 & 0.36 & 0.51 & 0.27 & 0.39 & 2,027 & 2,878 \\
\hline Vibrio spp., other & 0.68 & 0.42 & 0.49 & 0.31 & 0.37 & 4,616 & 5,467 \\
\hline Yersinia enterocolitica & 3.09 & 1.77 & 5.50 & 1.34 & 4.14 & 4,325 & 13,398 \\
\hline \multicolumn{8}{|l|}{ Parasitic } \\
\hline 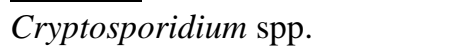 & 2.90 & 0.82 & 1.29 & 0.62 & 0.97 & 2,120 & 3,350 \\
\hline Cyclospora cayetanensis & 0.09 & 0.01 & 0.02 & 0.01 & 0.02 & 981 & 1,733 \\
\hline Giardia intestinalis & 5.09 & 1.67 & 2.89 & 1.26 & 2.18 & 2,466 & 4,276 \\
\hline Toxoplasma gondii & 2.74 & 13.73 & 15.81 & 10.34 & 11.90 & 37,696 & 43,405 \\
\hline Trichinella spp. & $<0.01$ & 0.01 & 0.01 & $<0.01$ & 0.01 & 9,652 & 17,585 \\
\hline \multicolumn{8}{|l|}{ Viral } \\
\hline$\overline{\text { Astrovirus }}$ & 0.49 & 0.06 & 0.09 & 0.04 & 0.07 & 849 & 1,451 \\
\hline Hepatitis A virus & 0.03 & 0.15 & 0.16 & 0.11 & 0.12 & 37,657 & 39,313 \\
\hline Norovirus & 172.77 & 12.66 & 17.37 & 9.53 & 13.08 & 552 & 757 \\
\hline Rotavirus & 0.49 & 0.05 & 0.09 & 0.04 & 0.07 & 843 & 1,347 \\
\hline Sapovirus & 0.49 & 0.05 & 0.08 & 0.03 & 0.06 & 713 & 1,226 \\
\hline Known & & 74.26 & 143.62 & 55.90 & 108.12 & 1,926 & 3,726 \\
\hline Unknown & $1,214.46$ & 148.86 & 215.18 & 112.07 & 161.99 & 923 & 1,334 \\
\hline Total & & 223.12 & 358.79 & 167.97 & 270.11 & 1,116 & 1,795 \\
\hline
\end{tabular}

${ }^{1}$ Incidence per 10,000 residents. 
TABLE A21. Maryland Cost per Case of Foodborne Illness (by pathogen, \$2013)

\begin{tabular}{|c|c|c|c|c|c|c|c|}
\hline \multirow[b]{2}{*}{ Disease or Agent } & \multirow{2}{*}{$\begin{array}{l}\text { Illness } \\
\text { Incidence }^{1}\end{array}$} & \multicolumn{2}{|c|}{$\begin{array}{l}\text { Total Cost } \\
\text { (\$million) }\end{array}$} & \multicolumn{2}{|c|}{$\begin{array}{l}\text { Cost per } \\
\text { Resident }\end{array}$} & \multicolumn{2}{|c|}{$\begin{array}{c}\text { Cost } \\
\text { per Case }\end{array}$} \\
\hline & & Basic & Enhanced & Basic & Enhanced & Basic 1 & Enhanced \\
\hline \multicolumn{8}{|l|}{ Bacterial } \\
\hline$\overline{\text { Bacillus cereus }}$ & 2.01 & 0.24 & 0.42 & 0.04 & 0.07 & 205 & 357 \\
\hline Brucella spp. & 0.01 & 0.19 & 0.26 & 0.03 & 0.04 & 22,542 & 31,810 \\
\hline Campylobacter spp. & 26.73 & 39.04 & 220.88 & 6.58 & 37.26 & 2,463 & 13,938 \\
\hline Clostridium botulinum & $<0.01$ & 2.01 & 2.59 & 0.34 & 0.44 & $1,932,835$ & $2,498,991$ \\
\hline Clostridium perfringens & 30.56 & 9.87 & 13.36 & 1.67 & 2.25 & 545 & 737 \\
\hline STEC O157:H7 & 1.82 & 15.73 & 16.81 & 2.65 & 2.83 & 14,557 & 15,553 \\
\hline STEC non-0157 & 3.25 & 2.18 & 4.19 & 0.37 & 0.71 & 1,128 & 2,172 \\
\hline ETEC & 0.57 & 0.37 & 0.72 & 0.06 & 0.12 & 1,101 & 2,145 \\
\hline Other diarrheogenic E. coli, & 0.38 & 0.25 & 0.48 & 0.04 & 0.08 & 1,101 & 2,148 \\
\hline Listeria monocytogenes & 0.06 & 70.12 & 71.03 & 11.83 & 11.98 & $1,869,555$ & $1,893,900$ \\
\hline Salmonella, spp., Nontyphoidal & 32.25 & 114.01 & 351.58 & 19.23 & 59.30 & 5,963 & 18,389 \\
\hline S. enterica serotype Typhi & 0.10 & 0.24 & 1.05 & 0.04 & 0.18 & 3,878 & 17,229 \\
\hline Shigella, spp & 3.72 & 5.68 & 36.30 & 0.96 & 6.12 & 2,579 & 16,472 \\
\hline Staphylococcus aureus & 7.63 & 3.21 & 4.78 & 0.54 & 0.81 & 710 & 1,057 \\
\hline Streptococcus spp. Group A & 0.36 & 0.37 & 0.72 & 0.06 & 0.12 & 1,737 & 3,438 \\
\hline Vibrio cholerae, toxigenic & 0.01 & 0.01 & 0.01 & $<0.01$ & $<0.01$ & 1,827 & 3,438 \\
\hline Vibrio vulnificus & 0.01 & 17.93 & 17.95 & 3.02 & 3.03 & $4,188,511$ & $4,191,417$ \\
\hline Vibrio parahaemolyticus & 2.61 & 4.15 & 6.19 & 0.70 & 1.04 & 2,683 & 4,002 \\
\hline Vibrio spp., other & 1.32 & 5.03 & 6.06 & 0.85 & 1.02 & 6,417 & 7,735 \\
\hline Yersinia enterocolitica & 3.09 & 10.66 & 34.95 & 1.80 & 5.89 & 5,819 & 19,083 \\
\hline \multicolumn{8}{|l|}{ Parasitic } \\
\hline$\overline{\text { Cryptosporidium spp. }}$ & 0.59 & 0.95 & 1.62 & 0.16 & 0.27 & 2,734 & 4,640 \\
\hline Cyclospora cayetanensis & 0.23 & 0.16 & 0.32 & 0.03 & 0.05 & 1,221 & 2,385 \\
\hline Giardia intestinalis & 1.34 & 2.47 & 4.70 & 0.42 & 0.79 & 3,119 & 5,922 \\
\hline Toxoplasma gondii & 2.74 & 82.92 & 97.09 & 13.99 & 16.38 & 51,003 & 59,719 \\
\hline Trichinella spp. & $<0.01$ & 0.03 & 0.07 & 0.01 & 0.01 & 11,818 & 24,047 \\
\hline \multicolumn{8}{|l|}{ Viral } \\
\hline$\overline{\text { Astrovirus }}$ & 0.49 & 0.30 & 0.57 & 0.05 & 0.10 & 1,025 & 1,959 \\
\hline Hepatitis A virus & 0.06 & 1.89 & 1.98 & 0.32 & 0.33 & 53,040 & 55,597 \\
\hline Norovirus & 172.77 & 71.79 & 104.38 & 12.11 & 17.60 & 701 & 1,019 \\
\hline Rotavirus & 0.49 & 0.28 & 0.50 & 0.05 & 0.09 & 961 & 1,744 \\
\hline Sapovirus & 0.49 & 0.25 & 0.48 & 0.04 & 0.08 & 869 & 1,663 \\
\hline Known & & 462.31 & $1,002.04$ & 77.98 & 169.01 & 2,637 & 5,716 \\
\hline Unknown & $1,214.46$ & 859.02 & $1,317.46$ & 144.89 & 222.21 & 1,193 & 1,830 \\
\hline Total & & $1,321.33$ & $2,319.50$ & 222.87 & 391.23 & 1,476 & 2,591 \\
\hline
\end{tabular}

${ }^{1}$ Incidence per 10,000 residents. 
TABLE A22. Massachusetts Cost per Case of Foodborne Illness (by pathogen, \$2013)

\begin{tabular}{|c|c|c|c|c|c|c|c|}
\hline \multirow[b]{2}{*}{ Disease or Agent } & \multirow{2}{*}{$\begin{array}{c}\text { Illness } \\
\text { Incidence }^{1}\end{array}$} & \multicolumn{2}{|c|}{$\begin{array}{l}\text { Total Cost } \\
\text { (\$million) }\end{array}$} & \multicolumn{2}{|c|}{$\begin{array}{l}\text { Cost per } \\
\text { Resident }\end{array}$} & \multicolumn{2}{|c|}{$\begin{array}{c}\text { Cost } \\
\text { per Case }\end{array}$} \\
\hline & & Basic & Enhanced & Basic & Enhanced & Basic & Enhanced \\
\hline \multicolumn{8}{|l|}{ Bacterial } \\
\hline$\overline{\text { Bacillus cereus }}$ & 2.01 & 0.29 & 0.45 & 0.04 & 0.07 & 213 & 336 \\
\hline Brucella spp. & 0.01 & 0.12 & 0.17 & 0.02 & 0.02 & 22,509 & 30,193 \\
\hline Campylobacter spp. & 26.73 & 44.02 & 224.80 & 6.58 & 33.59 & 2,460 & 12,565 \\
\hline Clostridium botulinum & $<0.01$ & 2.08 & 2.67 & 0.31 & 0.40 & $1,778,985$ & $2,278,394$ \\
\hline Clostridium perfringens & 30.56 & 10.67 & 13.87 & 1.59 & 2.07 & 522 & 678 \\
\hline STEC 0157:H7 & 2.09 & 18.86 & 19.99 & 2.82 & 2.99 & 13,479 & 14,282 \\
\hline STEC non-0157 & 3.73 & 2.99 & 5.11 & 0.45 & 0.76 & 1,197 & 2,046 \\
\hline ETEC & 0.57 & 0.44 & 0.76 & 0.07 & 0.11 & 1,155 & 2,004 \\
\hline Other diarrheogenic E. coli, & 0.38 & 0.29 & 0.51 & 0.04 & 0.08 & 1,155 & 2,006 \\
\hline Listeria monocytogenes & 0.08 & 88.92 & 89.65 & 13.29 & 13.40 & $1,701,692$ & $1,715,780$ \\
\hline Salmonella, spp., Nontyphoidal & 37.85 & 145.46 & 422.13 & 21.73 & 63.07 & 5,742 & $\quad 16,663$ \\
\hline S. enterica serotype Typhi & 0.10 & 0.32 & 1.08 & 0.05 & 0.16 & 4,873 & 16,558 \\
\hline Shigella, spp & 2.07 & 3.64 & 20.58 & 0.54 & 3.08 & 2,624 & 14,850 \\
\hline Staphylococcus aureus & 7.63 & 3.65 & 5.09 & 0.55 & 0.76 & 715 & 997 \\
\hline Streptococcus spp. Group A & 0.36 & 0.43 & 0.76 & 0.06 & 0.11 & 1,817 & 3,200 \\
\hline Vibrio cholerae, toxigenic & $<0.01$ & $<0.01$ & $<0.01$ & $<0.01$ & $<0.01$ & 1,983 & $3 \quad 3,292$ \\
\hline Vibrio vulnificus & $<0.01$ & 6.42 & 6.42 & 0.96 & 0.96 & $3,747,470$ & $3,749,885$ \\
\hline Vibrio parahaemolyticus & 0.92 & 1.62 & 2.28 & 0.24 & 0.34 & 2,622 & 3,695 \\
\hline Vibrio spp., other & 0.47 & 1.86 & 2.20 & 0.28 & 0.33 & 5,944 & 7,015 \\
\hline Yersinia enterocolitica & 3.09 & 11.58 & 35.56 & 1.73 & 5.31 & 5,602 & 17,202 \\
\hline \multicolumn{8}{|l|}{ Parasitic } \\
\hline$\overline{\text { Cryptosporidium spp. }}$ & 1.73 & 3.19 & 4.99 & 0.48 & 0.75 & 2,762 & 4,312 \\
\hline Cyclospora cayetanensis & 0.64 & 0.55 & 0.95 & 0.08 & 0.14 & 1,281 & 2,227 \\
\hline Giardia intestinalis & 3.88 & 8.40 & 14.32 & 1.26 & 2.14 & 3,236 & 5,515 \\
\hline Toxoplasma gondii & 2.74 & 88.20 & 101.45 & 13.18 & 15.16 & 48,060 & 55,279 \\
\hline Trichinella spp. & $<0.01$ & 0.04 & 0.07 & 0.01 & 0.01 & 12,618 & 22,623 \\
\hline \multicolumn{8}{|l|}{ Viral } \\
\hline Astrovirus & 0.49 & 0.36 & 0.61 & 0.05 & 0.09 & 1,097 & 1,856 \\
\hline Hepatitis A virus & 0.09 & 3.04 & 3.18 & 0.45 & 0.47 & 48,160 & 50,248 \\
\hline Norovirus & 172.77 & 81.09 & 110.95 & 12.12 & 16.58 & 701 & 960 \\
\hline Rotavirus & 0.49 & 0.35 & 0.56 & 0.05 & 0.08 & 1,069 & 1,704 \\
\hline Sapovirus & 0.49 & 0.30 & 0.51 & 0.05 & 0.08 & 923 & 1,569 \\
\hline Known & & 529.19 & $1,091.68$ & 79.07 & 163.11 & 2,618 & 5,402 \\
\hline Unknown & $1,214.46$ & 964.77 & $1,385.72$ & 144.15 & 207.04 & 1,187 & 1,705 \\
\hline Total & & $1,493.96$ & $2,477.39$ & 223.22 & 370.16 & 1,472 & 2,441 \\
\hline
\end{tabular}

${ }^{1}$ Incidence per 10,000 residents. 
TABLE A23. Michigan Cost per Case of Foodborne Illness (by pathogen, \$2013)

\begin{tabular}{|c|c|c|c|c|c|c|c|}
\hline \multirow[b]{2}{*}{ Disease or Agent } & \multirow{2}{*}{$\begin{array}{l}\text { Illness } \\
\text { Incidence }^{1}\end{array}$} & \multicolumn{2}{|c|}{$\begin{array}{l}\text { Total Cost } \\
\text { (\$million) }\end{array}$} & \multicolumn{2}{|c|}{$\begin{array}{l}\text { Cost per } \\
\text { Resident }\end{array}$} & \multicolumn{2}{|c|}{$\begin{array}{c}\text { Cost } \\
\text { per Case }\end{array}$} \\
\hline & & Basic & Enhanced & Basic & Enhanced & Basic 1 & Enhanced \\
\hline \multicolumn{8}{|l|}{ Bacterial } \\
\hline$\overline{\text { Bacillus cereus }}$ & 2.01 & 0.33 & 0.53 & 0.03 & 0.05 & 165 & 269 \\
\hline Brucella spp. & 0.03 & 0.48 & 0.65 & 0.05 & 0.07 & 17,787 & 24,189 \\
\hline Campylobacter spp. & 26.73 & 50.31 & 263.65 & 5.08 & 26.64 & 1,902 & 9,967 \\
\hline Clostridium botulinum & $<0.01$ & 2.47 & 3.16 & 0.25 & 0.32 & $1,427,930$ & $1,826,081$ \\
\hline Clostridium perfringens & 30.56 & 12.28 & 16.28 & 1.24 & 1.65 & 406 & 538 \\
\hline STEC O157:H7 & 1.95 & 20.77 & 22.09 & 2.10 & 2.23 & 10,763 & 11,446 \\
\hline STEC non-0157 & 3.48 & 3.02 & 5.49 & 0.31 & 0.56 & 877 & 1,595 \\
\hline ETEC & 0.57 & 0.47 & 0.87 & 0.05 & 0.09 & 835 & 1,553 \\
\hline Other diarrheogenic E. coli, & 0.38 & 0.31 & 0.58 & 0.03 & 0.06 & 835 & 1,555 \\
\hline Listeria monocytogenes & 0.05 & 65.03 & 65.76 & 6.57 & 6.65 & $1,358,040$ & $1,373,424$ \\
\hline Salmonella, spp., Nontyphoidal & 19.90 & 88.71 & 260.62 & 8.96 & 26.34 & 4,504 & 13,233 \\
\hline S. enterica serotype Typhi & 0.04 & 0.15 & 0.50 & 0.02 & 0.05 & 4,138 & 13,506 \\
\hline Shigella, spp & 1.59 & 3.11 & 18.44 & 0.31 & 1.86 & 1,984 & 11,748 \\
\hline Staphylococcus aureus & 7.63 & 4.19 & 5.99 & 0.42 & 0.61 & 555 & 794 \\
\hline Streptococcus spp. Group A & 0.36 & 0.46 & 0.87 & 0.05 & 0.09 & 1,300 & 2,469 \\
\hline Vibrio cholerae, toxigenic & $<0.01$ & $<0.01$ & $<0.01$ & $<0.01$ & $<0.01$ & 1,484 & 2,592 \\
\hline Vibrio vulnificus & $<0.01$ & 2.38 & 2.38 & 0.24 & 0.24 & $2,979,760$ & $2,981,769$ \\
\hline Vibrio parahaemolyticus & 0.29 & 0.57 & 0.83 & 0.06 & 0.08 & 1,982 & 2,888 \\
\hline Vibrio spp., other & 0.15 & 0.67 & 0.81 & 0.07 & 0.08 & 4,615 & 5,521 \\
\hline Yersinia enterocolitica & 3.09 & 12.99 & 41.43 & 1.31 & 4.19 & 4,250 & 13,554 \\
\hline \multicolumn{8}{|l|}{ Parasitic } \\
\hline$\overline{\text { Cryptosporidium spp. }}$ & 1.92 & 3.88 & 6.36 & 0.39 & 0.64 & 2,041 & 3,351 \\
\hline Cyclospora cayetanensis & 0.15 & 0.14 & 0.26 & 0.01 & 0.03 & 926 & 1,726 \\
\hline Giardia intestinalis & 2.46 & 5.68 & 10.36 & 0.57 & 1.05 & 2,335 & 4,261 \\
\hline Toxoplasma gondii & 2.74 & 103.64 & 119.97 & 10.47 & 12.12 & 38,194 & 44,214 \\
\hline Trichinella spp. & $<0.01$ & 0.04 & 0.09 & $<0.01$ & 0.01 & 9,153 & 17,569 \\
\hline \multicolumn{8}{|l|}{ Viral } \\
\hline$\overline{\text { Astrovirus }}$ & 0.49 & 0.39 & 0.70 & 0.04 & 0.07 & 810 & 1,452 \\
\hline Hepatitis A virus & 0.05 & 1.88 & 1.97 & 0.19 & 0.20 & 38,247 & 40,006 \\
\hline Norovirus & 172.77 & 93.28 & 130.63 & 9.43 & 13.20 & 546 & 764 \\
\hline Rotavirus & 0.49 & 0.40 & 0.66 & 0.04 & 0.07 & 823 & 1,360 \\
\hline Sapovirus & 0.49 & 0.33 & 0.59 & 0.03 & 0.06 & 679 & 1,225 \\
\hline Known & & 478.36 & 982.54 & 48.34 & 99.29 & 1,724 & 3,542 \\
\hline Unknown & $1,214.46$ & $1,085.07$ & $1,610.82$ & 109.65 & 162.78 & 903 & 1,340 \\
\hline Total & & $1,563.43$ & $2,593.35$ & 157.99 & 262.07 & 1,057 & 1,753 \\
\hline
\end{tabular}

${ }^{1}$ Incidence per 10,000 residents. 
TABLE A24. Minnesota Cost per Case of Foodborne Illness (by pathogen, \$2013)

\begin{tabular}{|c|c|c|c|c|c|c|c|}
\hline \multirow[b]{2}{*}{ Disease or Agent } & \multirow{2}{*}{$\begin{array}{l}\text { Illness } \\
\text { Incidence }^{1}\end{array}$} & \multicolumn{2}{|c|}{$\begin{array}{l}\text { Total Cost } \\
\text { (\$million) }\end{array}$} & \multicolumn{2}{|c|}{$\begin{array}{l}\text { Cost per } \\
\text { Resident }\end{array}$} & \multicolumn{2}{|c|}{$\begin{array}{c}\text { Cost } \\
\text { per Case }\end{array}$} \\
\hline & & Basic & Enhanced & Basic & Enhanced & Basic 1 & Enhanced \\
\hline \multicolumn{8}{|l|}{ Bacterial } \\
\hline$\overline{\text { Bacillus cereus }}$ & 2.01 & 0.21 & 0.35 & 0.04 & 0.06 & 195 & 320 \\
\hline Brucella spp. & 0.02 & 0.28 & 0.38 & 0.05 & 0.07 & 21,242 & 28,959 \\
\hline Campylobacter spp. & 26.73 & 33.37 & 176.29 & 6.16 & 32.52 & 2,303 & 12,167 \\
\hline Clostridium botulinum & $<0.01$ & 1.63 & 2.09 & 0.30 & 0.39 & $1,720,446$ & $2,207,584$ \\
\hline Clostridium perfringens & 30.56 & 8.15 & 10.78 & 1.50 & 1.99 & 492 & 651 \\
\hline STEC O157:H7 & 5.28 & 37.14 & 39.48 & 6.85 & 7.28 & 12,990 & 13,807 \\
\hline STEC non-0157 & 9.42 & 5.55 & 9.94 & 1.02 & 1.83 & 1,086 & 1,947 \\
\hline ETEC & 0.57 & 0.32 & 0.59 & 0.06 & 0.11 & 1,047 & 1,907 \\
\hline Other diarrheogenic E. coli, & 0.38 & 0.22 & 0.39 & 0.04 & 0.07 & 1,046 & 1,910 \\
\hline Listeria monocytogenes & 0.03 & 22.49 & 22.73 & 4.15 & 4.19 & $1,647,322$ & $1,664,410$ \\
\hline Salmonella, spp., Nontyphoidal & 26.30 & 77.70 & 229.82 & 14.33 & 42.40 & 5,450 & 16,121 \\
\hline S. enterica serotype Typhi & 0.05 & 0.11 & 0.40 & 0.02 & 0.07 & 4,477 & 15,917 \\
\hline Shigella, spp & 2.38 & 3.13 & 18.52 & 0.58 & 3.42 & 2,430 & 14,369 \\
\hline Staphylococcus aureus & 7.63 & 2.76 & 3.94 & 0.51 & 0.73 & 667 & 953 \\
\hline Streptococcus spp. Group A & 0.36 & 0.32 & 0.59 & 0.06 & 0.11 & 1,644 & 3,046 \\
\hline Vibrio cholerae, toxigenic & $<0.01$ & $<0.01$ & $<0.01$ & $<0.01$ & $<0.01$ & 1,802 & 3,130 \\
\hline Vibrio vulnificus & $<0.01$ & 3.81 & 3.81 & 0.70 & 0.70 & $3,639,431$ & $3,641,853$ \\
\hline Vibrio parahaemolyticus & 0.70 & 0.93 & 1.34 & 0.17 & 0.25 & 2,452 & 3,539 \\
\hline Vibrio spp., other & 0.35 & 1.09 & 1.30 & 0.20 & 0.24 & 5,679 & 6,766 \\
\hline Yersinia enterocolitica & 3.09 & 8.82 & 27.84 & 1.63 & 5.14 & 5,266 & 16,626 \\
\hline \multicolumn{8}{|l|}{ Parasitic } \\
\hline$\overline{\text { Cryptosporidium spp. }}$ & 4.00 & 5.52 & 8.93 & 1.02 & 1.65 & 2,546 & 4,118 \\
\hline Cyclospora cayetanensis & 0.09 & 0.06 & 0.11 & 0.01 & 0.02 & 1,161 & 2,120 \\
\hline Giardia intestinalis & 5.86 & 9.35 & 16.69 & 1.73 & 3.08 & 2,945 & 5,256 \\
\hline Toxoplasma gondii & 2.74 & 68.47 & 79.26 & 12.63 & 14.62 & 46,069 & 53,324 \\
\hline Trichinella spp. & $<0.01$ & 0.03 & 0.06 & 0.01 & 0.01 & 11,428 & 21,541 \\
\hline \multicolumn{8}{|l|}{ Viral } \\
\hline$\overline{\text { Astrovirus }}$ & 0.49 & 0.26 & 0.47 & 0.05 & 0.09 & 996 & 1,766 \\
\hline Hepatitis A virus & 0.03 & 0.84 & 0.88 & 0.16 & 0.16 & 46,570 & 48,683 \\
\hline Norovirus & 172.77 & 61.39 & 85.94 & 11.33 & 15.85 & 656 & 918 \\
\hline Rotavirus & 0.49 & 0.26 & 0.43 & 0.05 & 0.08 & 974 & 1,618 \\
\hline Sapovirus & 0.49 & 0.22 & 0.39 & 0.04 & 0.07 & 838 & 1,493 \\
\hline Known & & 354.43 & 743.71 & 65.39 & 137.21 & 2,159 & 4,531 \\
\hline Unknown & $1,214.46$ & 727.83 & $1,073.42$ & 134.28 & 198.03 & 1,106 & 1,631 \\
\hline Total & & $1,082.26$ & $1,817.13$ & 199.67 & 335.24 & 1,316 & 2,210 \\
\hline
\end{tabular}

${ }^{1}$ Incidence per 10,000 residents. 
TABLE A25. Mississippi Cost per Case of Foodborne Illness (by pathogen, \$2013)

\begin{tabular}{|c|c|c|c|c|c|c|c|}
\hline \multirow[b]{2}{*}{ Disease or Agent } & \multirow{2}{*}{$\begin{array}{c}\text { Illness } \\
\text { Incidence }^{1} \\
\end{array}$} & \multicolumn{2}{|c|}{$\begin{array}{l}\text { Total Cost } \\
\text { (\$million) }\end{array}$} & \multicolumn{2}{|c|}{$\begin{array}{l}\text { Cost per } \\
\text { Resident }\end{array}$} & \multicolumn{2}{|c|}{$\begin{array}{c}\text { Cost } \\
\text { per Case }\end{array}$} \\
\hline & & Basic & Enhanced & Basic & Enhanced & Basic 1 & Enhanced \\
\hline \multicolumn{8}{|l|}{ Bacterial } \\
\hline$\overline{\text { Bacillus cereus }}$ & 2.01 & 0.08 & 0.13 & 0.03 & 0.04 & 132 & 210 \\
\hline Brucella spp. & 0.01 & 0.06 & 0.08 & 0.02 & 0.03 & 13,997 & 18,783 \\
\hline Campylobacter spp. & 26.73 & 11.78 & 59.76 & 3.94 & 19.98 & 1,473 & 7,474 \\
\hline Clostridium botulinum & $<0.01$ & 0.57 & 0.73 & 0.19 & 0.24 & $1,093,257$ & $1,389,481$ \\
\hline Clostridium perfringens & 30.56 & 2.85 & 3.75 & 0.95 & 1.26 & 312 & 411 \\
\hline STEC 0157:H7 & 0.69 & 1.71 & 1.82 & 0.57 & 0.61 & 8,234 & 8,746 \\
\hline STEC non-0157 & 1.24 & 0.25 & 0.45 & 0.08 & 0.15 & 671 & 1,208 \\
\hline ETEC & 0.57 & 0.11 & 0.20 & 0.04 & 0.07 & 628 & 1,165 \\
\hline Other diarrheogenic E. coli, & 0.38 & 0.07 & 0.13 & 0.02 & 0.04 & 627 & 1,166 \\
\hline Listeria monocytogenes & 0.02 & 6.93 & 7.01 & 2.32 & 2.34 & $1,028,656$ & $1,040,450$ \\
\hline Salmonella, spp., Nontyphoidal & 76.02 & 78.76 & 226.47 & 26.33 & 75.71 & 3,464 & 9,960 \\
\hline S. enterica serotype Typhi & 0.01 & 0.01 & 0.03 & $<0.01$ & 0.01 & 3,734 & 10,707 \\
\hline Shigella, spp & 7.12 & 3.24 & 18.70 & 1.08 & 6.25 & 1,522 & 8,787 \\
\hline Staphylococcus aureus & 7.63 & 0.99 & 1.40 & 0.33 & 0.47 & 435 & 614 \\
\hline Streptococcus spp. Group A & 0.36 & 0.10 & 0.20 & 0.03 & 0.07 & 964 & 1,839 \\
\hline Vibrio cholerae, toxigenic & $<0.01$ & $<0.01$ & $<0.01$ & $<0.01$ & $<0.01$ & 1,166 & 1,995 \\
\hline Vibrio vulnificus & $<0.01$ & 2.76 & 2.76 & 0.92 & 0.92 & $2,229,050$ & $2,230,552$ \\
\hline Vibrio parahaemolyticus & 1.49 & 0.66 & 0.97 & 0.22 & 0.32 & 1,489 & 2,167 \\
\hline Vibrio spp., other & 0.76 & 0.78 & 0.93 & 0.26 & 0.31 & 3,447 & 4,125 \\
\hline Yersinia enterocolitica & 3.09 & 2.93 & 9.33 & 0.98 & 3.12 & 3,174 & 10,101 \\
\hline \multicolumn{8}{|l|}{ Parasitic } \\
\hline$\overline{\text { Cryptosporidium spp. }}$ & 0.83 & 0.38 & 0.63 & 0.13 & 0.21 & 1,528 & 2,508 \\
\hline Cyclospora cayetanensis & $<0.01$ & $<0.01$ & $<0.01$ & $<0.01$ & $<0.01$ & 695 & 1,294 \\
\hline Giardia intestinalis & 2.11 & 1.10 & 2.01 & 0.37 & 0.67 & 1,735 & 3,176 \\
\hline Toxoplasma gondii & 2.74 & 24.07 & 27.77 & 8.05 & 9.28 & 29,351 & 33,852 \\
\hline Trichinella spp. & $<0.01$ & 0.01 & 0.02 & $<0.01$ & 0.01 & 6,929 & 13,227 \\
\hline \multicolumn{8}{|l|}{ Viral } \\
\hline$\overline{\text { Astrovirus }}$ & 0.49 & 0.09 & 0.16 & 0.03 & 0.05 & 626 & 1,106 \\
\hline Hepatitis A virus & 0.02 & 0.19 & 0.19 & 0.06 & 0.07 & 28,818 & 30,135 \\
\hline Norovirus & 172.77 & 22.04 & 30.50 & 7.37 & 10.20 & 427 & 590 \\
\hline Rotavirus & 0.49 & 0.10 & 0.16 & 0.03 & 0.05 & 668 & 1,071 \\
\hline Sapovirus & 0.49 & 0.08 & 0.14 & 0.03 & 0.05 & 521 & 930 \\
\hline Known & & 162.70 & 396.41 & 54.39 & 132.53 & 1,606 & 3,914 \\
\hline Unknown & $1,214.46$ & 250.41 & 369.40 & 83.71 & 123.49 & 689 & 1,017 \\
\hline Total & & 413.10 & 765.81 & 138.11 & 256.02 & 889 & 1,648 \\
\hline
\end{tabular}

${ }^{1}$ Incidence per 10,000 residents. 
TABLE A26. Missouri Cost per Case of Foodborne Illness (by pathogen, \$2013)

\begin{tabular}{|c|c|c|c|c|c|c|c|}
\hline \multirow[b]{2}{*}{ Disease or Agent } & \multirow{2}{*}{$\begin{array}{l}\text { Illness } \\
\text { Incidence }^{1}\end{array}$} & \multicolumn{2}{|c|}{$\begin{array}{l}\text { Total Cost } \\
\text { (\$million) }\end{array}$} & \multicolumn{2}{|c|}{$\begin{array}{l}\text { Cost per } \\
\text { Resident }\end{array}$} & \multicolumn{2}{|c|}{$\begin{array}{c}\text { Cost } \\
\text { per Case }\end{array}$} \\
\hline & & Basic & Enhanced & Basic & Enhanced & Basic 1 & Enhanced \\
\hline \multicolumn{8}{|l|}{ Bacterial } \\
\hline$\overline{\text { Bacillus cereus }}$ & 2.01 & 0.20 & 0.33 & 0.03 & 0.05 & 166 & 268 \\
\hline Brucella spp. & 0.01 & 0.16 & 0.22 & 0.03 & 0.04 & 18,326 & 24,648 \\
\hline Campylobacter spp. & 26.73 & 31.39 & 160.93 & 5.19 & 26.63 & 1,943 & 9,961 \\
\hline Clostridium botulinum & $<0.01$ & 1.53 & 1.94 & 0.25 & 0.32 & $1,442,546$ & $1,838,413$ \\
\hline Clostridium perfringens & 30.56 & 7.51 & 9.92 & 1.24 & 1.64 & 407 & 537 \\
\hline STEC O157:H7 & 3.87 & 25.43 & 27.00 & 4.21 & 4.47 & 10,867 & 11,539 \\
\hline STEC non-0157 & 6.91 & 3.75 & 6.70 & 0.62 & 1.11 & 897 & 1,604 \\
\hline ETEC & 0.57 & 0.29 & 0.53 & 0.05 & 0.09 & 848 & 1,555 \\
\hline Other diarrheogenic E. coli, & 0.38 & 0.19 & 0.36 & 0.03 & 0.06 & 848 & 1,556 \\
\hline Listeria monocytogenes & 0.03 & 28.32 & 28.63 & 4.69 & 4.74 & $1,364,664$ & $1,379,296$ \\
\hline Salmonella, spp., Nontyphoidal & 28.65 & 79.26 & 229.49 & 13.11 & 37.97 & 4,577 & 13,253 \\
\hline S. enterica serotype Typhi & 0.02 & 0.05 & 0.15 & 0.01 & 0.03 & 4,569 & 13,875 \\
\hline Shigella, spp & 7.58 & 9.29 & 53.77 & 1.54 & 8.90 & 2,026 & 11,731 \\
\hline Staphylococcus aureus & 7.63 & 2.61 & 3.69 & 0.43 & 0.61 & 566 & 801 \\
\hline Streptococcus spp. Group A & 0.36 & 0.28 & 0.53 & 0.05 & 0.09 & 1,317 & 2,468 \\
\hline Vibrio cholerae, toxigenic & $<0.01$ & $<0.01$ & $<0.01$ & $<0.01$ & $<0.01$ & 1,537 & 2,628 \\
\hline Vibrio vulnificus & $<0.01$ & 1.36 & 1.36 & 0.22 & 0.22 & $2,974,269$ & $2,976,253$ \\
\hline Vibrio parahaemolyticus & 0.27 & 0.33 & 0.48 & 0.05 & 0.08 & 2,000 & 2,893 \\
\hline Vibrio spp., other & 0.14 & 0.39 & 0.46 & 0.06 & 0.08 & 4,620 & 5,512 \\
\hline Yersinia enterocolitica & 3.09 & 7.99 & 25.24 & 1.32 & 4.18 & 4,278 & 13,520 \\
\hline \multicolumn{8}{|l|}{ Parasitic } \\
\hline$\overline{\text { Cryptosporidium spp. }}$ & 3.03 & 3.79 & 6.16 & 0.63 & 1.02 & 2,068 & 3,359 \\
\hline Cyclospora cayetanensis & 0.06 & 0.03 & 0.06 & 0.01 & 0.01 & 939 & 1,727 \\
\hline Giardia intestinalis & 2.79 & 4.00 & 7.20 & 0.66 & 1.19 & 2,371 & 4,268 \\
\hline Toxoplasma gondii & 2.74 & 64.22 & 74.07 & 10.63 & 12.26 & 38,750 & 44,693 \\
\hline Trichinella spp. & $<0.01$ & 0.03 & 0.05 & $<0.01$ & 0.01 & 9,392 & 17,689 \\
\hline \multicolumn{8}{|l|}{ Viral } \\
\hline$\overline{\text { Astrovirus }}$ & 0.49 & 0.25 & 0.43 & 0.04 & 0.07 & 832 & 1,464 \\
\hline Hepatitis A virus & 0.02 & 0.53 & 0.56 & 0.09 & 0.09 & 38,329 & 40,063 \\
\hline Norovirus & 172.77 & 58.03 & 80.50 & 9.60 & 13.32 & 556 & 771 \\
\hline Rotavirus & 0.49 & 0.25 & 0.41 & 0.04 & 0.07 & 863 & 1,392 \\
\hline Sapovirus & 0.49 & 0.20 & 0.36 & 0.03 & 0.06 & 694 & 1,232 \\
\hline Known & & 331.67 & 721.53 & 54.87 & 119.38 & 1,819 & 3,957 \\
\hline Unknown & $1,214.46$ & 671.85 & 988.25 & 111.16 & 163.50 & 915 & 1,346 \\
\hline Total & & $1,003.52$ & $1,709.78$ & 166.03 & 282.88 & 1,095 & 1,866 \\
\hline
\end{tabular}

${ }^{1}$ Incidence per 10,000 residents. 
TABLE A27. Montana Cost per Case of Foodborne Illness (by pathogen, \$2013)

\begin{tabular}{|c|c|c|c|c|c|c|c|}
\hline \multirow[b]{2}{*}{ Disease or Agent } & \multirow{2}{*}{$\begin{array}{l}\text { Illness } \\
\text { Incidence }^{1}\end{array}$} & \multicolumn{2}{|c|}{$\begin{array}{l}\text { Total Cost } \\
\text { (\$million) }\end{array}$} & \multicolumn{2}{|c|}{$\begin{array}{l}\text { Cost per } \\
\text { Resident }\end{array}$} & \multicolumn{2}{|c|}{$\begin{array}{c}\text { Cost } \\
\text { per Case }\end{array}$} \\
\hline & & Basic & Enhanced & Basic & Enhanced & Basic 1 & Enhanced \\
\hline \multicolumn{8}{|l|}{ Bacterial } \\
\hline$\overline{\text { Bacillus cereus }}$ & 2.01 & 0.03 & 0.05 & 0.03 & 0.05 & 160 & 251 \\
\hline Brucella spp. & $<0.01$ & $<0.01$ & $<0.01$ & $<0.01$ & $<0.01$ & 15,766 & 21,405 \\
\hline Campylobacter spp. & 26.73 & 4.70 & 24.44 & 4.63 & 24.07 & 1,731 & 9,006 \\
\hline Clostridium botulinum & $<0.01$ & 0.23 & 0.29 & 0.22 & 0.28 & $1,268,747$ & $1,628,112$ \\
\hline Clostridium perfringens & 30.56 & 1.18 & 1.54 & 1.16 & 1.52 & 380 & 496 \\
\hline STEC 0157:H7 & 3.19 & 3.12 & 3.31 & 3.07 & 3.26 & 9,618 & 10,213 \\
\hline STEC non-0157 & 5.70 & 0.48 & 0.84 & 0.47 & 0.83 & 833 & 1,460 \\
\hline ETEC & 0.57 & 0.05 & 0.08 & 0.05 & 0.08 & 805 & 1,432 \\
\hline Other diarrheogenic E. coli, & 0.38 & 0.03 & 0.06 & 0.03 & 0.05 & 804 & 1,433 \\
\hline Listeria monocytogenes & 0.02 & 2.44 & 2.46 & 2.40 & 2.42 & $1,215,998$ & $1,227,790$ \\
\hline Salmonella, spp., Nontyphoidal & 25.90 & 10.67 & 31.36 & 10.51 & 30.89 & 4,060 & 11,927 \\
\hline S. enterica serotype Typhi & $<0.01$ & $<0.01$ & 0.01 & $<0.01$ & 0.01 & 3,321 & 11,750 \\
\hline Shigella, spp & 1.82 & 0.34 & 1.96 & 0.33 & 1.93 & 1,833 & 10,637 \\
\hline Staphylococcus aureus & 7.63 & 0.40 & 0.56 & 0.39 & 0.55 & 511 & 720 \\
\hline Streptococcus spp. Group A & 0.36 & 0.05 & 0.08 & 0.04 & 0.08 & 1,258 & 2,279 \\
\hline Vibrio cholerae, toxigenic & $<0.01$ & $<0.01$ & $<0.01$ & $<0.01$ & $<0.01$ & 1,374 & 2,342 \\
\hline Vibrio vulnificus & $<0.01$ & 0.77 & 0.77 & 0.76 & 0.76 & $2,687,003$ & $2,688,774$ \\
\hline Vibrio parahaemolyticus & 1.02 & 0.19 & 0.27 & 0.19 & 0.27 & 1,846 & 2,638 \\
\hline Vibrio spp., other & 0.52 & 0.22 & 0.26 & 0.22 & 0.26 & 4,230 & 5,021 \\
\hline Yersinia enterocolitica & 3.09 & 1.24 & 3.86 & 1.22 & 3.80 & 3,942 & 12,311 \\
\hline \multicolumn{8}{|l|}{ Parasitic } \\
\hline$\overline{\text { Cryptosporidium spp. }}$ & 4.44 & 0.87 & 1.38 & 0.85 & 1.36 & 1,921 & 3,066 \\
\hline Cyclospora cayetanensis & $<0.01$ & $<0.01$ & $<0.01$ & $<0.01$ & $<0.01$ & 892 & 1,591 \\
\hline Giardia intestinalis & 3.38 & 0.77 & 1.34 & 0.75 & 1.32 & 2,231 & 3,915 \\
\hline Toxoplasma gondii & 2.74 & 9.49 & 10.96 & 9.34 & 10.80 & 34,074 & 39,374 \\
\hline Trichinella spp. & $<0.01$ & $<0.01$ & 0.01 & $<0.01$ & 0.01 & 8,643 & 16,017 \\
\hline \multicolumn{8}{|l|}{ Viral } \\
\hline$\overline{\text { Astrovirus }}$ & 0.49 & 0.04 & 0.07 & 0.04 & 0.06 & 763 & 1,323 \\
\hline Hepatitis A virus & 0.03 & 0.10 & 0.10 & 0.10 & 0.10 & 34,456 & 35,996 \\
\hline Norovirus & 172.77 & 8.79 & 12.13 & 8.65 & 11.95 & 501 & 692 \\
\hline Rotavirus & 0.49 & 0.04 & 0.06 & 0.04 & 0.06 & 743 & 1,212 \\
\hline Sapovirus & 0.49 & 0.03 & 0.06 & 0.03 & 0.05 & 644 & 1,121 \\
\hline Known & & 46.24 & 98.32 & 45.55 & 96.85 & 1,548 & 3,291 \\
\hline Unknown & $1,214.46$ & 103.41 & 150.56 & 101.87 & 148.31 & 839 & 1,221 \\
\hline Total & & 149.65 & 248.88 & 147.41 & 245.16 & 977 & 1,625 \\
\hline
\end{tabular}

${ }^{1}$ Incidence per 10,000 residents. 
TABLE A28. Nebraska Cost per Case of Foodborne Illness (by pathogen, \$2013)

\begin{tabular}{|c|c|c|c|c|c|c|c|}
\hline \multirow[b]{2}{*}{ Disease or Agent } & \multirow{2}{*}{$\begin{array}{c}\text { Illness } \\
\text { Incidence }^{1}\end{array}$} & \multicolumn{2}{|c|}{$\begin{array}{l}\text { Total Cost } \\
\text { (\$million) }\end{array}$} & \multicolumn{2}{|c|}{$\begin{array}{l}\text { Cost per } \\
\text { Resident }\end{array}$} & \multicolumn{2}{|c|}{$\begin{array}{c}\text { Cost } \\
\text { per Case }\end{array}$} \\
\hline & & Basic & Enhanced & Basic & Enhanced & Basic & Enhanced \\
\hline \multicolumn{8}{|l|}{ Bacterial } \\
\hline$\overline{\text { Bacillus cereus }}$ & 2.01 & 0.06 & 0.10 & 0.03 & 0.06 & 173 & 278 \\
\hline Brucella spp. & 0.04 & 0.15 & 0.21 & 0.08 & 0.11 & 18,414 & 24,941 \\
\hline Campylobacter spp. & 26.73 & 9.95 & 51.80 & 5.33 & 27.72 & 1,993 & 10,370 \\
\hline Clostridium botulinum & $<0.01$ & 0.48 & 0.62 & 0.26 & 0.33 & $1,473,952$ & $1,887,705$ \\
\hline Clostridium perfringens & 30.56 & 2.43 & 3.19 & 1.30 & 1.71 & 426 & 560 \\
\hline STEC 0157:H7 & 6.26 & 13.04 & 13.84 & 6.98 & 7.41 & 11,137 & 11,827 \\
\hline STEC non-0157 & 11.18 & 1.97 & 3.49 & 1.06 & 1.87 & 943 & 1,671 \\
\hline ETEC & 0.57 & 0.10 & 0.17 & 0.05 & 0.09 & 906 & 1,633 \\
\hline Other diarrheogenic E. coli, & 0.38 & 0.06 & 0.12 & 0.03 & 0.06 & 905 & 1,634 \\
\hline Listeria monocytogenes & 0.04 & 11.53 & 11.64 & 6.17 & 6.23 & $1,407,288$ & $1,421,384$ \\
\hline Salmonella, spp., Nontyphoidal & 27.96 & 24.52 & 71.87 & 13.12 & 38.46 & 4,693 & 13,754 \\
\hline S. enterica serotype Typhi & 0.04 & 0.03 & 0.10 & 0.02 & 0.05 & 4,070 & 13,781 \\
\hline Shigella, spp & 4.05 & 1.59 & 9.26 & 0.85 & 4.96 & 2,102 & 12,241 \\
\hline Staphylococcus aureus & 7.63 & 0.83 & 1.17 & 0.44 & 0.63 & 580 & 822 \\
\hline Streptococcus spp. Group A & 0.36 & 0.09 & 0.17 & 0.05 & 0.09 & 1,418 & 2,602 \\
\hline Vibrio cholerae, toxigenic & $<0.01$ & $<0.01$ & $<0.01$ & $<0.01$ & $<0.01$ & 1,575 & 2,697 \\
\hline Vibrio vulnificus & $<0.01$ & 1.64 & 1.64 & 0.88 & 0.88 & $3,097,768$ & $3,099,817$ \\
\hline Vibrio parahaemolyticus & 1.02 & 0.40 & 0.58 & 0.22 & 0.31 & 2,106 & 3,024 \\
\hline Vibrio spp., other & 0.52 & 0.47 & 0.56 & 0.25 & 0.30 & 4,849 & 5,766 \\
\hline Yersinia enterocolitica & 3.09 & 2.60 & 8.17 & 1.39 & 4.37 & 4,510 & 14,153 \\
\hline \multicolumn{8}{|l|}{ Parasitic } \\
\hline$\overline{\text { Cryptosporidium spp. }}$ & 5.04 & 2.06 & 3.31 & 1.10 & 1.77 & 2,191 & 3,518 \\
\hline Cyclospora cayetanensis & 0.05 & 0.01 & 0.02 & $<0.01$ & 0.01 & 1,004 & 1,814 \\
\hline Giardia intestinalis & 3.19 & 1.51 & 2.68 & 0.81 & 1.43 & 2,535 & 4,487 \\
\hline Toxoplasma gondii & 2.74 & 20.28 & 23.42 & 10.85 & 12.53 & 39,573 & 45,708 \\
\hline Trichinella spp. & $<0.01$ & 0.01 & 0.02 & $<0.01$ & 0.01 & 9,890 & 18,435 \\
\hline \multicolumn{8}{|l|}{ Viral } \\
\hline$\overline{\text { Astrovirus }}$ & 0.49 & 0.08 & 0.14 & 0.04 & 0.07 & 867 & 1,517 \\
\hline Hepatitis A virus & 0.04 & 0.29 & 0.30 & 0.15 & 0.16 & 39,747 & 41,532 \\
\hline Norovirus & 172.77 & 18.40 & 25.54 & 9.85 & 13.67 & 570 & 791 \\
\hline Rotavirus & 0.49 & 0.08 & 0.13 & 0.04 & 0.07 & 859 & 1,403 \\
\hline Sapovirus & 0.49 & 0.07 & 0.12 & 0.04 & 0.06 & 728 & 1,282 \\
\hline Known & & 114.74 & 234.37 & 61.41 & 125.43 & 1,995 & 4,076 \\
\hline Unknown & $1,214.46$ & 216.70 & 317.32 & 115.97 & 169.82 & 955 & 1,398 \\
\hline Total & & 331.43 & 551.69 & 177.38 & 295.25 & 1,165 & 1,940 \\
\hline
\end{tabular}

${ }^{1}$ Incidence per 10,000 residents. 
TABLE A29. Nevada Cost per Case of Foodborne Illness (by pathogen, \$2013)

\begin{tabular}{|c|c|c|c|c|c|c|c|}
\hline \multirow[b]{2}{*}{ Disease or Agent } & \multirow{2}{*}{$\begin{array}{l}\text { Illness } \\
\text { Incidence }^{1}\end{array}$} & \multicolumn{2}{|c|}{$\begin{array}{l}\text { Total Cost } \\
\text { (\$million) }\end{array}$} & \multicolumn{2}{|c|}{$\begin{array}{l}\text { Cost per } \\
\text { Resident }\end{array}$} & \multicolumn{2}{|c|}{$\begin{array}{c}\text { Cost } \\
\text { per Case }\end{array}$} \\
\hline & & Basic & Enhanced & Basic & Enhanced & Basic 1 & Enhanced \\
\hline \multicolumn{8}{|l|}{ Bacterial } \\
\hline$\overline{\text { Bacillus cereus }}$ & 2.01 & 0.09 & 0.15 & 0.03 & 0.05 & 164 & 262 \\
\hline Brucella spp. & 0.02 & 0.09 & 0.12 & 0.03 & 0.04 & 18,084 & 24,103 \\
\hline Campylobacter spp. & 26.73 & 14.18 & 71.16 & 5.08 & 25.51 & 1,901 & 9,542 \\
\hline Clostridium botulinum & $<0.01$ & 0.68 & 0.87 & 0.24 & 0.31 & $1,398,549$ & $1,775,827$ \\
\hline Clostridium perfringens & 30.56 & 3.36 & 4.42 & 1.20 & 1.58 & 394 & 518 \\
\hline STEC O157:H7 & 1.52 & 4.47 & 4.74 & 1.60 & 1.70 & 10,533 & 11,172 \\
\hline STEC non-0157 & 2.72 & 0.66 & 1.17 & 0.24 & 0.42 & 874 & 1,546 \\
\hline ETEC & 0.57 & 0.13 & 0.24 & 0.05 & 0.08 & 818 & 1,491 \\
\hline Other diarrheogenic E. coli, & 0.38 & 0.09 & 0.16 & 0.03 & 0.06 & 818 & 1,493 \\
\hline Listeria monocytogenes & 0.03 & 10.29 & 10.40 & 3.69 & 3.73 & $1,314,993$ & $1,328,859$ \\
\hline Salmonella, spp., Nontyphoidal & 17.11 & 21.27 & 60.74 & 7.62 & 21.77 & 4,456 & 12,724 \\
\hline S. enterica serotype Typhi & 0.03 & 0.04 & 0.11 & 0.01 & 0.04 & 4,850 & 13,718 \\
\hline Shigella, spp & 2.22 & 1.22 & 6.94 & 0.44 & 2.49 & 1,975 & 11,224 \\
\hline Staphylococcus aureus & 7.63 & 1.18 & 1.66 & 0.42 & 0.59 & 556 & 780 \\
\hline Streptococcus spp. Group A & 0.36 & 0.13 & 0.23 & 0.04 & 0.08 & 1,263 & 2,359 \\
\hline Vibrio cholerae, toxigenic & $<0.01$ & $<0.01$ & $<0.01$ & $<0.01$ & $<0.01$ & 1,520 & 2,558 \\
\hline Vibrio vulnificus & $<0.01$ & 1.19 & 1.19 & 0.43 & 0.43 & $2,844,907$ & $2,846,796$ \\
\hline Vibrio parahaemolyticus & 0.54 & 0.29 & 0.42 & 0.10 & 0.15 & 1,925 & 2,775 \\
\hline Vibrio spp., other & 0.27 & 0.34 & 0.40 & 0.12 & 0.14 & 4,422 & 5,272 \\
\hline Yersinia enterocolitica & 3.09 & 3.54 & 11.13 & 1.27 & 3.99 & 4,104 & 12,910 \\
\hline \multicolumn{8}{|l|}{ Parasitic } \\
\hline$\overline{\text { Cryptosporidium spp. }}$ & 0.52 & 0.29 & 0.46 & 0.10 & 0.17 & 1,991 & 3,220 \\
\hline Cyclospora cayetanensis & $<0.01$ & $<0.01$ & $<0.01$ & $<0.01$ & $<0.01$ & 906 & 1,656 \\
\hline Giardia intestinalis & 1.50 & 0.95 & 1.70 & 0.34 & 0.61 & 2,277 & 4,083 \\
\hline Toxoplasma gondii & 2.74 & 28.83 & 33.16 & 10.33 & 11.88 & 37,683 & 43,341 \\
\hline Trichinella spp. & $<0.01$ & 0.01 & 0.02 & $<0.01$ & 0.01 & 9,120 & 17,020 \\
\hline \multicolumn{8}{|l|}{ Viral } \\
\hline$\overline{\text { Astrovirus }}$ & 0.49 & 0.11 & 0.19 & 0.04 & 0.07 & 815 & 1,417 \\
\hline Hepatitis A virus & 0.03 & 0.30 & 0.32 & 0.11 & 0.11 & 36,824 & 38,475 \\
\hline Norovirus & 172.77 & 26.30 & 36.17 & 9.43 & 12.97 & 546 & 750 \\
\hline Rotavirus & 0.49 & 0.12 & 0.19 & 0.04 & 0.07 & 868 & 1,371 \\
\hline Sapovirus & 0.49 & 0.09 & 0.16 & 0.03 & 0.06 & 677 & 1,189 \\
\hline Known & & 120.25 & 248.65 & 43.10 & 89.12 & 1,568 & 3,243 \\
\hline Unknown & $1,214.46$ & 301.03 & 440.07 & 107.89 & 157.72 & 888 & 1,299 \\
\hline Total & & 421.29 & 688.72 & 150.99 & 246.84 & 1,014 & 1,657 \\
\hline
\end{tabular}

${ }^{1}$ Incidence per 10,000 residents. 
TABLE A30. New Hampshire Cost per Case of Foodborne Illness (by pathogen, \$2013)

\begin{tabular}{|c|c|c|c|c|c|c|c|}
\hline \multirow[b]{2}{*}{ Disease or Agent } & \multirow{2}{*}{$\begin{array}{l}\text { Illness } \\
\text { Incidence }^{1}\end{array}$} & \multicolumn{2}{|c|}{$\begin{array}{l}\text { Total Cost } \\
\text { (\$million) }\end{array}$} & \multicolumn{2}{|c|}{$\begin{array}{l}\text { Cost per } \\
\text { Resident }\end{array}$} & \multicolumn{2}{|c|}{$\begin{array}{c}\text { Cost } \\
\text { per Case }\end{array}$} \\
\hline & & Basic & Enhanced & Basic & Enhanced & Basic 1 & Enhanced \\
\hline \multicolumn{8}{|l|}{ Bacterial } \\
\hline$\overline{\text { Bacillus cereus }}$ & 2.01 & 0.05 & 0.09 & 0.04 & 0.07 & 196 & 339 \\
\hline Brucella spp. & 0.01 & 0.03 & 0.04 & 0.02 & 0.03 & 22,263 & 31,039 \\
\hline Campylobacter spp. & 26.73 & 8.47 & 46.86 & 6.40 & 35.41 & 2,393 & 13,246 \\
\hline Clostridium botulinum & $<0.01$ & 0.43 & 0.56 & 0.33 & 0.42 & $1,865,921$ & $2,401,413$ \\
\hline Clostridium perfringens & 30.56 & 2.09 & 2.83 & 1.58 & 2.14 & 517 & 699 \\
\hline STEC O157:H7 & 2.80 & 5.20 & 5.54 & 3.93 & 4.19 & 14,029 & 14,972 \\
\hline STEC non-0157 & 5.00 & 0.72 & 1.37 & 0.54 & 1.03 & 1,082 & 2,072 \\
\hline ETEC & 0.57 & 0.08 & 0.15 & 0.06 & 0.12 & 1,043 & 2,033 \\
\hline Other diarrheogenic E. coli, & 0.38 & 0.05 & 0.10 & 0.04 & 0.08 & 1,043 & 2,035 \\
\hline Listeria monocytogenes & 0.07 & 15.98 & 16.18 & 12.07 & 12.23 & $1,790,840$ & $1,814,016$ \\
\hline Salmonella, spp., Nontyphoidal & 28.48 & 21.75 & 66.05 & 16.44 & 49.90 & 5,772 & 17,526 \\
\hline S. enterica serotype Typhi & 0.04 & 0.02 & 0.09 & 0.02 & 0.07 & 4,439 & 17,068 \\
\hline Shigella, spp & 0.63 & 0.21 & 1.30 & 0.16 & 0.99 & 2,491 & 15,633 \\
\hline Staphylococcus aureus & 7.63 & 0.70 & 1.03 & 0.53 & 0.78 & 689 & 1,017 \\
\hline Streptococcus spp. Group A & 0.36 & 0.08 & 0.15 & 0.06 & 0.12 & 1,639 & 3,249 \\
\hline Vibrio cholerae, toxigenic & $<0.01$ & $<0.01$ & $<0.01$ & $<0.01$ & $<0.01$ & 1,794 & 3,321 \\
\hline Vibrio vulnificus & $<0.01$ & 1.21 & 1.21 & 0.91 & 0.92 & $3,977,260$ & $3,980,012$ \\
\hline Vibrio parahaemolyticus & 0.83 & 0.28 & 0.42 & 0.21 & 0.32 & 2,552 & 3,801 \\
\hline Vibrio spp., other & 0.42 & 0.34 & 0.41 & 0.26 & 0.31 & 6,083 & 7,332 \\
\hline Yersinia enterocolitica & 3.09 & 2.26 & 7.39 & 1.71 & 5.58 & 5,524 & 18,071 \\
\hline \multicolumn{8}{|l|}{ Parasitic } \\
\hline$\overline{\text { Cryptosporidium spp. }}$ & 3.12 & 1.07 & 1.82 & 0.81 & 1.37 & 2,601 & 4,407 \\
\hline Cyclospora cayetanensis & 0.13 & 0.02 & 0.04 & 0.01 & 0.03 & 1,157 & 2,259 \\
\hline Giardia intestinalis & 2.44 & 0.95 & 1.81 & 0.72 & 1.37 & 2,956 & 5,611 \\
\hline Toxoplasma gondii & 2.74 & 17.93 & 20.92 & 13.55 & 15.81 & 49,398 & 57,651 \\
\hline Trichinella spp. & $<0.01$ & 0.01 & 0.01 & 0.01 & 0.01 & 11,370 & 22,953 \\
\hline \multicolumn{8}{|l|}{ Viral } \\
\hline$\overline{\text { Astrovirus }}$ & 0.49 & 0.06 & 0.12 & 0.05 & 0.09 & 992 & 1,877 \\
\hline Hepatitis A virus & 0.06 & 0.38 & 0.39 & 0.28 & 0.30 & 50,589 & 53,011 \\
\hline Norovirus & 172.77 & 15.54 & 22.43 & 11.74 & 16.95 & 680 & 981 \\
\hline Rotavirus & 0.49 & 0.06 & 0.11 & 0.05 & 0.08 & 969 & 1,710 \\
\hline Sapovirus & 0.49 & 0.05 & 0.10 & 0.04 & 0.08 & 835 & 1,588 \\
\hline Known & & 96.01 & 199.53 & 72.54 & 150.77 & 2,482 & 5,158 \\
\hline Unknown & $1,214.46$ & 183.75 & 280.69 & 138.84 & 212.09 & 1,143 & 1,746 \\
\hline Total & & 279.76 & 480.22 & 211.38 & 362.85 & 1,403 & 2,408 \\
\hline
\end{tabular}

${ }^{1}$ Incidence per 10,000 residents. 
TABLE A31. New Jersey Cost per Case of Foodborne Illness (by pathogen, \$2013)

\begin{tabular}{|c|c|c|c|c|c|c|c|}
\hline \multirow[b]{2}{*}{ Disease or Agent } & \multirow{2}{*}{$\begin{array}{l}\text { Illness } \\
\text { Incidence }^{1}\end{array}$} & \multicolumn{2}{|c|}{$\begin{array}{l}\text { Total Cost } \\
\text { (\$million) }\end{array}$} & \multicolumn{2}{|c|}{$\begin{array}{l}\text { Cost per } \\
\text { Resident }\end{array}$} & \multicolumn{2}{|c|}{$\begin{array}{c}\text { Cost } \\
\text { per Case }\end{array}$} \\
\hline & & Basic & Enhanced & Basic & Enhanced & Basic 1 & Enhanced \\
\hline \multicolumn{8}{|l|}{ Bacterial } \\
\hline$\overline{\text { Bacillus cereus }}$ & 2.01 & 0.36 & 0.61 & 0.04 & 0.07 & 202 & 342 \\
\hline Brucella spp. & 0.01 & 0.21 & 0.29 & 0.02 & 0.03 & 23,770 & 32,328 \\
\hline Campylobacter spp. & 26.73 & 59.47 & 313.17 & 6.68 & 35.19 & 2,500 & 13,165 \\
\hline Clostridium botulinum & $<0.01$ & 2.97 & 3.79 & 0.33 & 0.43 & $1,904,200$ & $2,430,501$ \\
\hline Clostridium perfringens & 30.56 & 14.14 & 18.96 & 1.59 & 2.13 & 520 & 697 \\
\hline STEC O157:H7 & 1.60 & 20.32 & 21.62 & 2.28 & 2.43 & 14,299 & 15,216 \\
\hline STEC non-0157 & 2.85 & 2.85 & 5.30 & 0.32 & 0.60 & 1,125 & 2,087 \\
\hline ETEC & 0.57 & 0.54 & 1.02 & 0.06 & 0.11 & 1,062 & 2,025 \\
\hline Other diarrheogenic E. coli, & 0.38 & 0.36 & 0.68 & 0.04 & 0.08 & 1,062 & 2,027 \\
\hline Listeria monocytogenes & 0.08 & 132.98 & 134.58 & 14.94 & 15.12 & $1,803,506$ & $1,825,268$ \\
\hline Salmonella, spp., Nontyphoidal & 26.78 & 142.01 & 417.19 & 15.96 & 46.88 & 5,959 & 17,505 \\
\hline S. enterica serotype Typhi & 0.14 & 0.72 & 2.27 & 0.08 & 0.26 & 5,794 & 18,194 \\
\hline Shigella, spp & 4.03 & 9.29 & 55.58 & 1.04 & 6.25 & 2,590 & 15,502 \\
\hline Staphylococcus aureus & 7.63 & 4.89 & 7.06 & 0.55 & 0.79 & 720 & 1,040 \\
\hline Streptococcus spp. Group A & 0.36 & 0.52 & 1.02 & 0.06 & 0.11 & 1,653 & 3,220 \\
\hline Vibrio cholerae, toxigenic & $<0.01$ & 0.01 & 0.01 & $<0.01$ & $<0.01$ & 1,932 & 3,417 \\
\hline Vibrio vulnificus & $<0.01$ & 11.93 & 11.93 & 1.34 & 1.34 & $3,941,778$ & $3,944,463$ \\
\hline Vibrio parahaemolyticus & 1.23 & 2.81 & 4.14 & 0.32 & 0.47 & 2,575 & 3,791 \\
\hline Vibrio spp., other & 0.62 & 3.35 & 4.02 & 0.38 & 0.45 & 6,050 & 7,265 \\
\hline Yersinia enterocolitica & 3.09 & 15.23 & 49.10 & 1.71 & 5.52 & 5,541 & 17,859 \\
\hline \multicolumn{8}{|l|}{ Parasitic } \\
\hline$\overline{\text { Cryptosporidium spp. }}$ & 0.42 & 0.99 & 1.64 & 0.11 & 0.18 & 2,640 & 4,397 \\
\hline Cyclospora cayetanensis & 0.58 & 0.61 & 1.16 & 0.07 & 0.13 & 1,177 & 2,250 \\
\hline Giardia intestinalis & 1.84 & 4.91 & 9.14 & 0.55 & 1.03 & 2,998 & 5,581 \\
\hline Toxoplasma gondii & 2.74 & 124.07 & 143.71 & 13.94 & 16.15 & 50,843 & 58,890 \\
\hline Trichinella spp. & $<0.01$ & 0.05 & 0.10 & 0.01 & 0.01 & 11,843 & 23,119 \\
\hline \multicolumn{8}{|l|}{ Viral } \\
\hline$\overline{\text { Astrovirus }}$ & 0.49 & 0.45 & 0.83 & 0.05 & 0.09 & 1,045 & 1,905 \\
\hline Hepatitis A virus & 0.06 & 2.51 & 2.63 & 0.28 & 0.30 & 50,608 & 52,966 \\
\hline Norovirus & 172.77 & 109.09 & 154.15 & 12.26 & 17.32 & 710 & 1,003 \\
\hline Rotavirus & 0.49 & 0.47 & 0.78 & 0.05 & 0.09 & 1,085 & 1,805 \\
\hline Sapovirus & 0.49 & 0.38 & 0.70 & 0.04 & 0.08 & 870 & 1,602 \\
\hline Known & & 668.49 & $1,367.19$ & 75.12 & 153.63 & 2,603 & 5,324 \\
\hline Unknown & $1,214.46$ & $1,265.93$ & $1,900.06$ & 142.25 & 213.51 & 1,171 & 1,758 \\
\hline Total & & $1,934.42$ & $3,267.25$ & 217.37 & 367.13 & 1,446 & 2,443 \\
\hline
\end{tabular}

${ }^{1}$ Incidence per 10,000 residents. 
TABLE A32. New Mexico Cost per Case of Foodborne Illness (by pathogen, \$2013)

\begin{tabular}{|c|c|c|c|c|c|c|c|}
\hline \multirow[b]{2}{*}{ Disease or Agent } & \multirow{2}{*}{$\begin{array}{l}\text { Illness } \\
\text { Incidence }^{1}\end{array}$} & \multicolumn{2}{|c|}{$\begin{array}{l}\text { Total Cost } \\
\text { (\$million) }\end{array}$} & \multicolumn{2}{|c|}{$\begin{array}{l}\text { Cost per } \\
\text { Resident }\end{array}$} & \multicolumn{2}{|c|}{$\begin{array}{c}\text { Cost } \\
\text { per Case }\end{array}$} \\
\hline & & Basic & Enhanced & Basic & Enhanced & Basic 1 & Enhanced \\
\hline \multicolumn{8}{|l|}{ Bacterial } \\
\hline$\overline{\text { Bacillus cereus }}$ & 2.01 & 0.06 & 0.10 & 0.03 & 0.05 & 151 & 241 \\
\hline Brucella spp. & 0.05 & 0.15 & 0.21 & 0.07 & 0.10 & 15,965 & 21,521 \\
\hline Campylobacter spp. & 26.73 & 9.49 & 48.73 & 4.55 & 23.37 & 1,703 & 8,742 \\
\hline Clostridium botulinum & $<0.01$ & 0.46 & 0.59 & 0.22 & 0.28 & $1,261,473$ & $1,609,021$ \\
\hline Clostridium perfringens & 30.56 & 2.31 & 3.04 & 1.11 & 1.46 & 363 & 477 \\
\hline STEC O157:H7 & 2.45 & 4.87 & 5.17 & 2.34 & 2.48 & 9,516 & 10,107 \\
\hline STEC non-0157 & 4.38 & 0.72 & 1.29 & 0.35 & 0.62 & 789 & 1,411 \\
\hline ETEC & 0.57 & 0.09 & 0.16 & 0.04 & 0.08 & 748 & 1,369 \\
\hline Other diarrheogenic E. coli, & 0.38 & 0.06 & 0.11 & 0.03 & 0.05 & 748 & 1,371 \\
\hline Listeria monocytogenes & 0.05 & 12.18 & 12.32 & 5.84 & 5.91 & $1,195,057$ & $1,207,991$ \\
\hline Salmonella, spp., Nontyphoidal & 33.85 & 28.28 & 82.04 & 13.56 & 39.34 & 4,006 & 11,623 \\
\hline S. enterica serotype Typhi & 0.02 & 0.01 & 0.04 & 0.01 & 0.02 & 3,926 & 12,097 \\
\hline Shigella, spp & 5.67 & 2.10 & 12.18 & 1.01 & 5.84 & 1,775 & 10,296 \\
\hline Staphylococcus aureus & 7.63 & 0.80 & 1.12 & 0.38 & 0.54 & 500 & 707 \\
\hline Streptococcus spp. Group A & 0.36 & 0.09 & 0.16 & 0.04 & 0.08 & 1,159 & 2,171 \\
\hline Vibrio cholerae, toxigenic & $<0.01$ & $<0.01$ & $<0.01$ & $<0.01$ & $<0.01$ & 1,347 & 2,306 \\
\hline Vibrio vulnificus & $<0.01$ & 0.40 & 0.40 & 0.19 & 0.19 & $2,608,860$ & $2,610,604$ \\
\hline Vibrio parahaemolyticus & 0.26 & 0.10 & 0.14 & 0.05 & 0.07 & 1,757 & 2,542 \\
\hline Vibrio spp., other & 0.13 & 0.11 & 0.13 & 0.05 & 0.06 & 4,057 & 4,841 \\
\hline Yersinia enterocolitica & 3.09 & 2.42 & 7.64 & 1.16 & 3.67 & 3,753 & 11,867 \\
\hline \multicolumn{8}{|l|}{ Parasitic } \\
\hline$\overline{\text { Cryptosporidium spp. }}$ & 3.40 & 1.29 & 2.09 & 0.62 & 1.00 & 1,814 & 2,948 \\
\hline Cyclospora cayetanensis & 0.27 & 0.05 & 0.09 & 0.02 & 0.04 & 829 & 1,521 \\
\hline Giardia intestinalis & 1.69 & 0.73 & 1.32 & 0.35 & 0.63 & 2,078 & 3,746 \\
\hline Toxoplasma gondii & 2.74 & 19.36 & 22.35 & 9.29 & 10.72 & 33,864 & 39,087 \\
\hline Trichinella spp. & $<0.01$ & 0.01 & 0.02 & $<0.01$ & 0.01 & 8,205 & 15,499 \\
\hline \multicolumn{8}{|l|}{ Viral } \\
\hline$\overline{\text { Astrovirus }}$ & 0.49 & 0.07 & 0.13 & 0.04 & 0.06 & 731 & 1,287 \\
\hline Hepatitis A virus & 0.03 & 0.23 & 0.24 & 0.11 & 0.12 & 33,610 & 35,134 \\
\hline Norovirus & 172.77 & 17.68 & 24.49 & 8.48 & 11.75 & 491 & 680 \\
\hline Rotavirus & 0.49 & 0.08 & 0.12 & 0.04 & 0.06 & 755 & 1,220 \\
\hline Sapovirus & 0.49 & 0.06 & 0.11 & 0.03 & 0.05 & 611 & 1,084 \\
\hline Known & & 104.25 & 226.54 & 49.99 & 108.64 & 1,663 & 3,615 \\
\hline Unknown & $1,214.46$ & 204.07 & 300.04 & 97.86 & 143.88 & 806 & 1,185 \\
\hline Total & & 308.32 & 526.58 & 147.86 & 252.52 & 976 & 1,667 \\
\hline
\end{tabular}

${ }^{1}$ Incidence per 10,000 residents. 
TABLE A33. New York Cost per Case of Foodborne Illness (by pathogen, \$2013)

\begin{tabular}{|c|c|c|c|c|c|c|c|}
\hline \multirow[b]{2}{*}{ Disease or Agent } & \multirow{2}{*}{$\begin{array}{l}\text { Illness } \\
\text { Incidence }^{1}\end{array}$} & \multicolumn{2}{|c|}{$\begin{array}{l}\text { Total Cost } \\
\text { (\$million) }\end{array}$} & \multicolumn{2}{|c|}{$\begin{array}{l}\text { Cost per } \\
\text { Resident }\end{array}$} & \multicolumn{2}{|c|}{$\begin{array}{c}\text { Cost } \\
\text { per Case }\end{array}$} \\
\hline & & Basic & Enhanced & Basic & Enhanced & Basic 1 & Enhanced \\
\hline \multicolumn{8}{|l|}{ Bacterial } \\
\hline$\overline{\text { Bacillus cereus }}$ & 2.01 & 0.79 & 1.11 & 0.04 & 0.06 & 200 & 282 \\
\hline Brucella spp. & 0.01 & 0.47 & 0.60 & 0.02 & 0.03 & 19,059 & 24,326 \\
\hline Campylobacter spp. & 26.73 & 110.87 & 507.56 & 5.64 & 25.83 & 2,111 & 9,663 \\
\hline Clostridium botulinum & $<0.01$ & 4.78 & 6.06 & 0.24 & 0.31 & $1,389,265$ & $1,763,326$ \\
\hline Clostridium perfringens & 30.56 & 26.45 & 32.69 & 1.35 & 1.66 & 440 & 544 \\
\hline STEC O157:H7 & 1.66 & 34.70 & 36.43 & 1.77 & 1.85 & 10,631 & 11,159 \\
\hline STEC non-0157 & 2.97 & 6.41 & 9.70 & 0.33 & 0.49 & 1,100 & 1,664 \\
\hline ETEC & 0.57 & 1.17 & 1.80 & 0.06 & 0.09 & 1,055 & 1,619 \\
\hline Other diarrheogenic E. coli, & 0.38 & 0.79 & 1.21 & 0.04 & 0.06 & 1,055 & 1,621 \\
\hline Listeria monocytogenes & 0.09 & 233.26 & 233.84 & 11.87 & 11.90 & $1,316,799$ & $1,320,031$ \\
\hline Salmonella, spp., Nontyphoidal & 29.05 & 270.05 & 734.77 & 13.74 & 37.39 & 4,730 & 12,871 \\
\hline S. enterica serotype Typhi & 0.15 & 1.36 & 3.83 & 0.07 & 0.19 & 4,776 & 13,439 \\
\hline Shigella, spp & 3.21 & 14.47 & 71.98 & 0.74 & 3.66 & 2,298 & 11,425 \\
\hline Staphylococcus aureus & 7.63 & 9.38 & 12.18 & 0.48 & 0.62 & 626 & 813 \\
\hline Streptococcus spp. Group A & 0.36 & 1.15 & 1.79 & 0.06 & 0.09 & 1,652 & 2,572 \\
\hline Vibrio cholerae, toxigenic & $<0.01$ & $<0.01$ & $<0.01$ & $<0.01$ & $<0.01$ & 1,838 & 2,707 \\
\hline Vibrio vulnificus & $<0.01$ & 5.21 & 5.21 & 0.27 & 0.27 & $2,852,140$ & $2,853,800$ \\
\hline Vibrio parahaemolyticus & 0.34 & 1.46 & 1.93 & 0.07 & 0.10 & 2,219 & 2,932 \\
\hline Vibrio spp., other & 0.17 & 1.58 & 1.82 & 0.08 & 0.09 & 4,734 & 5,446 \\
\hline Yersinia enterocolitica & 3.09 & 28.27 & 80.41 & 1.44 & 4.09 & 4,657 & 13,246 \\
\hline \multicolumn{8}{|l|}{ Parasitic } \\
\hline$\overline{\text { Cryptosporidium spp. }}$ & 1.72 & 8.17 & 11.65 & 0.42 & 0.59 & 2,413 & 3,444 \\
\hline Cyclospora cayetanensis & 0.89 & 2.05 & 3.15 & 0.10 & 0.16 & 1,170 & 1,799 \\
\hline Giardia intestinalis & 4.06 & 23.20 & 35.31 & 1.18 & 1.80 & 2,904 & 4,420 \\
\hline Toxoplasma gondii & 2.74 & 207.66 & 234.29 & 10.57 & 11.92 & 38,538 & 43,480 \\
\hline Trichinella spp. & $<0.01$ & 0.11 & 0.18 & 0.01 & 0.01 & 11,540 & 18,260 \\
\hline \multicolumn{8}{|l|}{ Viral } \\
\hline$\overline{\text { Astrovirus }}$ & 0.49 & 0.97 & 1.45 & 0.05 & 0.07 & 1,011 & 1,515 \\
\hline Hepatitis A virus & 0.06 & 4.44 & 4.61 & 0.23 & 0.23 & 37,279 & 38,677 \\
\hline Norovirus & 172.77 & 206.70 & 264.89 & 10.52 & 13.48 & 609 & 780 \\
\hline Rotavirus & 0.49 & 0.96 & 1.37 & 0.05 & 0.07 & 1,003 & 1,423 \\
\hline Sapovirus & 0.49 & 0.81 & 1.23 & 0.04 & 0.06 & 849 & 1,278 \\
\hline Known & & $1,207.71$ & $2,303.06$ & 61.46 & 117.20 & 2,100 & 4,004 \\
\hline Unknown & $1,214.46$ & $2,443.90$ & $3,266.16$ & 124.36 & 166.21 & 1,024 & 1,369 \\
\hline Total & & $3,651.61$ & $5,569.22$ & 185.82 & 283.40 & 1,233 & 1,880 \\
\hline
\end{tabular}

${ }^{1}$ Incidence per 10,000 residents. 
TABLE A34. North Carolina Cost per Case of Foodborne Illness (by pathogen, \$2013)

\begin{tabular}{|c|c|c|c|c|c|c|c|}
\hline \multirow[b]{2}{*}{ Disease or Agent } & \multirow{2}{*}{$\begin{array}{c}\text { Illness } \\
\text { Incidence }^{1}\end{array}$} & \multicolumn{2}{|c|}{$\begin{array}{l}\text { Total Cost } \\
\text { (\$million) }\end{array}$} & \multicolumn{2}{|c|}{$\begin{array}{l}\text { Cost per } \\
\text { Resident }\end{array}$} & \multicolumn{2}{|c|}{$\begin{array}{c}\text { Cost } \\
\text { per Case }\end{array}$} \\
\hline & & Basic & Enhanced & Basic & Enhanced & Basic I & Enhanced \\
\hline \multicolumn{8}{|l|}{ Bacterial } \\
\hline$\overline{\text { Bacillus cereus }}$ & 2.01 & 0.31 & 0.47 & 0.03 & 0.05 & 158 & 239 \\
\hline Brucella spp. & 0.02 & 0.24 & 0.31 & 0.02 & 0.03 & 15,627 & 20,664 \\
\hline Campylobacter spp. & 26.73 & 44.90 & 221.22 & 4.56 & 22.46 & 1,706 & 8,404 \\
\hline Clostridium botulinum & $<0.01$ & 2.07 & 2.64 & 0.21 & 0.27 & $1,202,956$ & $1,534,089$ \\
\hline Clostridium perfringens & 30.56 & 10.97 & 14.04 & 1.11 & 1.43 & 364 & 467 \\
\hline STEC O157:H7 & 1.62 & 14.62 & 15.46 & 1.48 & 1.57 & 9,138 & 9,662 \\
\hline STEC non-0157 & 2.90 & 2.40 & 3.98 & 0.24 & 0.40 & 838 & 1,393 \\
\hline ETEC & 0.57 & 0.45 & 0.76 & 0.05 & 0.08 & 802 & 1,357 \\
\hline Other diarrheogenic E. coli, & 0.38 & 0.30 & 0.51 & 0.03 & 0.05 & 802 & 1,358 \\
\hline Listeria monocytogenes & 0.05 & 52.46 & 52.85 & 5.33 & 5.37 & $1,143,432$ & $1,151,917$ \\
\hline Salmonella, spp., Nontyphoidal & 40.35 & 156.23 & 443.76 & 15.86 & 45.06 & 3,932 & 11,169 \\
\hline S. enterica serotype Typhi & 0.03 & 0.11 & 0.34 & 0.01 & 0.03 & 3,732 & 11,470 \\
\hline Shigella, spp & 2.97 & 5.31 & 29.00 & 0.54 & 2.95 & 1,817 & 9,919 \\
\hline Staphylococcus aureus & 7.63 & 3.79 & 5.17 & 0.38 & 0.53 & 505 & 689 \\
\hline Streptococcus spp. Group A & 0.36 & 0.44 & 0.75 & 0.04 & 0.08 & 1,251 & 2,154 \\
\hline Vibrio cholerae, toxigenic & $<0.01$ & $<0.01$ & $<0.01$ & $<0.01$ & $<0.01$ & 1,405 & 2,261 \\
\hline Vibrio vulnificus & $<0.01$ & 5.80 & 5.80 & 0.59 & 0.59 & $2,497,177$ & $2,498,761$ \\
\hline Vibrio parahaemolyticus & 0.85 & 1.50 & 2.09 & 0.15 & 0.21 & 1,788 & 2,489 \\
\hline Vibrio spp., other & 0.43 & 1.70 & 1.99 & 0.17 & 0.20 & 3,994 & 4,694 \\
\hline Yersinia enterocolitica & 3.09 & 11.53 & 34.89 & 1.17 & 3.54 & 3,791 & 11,470 \\
\hline \multicolumn{8}{|l|}{ Parasitic } \\
\hline$\overline{\text { Cryptosporidium spp. }}$ & 0.79 & 1.48 & 2.27 & 0.15 & 0.23 & 1,889 & 2,901 \\
\hline Cyclospora cayetanensis & 0.11 & 0.09 & 0.16 & 0.01 & 0.02 & 889 & 1,507 \\
\hline Giardia intestinalis & 2.12 & 4.62 & 7.73 & 0.47 & 0.78 & 2,216 & 3,705 \\
\hline Toxoplasma gondii & 2.74 & 88.30 & 101.08 & 8.97 & 10.26 & 32,698 & 37,430 \\
\hline Trichinella spp. & $<0.01$ & 0.04 & 0.07 & $<0.01$ & 0.01 & 8,731 & 15,274 \\
\hline \multicolumn{8}{|l|}{ Viral } \\
\hline$\overline{\text { Astrovirus }}$ & 0.49 & 0.37 & 0.61 & 0.04 & 0.06 & 772 & 1,267 \\
\hline Hepatitis A virus & 0.03 & 1.09 & 1.13 & 0.11 & 0.11 & 32,307 & 33,672 \\
\hline Norovirus & 172.77 & 83.90 & 112.60 & 8.52 & 11.43 & 493 & 662 \\
\hline Rotavirus & 0.49 & 0.37 & 0.57 & 0.04 & 0.06 & 772 & 1,187 \\
\hline Sapovirus & 0.49 & 0.31 & 0.51 & 0.03 & 0.05 & 648 & 1,070 \\
\hline Known & & 495.70 & $1,062.80$ & 50.33 & 107.92 & 1,675 & 3,591 \\
\hline Unknown & $1,214.46$ & 981.73 & $1,386.35$ & 99.69 & 140.77 & 821 & 1,159 \\
\hline Total & & $1,477.43$ & $2,449.15$ & 150.02 & 248.69 & 990 & 1,642 \\
\hline
\end{tabular}

${ }^{1}$ Incidence per 10,000 residents. 
TABLE A35. North Dakota Cost per Case of Foodborne Illness (by pathogen, \$2013)

\begin{tabular}{|c|c|c|c|c|c|c|c|}
\hline \multirow[b]{2}{*}{ Disease or Agent } & \multirow{2}{*}{$\begin{array}{c}\text { Illness } \\
\text { Incidence }^{1}\end{array}$} & \multicolumn{2}{|c|}{$\begin{array}{l}\text { Total Cost } \\
\text { (\$million) }\end{array}$} & \multicolumn{2}{|c|}{$\begin{array}{l}\text { Cost per } \\
\text { Resident }\end{array}$} & \multicolumn{2}{|c|}{$\begin{array}{c}\text { Cost } \\
\text { per Case }\end{array}$} \\
\hline & & Basic & Enhanced & Basic & Enhanced & Basic & Enhanced \\
\hline \multicolumn{8}{|l|}{ Bacterial } \\
\hline$\overline{\text { Bacillus cereus }}$ & 2.01 & 0.03 & 0.04 & 0.04 & 0.06 & 183 & 295 \\
\hline Brucella spp. & 0.02 & 0.03 & 0.04 & 0.04 & 0.05 & 18,982 & 25,908 \\
\hline Campylobacter spp. & 26.73 & 4.03 & 21.28 & 5.57 & 29.42 & 2,084 & 11,006 \\
\hline Clostridium botulinum & $<0.01$ & 0.20 & 0.25 & 0.27 & 0.35 & $1,543,530$ & $1,984,253$ \\
\hline Clostridium perfringens & 30.56 & 1.00 & 1.32 & 1.38 & 1.82 & 453 & 395 \\
\hline STEC 0157:H7 & 4.19 & 3.54 & 3.76 & 4.89 & 5.20 & 11,684 & 12,415 \\
\hline STEC non-0157 & 7.47 & 0.54 & 0.96 & 0.75 & 1.32 & 999 & 1,770 \\
\hline ETEC & 0.57 & 0.04 & 0.07 & 0.05 & 0.10 & 969 & 1,740 \\
\hline Other diarrheogenic E. coli, & 0.38 & 0.03 & 0.05 & 0.04 & 0.07 & 969 & $\quad 1,742$ \\
\hline Listeria monocytogenes & 0.04 & 4.05 & 4.09 & 5.60 & 5.66 & $1,483,512$ & $1,498,133$ \\
\hline Salmonella, spp., Nontyphoidal & 19.68 & 6.99 & 20.73 & 9.67 & 28.66 & 4,914 & 14,564 \\
\hline S. enterica serotype Typhi & 0.03 & 0.01 & 0.03 & 0.01 & 0.04 & 3,790 & 14,130 \\
\hline Shigella, spp & 3.33 & 0.53 & 3.13 & 0.74 & 4.33 & 2,211 & 13,009 \\
\hline Staphylococcus aureus & 7.63 & 0.34 & 0.48 & 0.46 & 0.66 & 608 & 864 \\
\hline Streptococcus spp. Group A & 0.36 & 0.04 & 0.07 & 0.05 & 0.10 & 1,524 & 2,779 \\
\hline Vibrio cholerae, toxigenic & $<0.01$ & $<0.01$ & $<0.01$ & $<0.01$ & $<0.01$ & 1,639 & 2,828 \\
\hline Vibrio vulnificus & $<0.01$ & 0.75 & 0.75 & 1.04 & 1.04 & $3,289,576$ & $3,291,751$ \\
\hline Vibrio parahaemolyticus & 1.14 & 0.18 & 0.27 & 0.26 & 0.37 & 2,241 & 3,214 \\
\hline Vibrio spp., other & 0.58 & 0.22 & 0.26 & 0.30 & 0.35 & 5,164 & 6,137 \\
\hline Yersinia enterocolitica & 3.09 & 1.07 & 3.37 & 1.48 & 4.66 & 4,806 & 15,072 \\
\hline \multicolumn{8}{|l|}{ Parasitic } \\
\hline$\overline{\text { Cryptosporidium spp. }}$ & 3.36 & 0.57 & 0.91 & 0.78 & 1.26 & 2,334 & 3,741 \\
\hline Cyclospora cayetanensis & $<0.01$ & $<0.01$ & $<0.01$ & $<0.01$ & $<0.01$ & 1,075 & 1,934 \\
\hline Giardia intestinalis & 2.07 & 0.41 & 0.72 & 0.56 & 0.99 & 2,714 & 4,782 \\
\hline Toxoplasma gondii & 2.74 & 8.21 & 9.50 & 11.34 & 13.13 & 41,370 & 47,880 \\
\hline Trichinella spp. & $<0.01$ & $<0.01$ & 0.01 & 0.01 & 0.01 & 10,466 & 19,528 \\
\hline \multicolumn{8}{|l|}{ Viral } \\
\hline$\overline{\text { Astrovirus }}$ & 0.49 & 0.03 & 0.06 & 0.04 & 0.08 & 913 & 1,601 \\
\hline Hepatitis A virus & 0.01 & 0.04 & 0.04 & 0.05 & 0.06 & 42,060 & 43,952 \\
\hline Norovirus & 172.77 & 7.46 & 10.39 & 10.31 & 14.36 & 597 & 831 \\
\hline Rotavirus & 0.49 & 0.03 & 0.05 & 0.04 & 0.07 & 876 & 1,452 \\
\hline Sapovirus & 0.49 & 0.03 & 0.05 & 0.04 & 0.07 & 771 & 1,357 \\
\hline Known & & 40.38 & 82.65 & 55.82 & 114.26 & 1,923 & 3,937 \\
\hline Unknown & $1,214.46$ & 88.73 & 130.02 & 122.66 & 179.74 & 1,010 & 1,480 \\
\hline Total & & 129.12 & 212.68 & 178.49 & 294.00 & 1,186 & 1,954 \\
\hline
\end{tabular}

${ }^{1}$ Incidence per 10,000 residents. 
TABLE A36. Ohio Cost per Case of Foodborne Illness (by pathogen, \$2013)

\begin{tabular}{|c|c|c|c|c|c|c|c|}
\hline \multirow[b]{2}{*}{ Disease or Agent } & \multirow{2}{*}{$\begin{array}{l}\text { Illness } \\
\text { Incidence }^{1}\end{array}$} & \multicolumn{2}{|c|}{$\begin{array}{l}\text { Total Cost } \\
\text { (\$million) }\end{array}$} & \multicolumn{2}{|c|}{$\begin{array}{l}\text { Cost per } \\
\text { Resident }\end{array}$} & \multicolumn{2}{|c|}{$\begin{array}{c}\text { Cost } \\
\text { per Case }\end{array}$} \\
\hline & & Basic & Enhanced & Basic & Enhanced & Basic 1 & Enhanced \\
\hline \multicolumn{8}{|l|}{ Bacterial } \\
\hline$\overline{\text { Bacillus cereus }}$ & 2.01 & 0.39 & 0.59 & 0.03 & 0.05 & 167 & 253 \\
\hline Brucella spp. & 0.01 & 0.20 & 0.26 & 0.02 & 0.02 & 17,053 & 22,397 \\
\hline Campylobacter spp. & 26.73 & 57.07 & 277.51 & 4.93 & 23.98 & 1,845 & 8,973 \\
\hline Clostridium botulinum & $<0.01$ & 2.62 & 3.34 & 0.23 & 0.29 & $1,296,073$ & $1,648,463$ \\
\hline Clostridium perfringens & 30.56 & 13.69 & 17.52 & 1.18 & 1.51 & 387 & 495 \\
\hline STEC O157:H7 & 1.96 & 22.26 & 23.52 & 1.92 & 2.03 & 9,834 & 10,389 \\
\hline STEC non-0157 & 3.49 & 3.65 & 6.02 & 0.32 & 0.52 & 903 & 1,490 \\
\hline ETEC & 0.57 & 0.56 & 0.95 & 0.05 & 0.08 & 859 & 1,447 \\
\hline Other diarrheogenic E. coli, & 0.38 & 0.38 & 0.64 & 0.03 & 0.05 & 859 & 1,448 \\
\hline Listeria monocytogenes & 0.06 & 78.38 & 78.95 & 6.77 & 6.82 & $1,226,627$ & $1,235,413$ \\
\hline Salmonella, spp., Nontyphoidal & 24.27 & 119.22 & 335.46 & 10.30 & 28.99 & 4,245 & 11,945 \\
\hline S. enterica serotype Typhi & 0.03 & 0.16 & 0.48 & 0.01 & 0.04 & 4,287 & 12,519 \\
\hline Shigella, spp & 4.72 & 10.71 & 57.76 & 0.93 & 4.99 & 1,962 & 10,584 \\
\hline Staphylococcus aureus & 7.63 & 4.80 & 6.52 & 0.41 & 0.56 & 543 & 738 \\
\hline Streptococcus spp. Group A & 0.36 & 0.55 & 0.94 & 0.05 & 0.08 & 1,338 & 2,295 \\
\hline Vibrio cholerae, toxigenic & $<0.01$ & $<0.01$ & $<0.01$ & $<0.01$ & $<0.01$ & 1,529 & 2,435 \\
\hline Vibrio vulnificus & $<0.01$ & 2.54 & 2.54 & 0.22 & 0.22 & $2,664,931$ & $2,666,611$ \\
\hline Vibrio parahaemolyticus & 0.30 & 0.66 & 0.91 & 0.06 & 0.08 & 1,915 & 2,658 \\
\hline Vibrio spp., other & 0.15 & 0.74 & 0.87 & 0.06 & 0.08 & 4,263 & 5,005 \\
\hline Yersinia enterocolitica & 3.09 & 14.50 & 43.70 & 1.25 & 3.78 & 4,058 & 12,227 \\
\hline \multicolumn{8}{|l|}{ Parasitic } \\
\hline$\overline{\text { Cryptosporidium spp. }}$ & 3.44 & 8.06 & 12.33 & 0.70 & 1.07 & 2,027 & 3,101 \\
\hline Cyclospora cayetanensis & 0.01 & 0.02 & 0.03 & $<0.01$ & $<0.01$ & 952 & 1,607 \\
\hline Giardia intestinalis & 2.51 & 6.90 & 11.48 & 0.60 & 0.99 & 2,378 & 3,956 \\
\hline Toxoplasma gondii & 2.74 & 112.04 & 127.97 & 9.68 & 11.06 & 35,313 & 40,333 \\
\hline Trichinella spp. & $<0.01$ & 0.05 & 0.09 & $<0.01$ & 0.01 & 9,440 & 16,378 \\
\hline \multicolumn{8}{|l|}{ Viral } \\
\hline$\overline{\text { Astrovirus }}$ & 0.49 & 0.47 & 0.77 & 0.04 & 0.07 & 834 & 1,360 \\
\hline Hepatitis A virus & 0.03 & 1.15 & 1.20 & 0.10 & 0.10 & 34,570 & 36,017 \\
\hline Norovirus & 172.77 & 106.18 & 141.93 & 9.18 & 12.27 & 531 & 710 \\
\hline Rotavirus & 0.49 & 0.48 & 0.73 & 0.04 & 0.06 & 848 & 1,287 \\
\hline Sapovirus & 0.49 & 0.39 & 0.65 & 0.03 & 0.06 & 698 & 1,145 \\
\hline Known & & 568.84 & $1,155.65$ & 49.16 & 99.88 & 1,700 & 3,453 \\
\hline Unknown & $1,214.46$ & 1238.60 & $1,742.49$ & 107.05 & 150.59 & 881 & 1,240 \\
\hline Total & & $1,807.44$ & $2,898.14$ & 156.21 & 250.47 & 1,039 & 1,666 \\
\hline
\end{tabular}

${ }^{1}$ Incidence per 10,000 residents. 
TABLE A37. Oklahoma Cost per Case of Foodborne Illness (by pathogen, \$2013)

\begin{tabular}{|c|c|c|c|c|c|c|c|}
\hline \multirow[b]{2}{*}{ Disease or Agent } & \multirow{2}{*}{$\begin{array}{c}\text { Illness } \\
\text { Incidence }^{1}\end{array}$} & \multicolumn{2}{|c|}{$\begin{array}{l}\text { Total Cost } \\
\text { (\$million) }\end{array}$} & \multicolumn{2}{|c|}{$\begin{array}{l}\text { Cost per } \\
\text { Resident }\end{array}$} & \multicolumn{2}{|c|}{$\begin{array}{c}\text { Cost } \\
\text { per Case }\end{array}$} \\
\hline & & Basic & Enhanced & Basic & Enhanced & Basic & Enhanced \\
\hline \multicolumn{8}{|l|}{ Bacterial } \\
\hline Bacillus cereus & 2.01 & 0.12 & 0.20 & 0.03 & 0.05 & 153 & 257 \\
\hline Brucella spp. & 0.01 & 0.09 & 0.13 & 0.02 & 0.03 & 16,992 & 23,322 \\
\hline Campylobacter spp. & 26.73 & 18.57 & 99.25 & 4.82 & 25.78 & 1,804 & 9,643 \\
\hline Clostridium botulinum & $<0.01$ & 0.93 & 1.19 & 0.24 & 0.31 & $1,382,510$ & $1,769,303$ \\
\hline Clostridium perfringens & 30.56 & 4.54 & 6.09 & 1.18 & 1.58 & 386 & 517 \\
\hline STEC 0157:H7 & 2.32 & 9.28 & 9.89 & 2.41 & 2.57 & 10,395 & 11,075 \\
\hline STEC non-0157 & 4.14 & 1.30 & 2.43 & 0.34 & 0.63 & 813 & 1,526 \\
\hline ETEC & 0.57 & 0.17 & 0.32 & 0.04 & 0.08 & 772 & 1,485 \\
\hline Other diarrheogenic E. coli, & 0.38 & 0.11 & 0.22 & 0.03 & 0.06 & 772 & 1,487 \\
\hline Listeria monocytogenes & 0.03 & 16.99 & 17.21 & 4.41 & 4.47 & $1,314,679$ & $1,331,274$ \\
\hline Salmonella, spp., Nontyphoidal & 35.87 & 59.53 & 176.79 & 15.46 & 45.91 & 4,310 & 12,799 \\
\hline S. enterica serotype Typhi & 0.02 & 0.03 & 0.09 & 0.01 & 0.02 & 3,936 & 13,057 \\
\hline Shigella, spp & 9.92 & 7.13 & 43.40 & 1.85 & 11.27 & 1,867 & 11,359 \\
\hline Staphylococcus aureus & 7.63 & 1.54 & 2.24 & 0.40 & 0.58 & 525 & 762 \\
\hline Streptococcus spp. Group A & 0.36 & 0.16 & 0.32 & 0.04 & 0.08 & 1,200 & 2,361 \\
\hline Vibrio cholerae, toxigenic & $<0.01$ & $<0.01$ & $<0.01$ & $<0.01$ & $<0.01$ & 1,381 & 2,482 \\
\hline Vibrio vulnificus & $<0.01$ & 0.71 & 0.71 & 0.19 & 0.19 & $2,888,007$ & $2,889,992$ \\
\hline Vibrio parahaemolyticus & 0.23 & 0.17 & 0.25 & 0.04 & 0.06 & 1,874 & 2,775 \\
\hline Vibrio spp., other & 0.12 & 0.20 & 0.24 & 0.05 & 0.06 & 4,426 & 5,326 \\
\hline Yersinia enterocolitica & 3.09 & 4.80 & 15.57 & 1.25 & 4.04 & 4,032 & 13,094 \\
\hline \multicolumn{8}{|l|}{ Parasitic } \\
\hline$\overline{\text { Cryptosporidium spp. }}$ & 1.72 & 1.27 & 2.13 & 0.33 & 0.55 & 1,911 & 3,213 \\
\hline Cyclospora cayetanensis & 0.01 & $<0.01$ & 0.01 & $<0.01$ & $<0.01$ & 856 & 1,650 \\
\hline Giardia intestinalis & 1.23 & 1.02 & 1.92 & 0.27 & 0.50 & 2,165 & 4,079 \\
\hline Toxoplasma gondii & 2.74 & 38.84 & 45.13 & 10.09 & 11.72 & 36,787 & 42,739 \\
\hline Trichinella spp. & $<0.01$ & 0.02 & 0.03 & $<0.01$ & 0.01 & 8,473 & 16,823 \\
\hline \multicolumn{8}{|l|}{ Viral } \\
\hline Astrovirus & 0.49 & 0.14 & 0.26 & 0.04 & 0.07 & 752 & 1,390 \\
\hline Hepatitis A virus & 0.02 & 0.24 & 0.26 & 0.06 & 0.07 & 36,984 & 38,730 \\
\hline Norovirus & 172.77 & 34.38 & 48.82 & 8.93 & 12.68 & 517 & 734 \\
\hline Rotavirus & 0.49 & 0.14 & 0.25 & 0.04 & 0.06 & 769 & 1,304 \\
\hline Sapovirus & 0.49 & 0.12 & 0.22 & 0.03 & 0.06 & 629 & 1,172 \\
\hline Known & & 202.56 & 475.58 & 52.60 & 123.51 & 1,731 & 4,064 \\
\hline Unknown & $1,214.46$ & 398.46 & 601.78 & 103.48 & 156.28 & 852 & 1,287 \\
\hline Total & & 601.02 & $1,077.36$ & 156.09 & 279.79 & 1,028 & 1,843 \\
\hline
\end{tabular}

${ }^{1}$ Incidence per 10,000 residents. 
TABLE A38. Oregon Cost per Case of Foodborne Illness (by pathogen, \$2013)

\begin{tabular}{|c|c|c|c|c|c|c|c|}
\hline \multirow[b]{2}{*}{ Disease or Agent } & \multirow{2}{*}{$\begin{array}{c}\text { Illness } \\
\text { Incidence }^{1}\end{array}$} & \multicolumn{2}{|c|}{$\begin{array}{l}\text { Total Cost } \\
\text { (\$million) }\end{array}$} & \multicolumn{2}{|c|}{$\begin{array}{l}\text { Cost per } \\
\text { Resident }\end{array}$} & \multicolumn{2}{|c|}{$\begin{array}{c}\text { Cost } \\
\text { per Case }\end{array}$} \\
\hline & & Basic & Enhanced & Basic & Enhanced & Basic 1 & Enhanced \\
\hline \multicolumn{8}{|l|}{ Bacterial } \\
\hline$\overline{\text { Bacillus cereus }}$ & 2.01 & 0.14 & 0.22 & 0.03 & 0.06 & 172 & 278 \\
\hline Brucella spp. & 0.02 & 0.12 & 0.17 & 0.03 & 0.04 & 18,083 & 24,606 \\
\hline Campylobacter spp. & 26.73 & 20.59 & 108.00 & 5.24 & 27.48 & 1,960 & 10,280 \\
\hline Clostridium botulinum & $<0.01$ & 1.00 & 1.29 & 0.26 & 0.33 & $1,457,957$ & $1,868,849$ \\
\hline Clostridium perfringens & 30.56 & 5.07 & 6.68 & 1.29 & 1.70 & 422 & 556 \\
\hline STEC 0157:H7 & 3.75 & 16.24 & 17.26 & 4.13 & 4.39 & 11,015 & 11,707 \\
\hline STEC non-0157 & 6.70 & 2.43 & 4.35 & 0.62 & 1.11 & 923 & 1,651 \\
\hline ETEC & 0.57 & 0.20 & 0.36 & 0.05 & 0.09 & 887 & 1,615 \\
\hline Other diarrheogenic E. coli, & 0.38 & 0.13 & 0.24 & 0.03 & 0.06 & 887 & 1,617 \\
\hline Listeria monocytogenes & 0.05 & 29.43 & 29.74 & 7.49 & 7.57 & $1,393,429$ & $1,408,044$ \\
\hline Salmonella, spp., Nontyphoidal & 22.21 & 40.38 & 118.96 & 10.27 & 30.27 & 4,626 & 13,628 \\
\hline S. enterica serotype Typhi & 0.04 & 0.06 & 0.21 & 0.02 & 0.05 & 3,936 & 13,588 \\
\hline Shigella, spp & 1.88 & 1.53 & 8.98 & 0.39 & 2.28 & 2,062 & 12,133 \\
\hline Staphylococcus aureus & 7.63 & 1.72 & 2.44 & 0.44 & 0.62 & 572 & 814 \\
\hline Streptococcus spp. Group A & 0.36 & 0.19 & 0.36 & 0.05 & 0.09 & 1,387 & 2,573 \\
\hline Vibrio cholerae, toxigenic & $<0.01$ & $<0.01$ & $<0.01$ & $<0.01$ & $<0.01$ & 1,539 & 2,662 \\
\hline Vibrio vulnificus & $<0.01$ & 5.26 & 5.26 & 1.34 & 1.34 & $3,072,100$ & $3,074,148$ \\
\hline Vibrio parahaemolyticus & 1.57 & 1.28 & 1.85 & 0.33 & 0.47 & 2,073 & 2,993 \\
\hline Vibrio spp., other & 0.80 & 1.50 & 1.79 & 0.38 & 0.46 & 4,795 & 5,714 \\
\hline Yersinia enterocolitica & 3.09 & 5.39 & 17.03 & 1.37 & 4.33 & 4,443 & 14,027 \\
\hline \multicolumn{8}{|l|}{ Parasitic } \\
\hline$\overline{\text { Cryptosporidium spp. }}$ & 2.37 & 2.00 & 3.24 & 0.51 & 0.82 & 2,148 & 3,478 \\
\hline Cyclospora cayetanensis & 0.10 & 0.04 & 0.07 & 0.01 & 0.02 & 984 & 1,795 \\
\hline Giardia intestinalis & 3.87 & 3.77 & 6.75 & 0.96 & 1.72 & 2,480 & 4,434 \\
\hline Toxoplasma gondii & 2.74 & 42.09 & 48.70 & 10.71 & 12.39 & 39,059 & 45,191 \\
\hline Trichinella spp. & $<0.01$ & 0.02 & 0.04 & $<0.01$ & 0.01 & 9,646 & 18,198 \\
\hline \multicolumn{8}{|l|}{ Viral } \\
\hline$\overline{\text { Astrovirus }}$ & 0.49 & 0.16 & 0.29 & 0.04 & 0.07 & 848 & 1,499 \\
\hline Hepatitis A virus & 0.04 & 0.56 & 0.58 & 0.14 & 0.15 & 39,373 & 41,160 \\
\hline Norovirus & 172.77 & 38.16 & 53.21 & 9.71 & 13.54 & 562 & 784 \\
\hline Rotavirus & 0.49 & 0.16 & 0.27 & 0.04 & 0.07 & 838 & 1,383 \\
\hline Sapovirus & 0.49 & 0.14 & 0.24 & 0.03 & 0.06 & 713 & 1,267 \\
\hline Known & & 219.77 & 438.56 & 55.92 & 111.59 & 1,917 & 3,825 \\
\hline Unknown & $1,214.46$ & 448.68 & 660.60 & 114.17 & 168.09 & 940 & 1,384 \\
\hline Total & & 668.45 & $1,099.16$ & 170.09 & 279.68 & 1,129 & 1,857 \\
\hline
\end{tabular}

${ }^{1}$ Incidence per 10,000 residents. 
TABLE A39. Pennsylvania Cost per Case of Foodborne Illness (by pathogen, \$2013)

\begin{tabular}{|c|c|c|c|c|c|c|c|}
\hline \multirow[b]{2}{*}{ Disease or Agent } & \multirow{2}{*}{$\begin{array}{c}\text { Illness } \\
\text { Incidence }^{1}\end{array}$} & \multicolumn{2}{|c|}{$\begin{array}{l}\text { Total Cost } \\
\text { (\$million) }\end{array}$} & \multicolumn{2}{|c|}{$\begin{array}{l}\text { Cost per } \\
\text { Resident }\end{array}$} & \multicolumn{2}{|c|}{$\begin{array}{c}\text { Cost } \\
\text { per Case }\end{array}$} \\
\hline & & Basic & Enhanced & Basic & Enhanced & Basic & Enhanced \\
\hline \multicolumn{8}{|l|}{ Bacterial } \\
\hline$\overline{\text { Bacillus cereus }}$ & 2.01 & 0.45 & 0.72 & 0.04 & 0.06 & 176 & 281 \\
\hline Brucella spp. & 0.01 & 0.22 & 0.30 & 0.02 & 0.02 & 19,147 & 25,622 \\
\hline Campylobacter spp. & 26.73 & 69.84 & 354.24 & 5.47 & 27.73 & 2,046 & 10,375 \\
\hline Clostridium botulinum & $<0.01$ & 3.35 & 4.27 & 0.26 & 0.33 & $1,497,561$ & $1,908,964$ \\
\hline Clostridium perfringens & 30.56 & 16.73 & 21.91 & 1.31 & 1.72 & 429 & 561 \\
\hline STEC O157:H7 & 1.60 & 23.08 & 24.48 & 1.81 & 1.92 & 11,305 & 11,989 \\
\hline STEC non-0157 & 2.85 & 3.51 & 6.13 & 0.27 & 0.48 & 962 & 1,683 \\
\hline ETEC & 0.57 & 0.66 & 1.18 & 0.05 & 0.09 & 913 & 1,634 \\
\hline Other diarrheogenic E. coli, & 0.38 & 0.44 & 0.79 & 0.03 & 0.06 & 913 & $3 \quad 1,636$ \\
\hline Listeria monocytogenes & 0.09 & 155.76 & 157.27 & 12.19 & 12.31 & $1,418,793$ & $1,432,585$ \\
\hline Salmonella, spp., Nontyphoidal & 30.01 & 183.65 & 528.95 & 14.38 & 41.41 & 4,791 & 13,800 \\
\hline S. enterica serotype Typhi & 0.05 & 0.28 & 0.86 & 0.02 & 0.07 & 4,703 & 14,356 \\
\hline Shigella, spp & 2.60 & 7.14 & 40.65 & 0.56 & 3.18 & 2,148 & 12,228 \\
\hline Staphylococcus aureus & 7.63 & 5.81 & 8.14 & 0.46 & 0.64 & 597 & 836 \\
\hline Streptococcus spp. Group A & 0.36 & 0.64 & 1.18 & 0.05 & 0.09 & 1,422 & 2,595 \\
\hline Vibrio cholerae, toxigenic & $<0.01$ & $<0.01$ & $<0.01$ & $<0.01$ & $<0.01$ & 1,637 & 2,749 \\
\hline Vibrio vulnificus & $<0.01$ & 3.53 & 3.54 & 0.28 & 0.28 & $3,094,399$ & $3,096,432$ \\
\hline Vibrio parahaemolyticus & 0.32 & 0.87 & 1.25 & 0.07 & 0.10 & 2,119 & 3,029 \\
\hline Vibrio spp., other & 0.16 & 1.01 & 1.20 & 0.08 & 0.09 & 4,847 & 5,757 \\
\hline Yersinia enterocolitica & 3.09 & 17.85 & 55.67 & 1.40 & 4.36 & 4,523 & 14,108 \\
\hline \multicolumn{8}{|l|}{ Parasitic } \\
\hline$\overline{\text { Cryptosporidium spp. }}$ & 2.49 & 7.03 & 11.22 & 0.55 & 0.88 & 2,207 & 3,523 \\
\hline Cyclospora cayetanensis & 0.78 & 1.01 & 1.82 & 0.08 & 0.14 & 1,012 & 1,815 \\
\hline Giardia intestinalis & 2.38 & 7.76 & 13.66 & 0.61 & 1.07 & 2,549 & 4,484 \\
\hline Toxoplasma gondii & 2.74 & 141.40 & 162.72 & 11.07 & 12.74 & 40,368 & 46,454 \\
\hline Trichinella spp. & $<0.01$ & 0.06 & 0.12 & $<0.01$ & 0.01 & 10,083 & 18,557 \\
\hline \multicolumn{8}{|l|}{ Viral } \\
\hline$\overline{\text { Astrovirus }}$ & 0.49 & 0.56 & 0.96 & 0.04 & 0.07 & 890 & 1,535 \\
\hline Hepatitis A virus & 0.06 & 2.98 & 3.12 & 0.23 & 0.24 & 39,913 & 41,682 \\
\hline Norovirus & 172.77 & 129.15 & 177.57 & 10.11 & 13.90 & 585 & 805 \\
\hline Rotavirus & 0.49 & 0.57 & 0.90 & 0.04 & 0.07 & 912 & 1,451 \\
\hline Sapovirus & 0.49 & 0.46 & 0.81 & 0.04 & 0.06 & 744 & 1,292 \\
\hline Known & & 785.83 & $1,585.62$ & 61.52 & 124.13 & 2,109 & 4,255 \\
\hline Unknown & $1,214.46$ & $1,503.34$ & $2,185.26$ & 117.69 & 171.07 & 969 & 1,409 \\
\hline Total & & $2,289.17$ & $3,770.87$ & 179.21 & 295.20 & 1,190 & 1,960 \\
\hline
\end{tabular}

${ }^{1}$ Incidence per 10,000 residents. 
TABLE A40. Rhode Island Cost per Case of Foodborne Illness (by pathogen, \$2013)

\begin{tabular}{|c|c|c|c|c|c|c|c|}
\hline \multirow[b]{2}{*}{ Disease or Agent } & \multirow{2}{*}{$\begin{array}{l}\text { Illness } \\
\text { Incidence }^{1}\end{array}$} & \multicolumn{2}{|c|}{$\begin{array}{l}\text { Total Cost } \\
\text { (\$million) }\end{array}$} & \multicolumn{2}{|c|}{$\begin{array}{l}\text { Cost per } \\
\text { Resident }\end{array}$} & \multicolumn{2}{|c|}{$\begin{array}{c}\text { Cost } \\
\text { per Case }\end{array}$} \\
\hline & & Basic & Enhanced & Basic & Enhanced & Basic 1 & Enhanced \\
\hline \multicolumn{8}{|l|}{ Bacterial } \\
\hline$\overline{\text { Bacillus cereus }}$ & 2.01 & 0.04 & 0.06 & 0.04 & 0.06 & 189 & 301 \\
\hline Brucella spp. & 0.01 & 0.01 & 0.02 & 0.01 & 0.02 & 19,877 & 26,781 \\
\hline Campylobacter spp. & 26.73 & 6.08 & 31.25 & 5.78 & 29.72 & 2,162 & 11,120 \\
\hline Clostridium botulinum & $<0.01$ & 0.29 & 0.37 & 0.28 & 0.35 & $1,579,040$ & $2,021,614$ \\
\hline Clostridium perfringens & 30.56 & 1.48 & 1.94 & 1.41 & 1.84 & 462 & 603 \\
\hline STEC O157:H7 & 1.37 & 1.72 & 1.83 & 1.64 & 1.74 & 11,950 & 12,676 \\
\hline STEC non-0157 & 2.45 & 0.27 & 0.46 & 0.25 & 0.44 & 1,037 & 1,803 \\
\hline ETEC & 0.57 & 0.06 & 0.10 & 0.06 & 0.10 & 997 & 1,763 \\
\hline Other diarrheogenic E. coli, & 0.38 & 0.04 & 0.07 & 0.04 & 0.07 & 997 & 1,765 \\
\hline Listeria monocytogenes & 0.08 & 13.18 & 13.30 & 12.53 & 12.65 & $1,508,047$ & $1,521,959$ \\
\hline Salmonella, spp., Nontyphoidal & 28.53 & 15.19 & 44.25 & 14.45 & 42.09 & 5,063 & 14,749 \\
\hline S. enterica serotype Typhi & 0.05 & 0.02 & 0.08 & 0.02 & 0.08 & 4,395 & 14,769 \\
\hline Shigella, spp & 1.33 & 0.32 & 1.84 & 0.30 & 1.75 & 2,290 & 13,130 \\
\hline Staphylococcus aureus & 7.63 & 0.51 & 0.71 & 0.48 & 0.68 & 631 & 885 \\
\hline Streptococcus spp. Group A & 0.36 & 0.06 & 0.10 & 0.06 & 0.10 & 1,562 & 2,810 \\
\hline Vibrio cholerae, toxigenic & $<0.01$ & $<0.01$ & $<0.01$ & $<0.01$ & $<0.01$ & 1,727 & 2,909 \\
\hline Vibrio vulnificus & $<0.01$ & 1.20 & 1.20 & 1.14 & 1.14 & $3,317,938$ & $3,320,107$ \\
\hline Vibrio parahaemolyticus & 1.24 & 0.30 & 0.43 & 0.28 & 0.40 & 2,289 & 3,257 \\
\hline Vibrio spp., other & 0.63 & 0.35 & 0.41 & 0.33 & 0.39 & 5,227 & 6,194 \\
\hline Yersinia enterocolitica & 3.09 & 1.59 & 4.93 & 1.51 & 4.69 & 4,892 & 15,191 \\
\hline \multicolumn{8}{|l|}{ Parasitic } \\
\hline$\overline{\text { Cryptosporidium spp. }}$ & 1.19 & 0.30 & 0.47 & 0.28 & 0.45 & 2,393 & 3,792 \\
\hline Cyclospora cayetanensis & 0.16 & 0.02 & 0.03 & 0.02 & 0.03 & 1,105 & 1,959 \\
\hline Giardia intestinalis & 3.48 & 1.02 & 1.77 & 0.97 & 1.68 & 2,785 & 4,842 \\
\hline Toxoplasma gondii & 2.74 & 12.26 & 14.13 & 11.66 & 13.44 & 42,527 & 49,015 \\
\hline Trichinella spp. & $<0.01$ & 0.01 & 0.01 & 0.01 & 0.01 & 10,870 & 19,887 \\
\hline \multicolumn{8}{|l|}{ Viral } \\
\hline$\overline{\text { Astrovirus }}$ & 0.49 & 0.05 & 0.08 & 0.05 & 0.08 & 952 & 1,637 \\
\hline Hepatitis A virus & 0.06 & 0.26 & 0.27 & 0.25 & 0.26 & 42,628 & 44,511 \\
\hline Norovirus & 172.77 & 11.24 & 15.48 & 10.69 & 14.72 & 619 & 852 \\
\hline Rotavirus & 0.49 & 0.05 & 0.08 & 0.05 & 0.07 & 939 & 1,512 \\
\hline Sapovirus & 0.49 & 0.04 & 0.07 & 0.04 & 0.07 & 800 & 1,383 \\
\hline Known & & 67.95 & 135.77 & 64.62 & 129.12 & 2,237 & 4,470 \\
\hline Unknown & $1,214.46$ & 132.67 & 192.36 & 126.17 & 182.94 & 1,039 & 1,506 \\
\hline Total & & 200.62 & 328.13 & 190.79 & 312.06 & 1,269 & 2,076 \\
\hline
\end{tabular}

${ }^{1}$ Incidence per 10,000 residents. 
TABLE A41. South Carolina Cost per Case of Foodborne Illness (by pathogen, \$2013)

\begin{tabular}{|c|c|c|c|c|c|c|c|}
\hline \multirow[b]{2}{*}{ Disease or Agent } & \multirow{2}{*}{$\begin{array}{c}\text { Illness } \\
\text { Incidence }^{1} \\
\end{array}$} & \multicolumn{2}{|c|}{$\begin{array}{l}\text { Total Cost } \\
\text { (\$million) }\end{array}$} & \multicolumn{2}{|c|}{$\begin{array}{l}\text { Cost per } \\
\text { Resident }\end{array}$} & \multicolumn{2}{|c|}{$\begin{array}{c}\text { Cost } \\
\text { per Case }\end{array}$} \\
\hline & & Basic & Enhanced & Basic & Enhanced & Basic I & Enhanced \\
\hline \multicolumn{8}{|l|}{ Bacterial } \\
\hline$\overline{\text { Bacillus cereus }}$ & 2.01 & 0.14 & 0.23 & 0.03 & 0.05 & 147 & 242 \\
\hline Brucella spp. & 0.02 & 0.16 & 0.21 & 0.03 & 0.04 & 16,305 & 22,125 \\
\hline Campylobacter spp. & 26.73 & 21.85 & 113.96 & 4.58 & 23.87 & 1,712 & 8,928 \\
\hline Clostridium botulinum & $<0.01$ & 1.08 & 1.38 & 0.23 & 0.29 & $1,298,151$ & $1,654,222$ \\
\hline Clostridium perfringens & 30.56 & 5.27 & 7.03 & 1.10 & 1.47 & 361 & 482 \\
\hline STEC O157:H7 & 0.58 & 2.71 & 2.88 & 0.57 & 0.60 & 9,756 & 10,380 \\
\hline STEC non-0157 & 1.04 & 0.38 & 0.71 & 0.08 & 0.15 & 768 & 1,423 \\
\hline ETEC & 0.57 & 0.19 & 0.37 & 0.04 & 0.08 & 721 & 1,376 \\
\hline Other diarrheogenic E. coli, & 0.38 & 0.13 & 0.25 & 0.03 & 0.05 & 721 & 1,378 \\
\hline Listeria monocytogenes & 0.04 & 24.32 & 24.62 & 5.09 & 5.16 & $1,225,716$ & $1,240,884$ \\
\hline Salmonella, spp., Nontyphoidal & 55.63 & 108.05 & 315.64 & 22.63 & 66.10 & 4,067 & 11,882 \\
\hline S. enterica serotype Typhi & 0.01 & 0.01 & 0.04 & $<0.01$ & 0.01 & 4,151 & 12,546 \\
\hline Shigella, spp & 3.71 & 3.13 & 18.62 & 0.66 & 3.90 & 1,765 & 10,502 \\
\hline Staphylococcus aureus & 7.63 & 1.82 & 2.62 & 0.38 & 0.55 & 500 & 718 \\
\hline Streptococcus spp. Group A & 0.36 & 0.19 & 0.37 & 0.04 & 0.08 & 1,113 & 2,180 \\
\hline Vibrio cholerae, toxigenic & $<0.01$ & $<0.01$ & $<0.01$ & $<0.01$ & $<0.01$ & 1,329 & 2,340 \\
\hline Vibrio vulnificus & $<0.01$ & 3.76 & 3.76 & 0.79 & 0.79 & $2,669,739$ & $2,671,564$ \\
\hline Vibrio parahaemolyticus & 1.06 & 0.89 & 1.31 & 0.19 & 0.27 & 1,745 & 2,573 \\
\hline Vibrio spp., other & 0.54 & 1.05 & 1.27 & 0.22 & 0.27 & 4,094 & 4,921 \\
\hline Yersinia enterocolitica & 3.09 & 5.52 & 17.82 & 1.16 & 3.73 & 3,741 & 12,081 \\
\hline \multicolumn{8}{|l|}{ Parasitic } \\
\hline 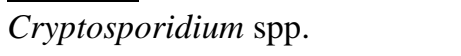 & 1.17 & 1.00 & 1.67 & 0.21 & 0.35 & 1,781 & 2,977 \\
\hline Cyclospora cayetanensis & 0.16 & 0.06 & 0.12 & 0.01 & 0.03 & 799 & 1,529 \\
\hline Giardia intestinalis & 0.95 & 0.92 & 1.72 & 0.19 & 0.36 & 2,013 & 3,771 \\
\hline Toxoplasma gondii & 2.74 & 45.40 & 52.56 & 9.51 & 11.01 & 34,671 & 40,144 \\
\hline Trichinella spp. & $<0.01$ & 0.02 & 0.04 & $<0.01$ & 0.01 & 7,985 & 15,661 \\
\hline \multicolumn{8}{|l|}{ Viral } \\
\hline$\overline{\text { Astrovirus }}$ & 0.49 & 0.17 & 0.30 & 0.03 & 0.06 & 715 & 1,301 \\
\hline Hepatitis A virus & 0.03 & 0.46 & 0.48 & 0.10 & 0.10 & 34,359 & 35,964 \\
\hline Norovirus & 172.77 & 40.56 & 57.03 & 8.50 & 11.94 & 492 & 691 \\
\hline Rotavirus & 0.49 & 0.18 & 0.29 & 0.04 & 0.06 & 756 & 1,247 \\
\hline Sapovirus & 0.49 & 0.14 & 0.25 & 0.03 & 0.05 & 595 & 1,094 \\
\hline Known & & 269.57 & 627.56 & 56.46 & 131.43 & 1,802 & 4,196 \\
\hline Unknown & $1,214.46$ & 464.35 & 696.07 & 97.25 & 145.78 & 801 & 1,200 \\
\hline Total & & 733.92 & $1,323.63$ & 153.71 & 277.21 & 1,006 & 1,815 \\
\hline
\end{tabular}

${ }^{1}$ Incidence per 10,000 residents. 
TABLE A42. South Dakota Cost per Case of Foodborne Illness (by pathogen, \$2013)

\begin{tabular}{|c|c|c|c|c|c|c|c|}
\hline \multirow[b]{2}{*}{ Disease or Agent } & \multirow{2}{*}{$\begin{array}{c}\text { Illness } \\
\text { Incidence }^{1} \\
\end{array}$} & \multicolumn{2}{|c|}{$\begin{array}{l}\text { Total Cost } \\
\text { (\$million) }\end{array}$} & \multicolumn{2}{|c|}{$\begin{array}{l}\text { Cost per } \\
\text { Resident }\end{array}$} & \multicolumn{2}{|c|}{$\begin{array}{c}\text { Cost } \\
\text { per Case }\end{array}$} \\
\hline & & Basic & Enhanced & Basic & Enhanced & Basic 1 & Enhanced \\
\hline \multicolumn{8}{|l|}{ Bacterial } \\
\hline Bacillus cereus & 2.01 & 0.03 & 0.04 & 0.03 & 0.05 & 159 & 263 \\
\hline Brucella spp. & 0.01 & 0.01 & 0.02 & 0.01 & 0.02 & 16,716 & 23,110 \\
\hline Campylobacter spp. & 26.73 & 4.09 & 22.12 & 4.84 & 26.18 & 1,809 & 9,794 \\
\hline Clostridium botulinum & $<0.01$ & 0.20 & 0.26 & 0.24 & 0.31 & $1,381,602$ & $1,775,650$ \\
\hline Clostridium perfringens & 30.56 & 1.02 & 1.37 & 1.21 & 1.62 & 397 & 529 \\
\hline STEC 0157:H7 & 6.97 & 6.13 & 6.53 & 7.26 & 7.73 & 10,419 & 11,103 \\
\hline STEC non-0157 & 12.44 & 0.88 & 1.63 & 1.04 & 1.93 & 834 & 1,552 \\
\hline ETEC & 0.57 & 0.04 & 0.07 & 0.05 & 0.09 & 803 & 1,521 \\
\hline Other diarrheogenic E. coli, & 0.38 & 0.03 & 0.05 & 0.03 & 0.06 & 803 & 1,523 \\
\hline Listeria monocytogenes & 0.03 & 2.89 & 2.93 & 3.42 & 3.47 & $1,324,110$ & $1,340,194$ \\
\hline Salmonella, spp., Nontyphoidal & 40.16 & 14.66 & 43.99 & 17.35 & 52.07 & 4,320 & 12,964 \\
\hline S. enterica serotype Typhi & 0.03 & 0.01 & 0.03 & 0.01 & 0.04 & 3,459 & 12,741 \\
\hline Shigella, spp & 7.43 & 1.19 & 7.25 & 1.40 & 8.58 & 1,889 & 11,556 \\
\hline Staphylococcus aureus & 7.63 & 0.34 & 0.49 & 0.40 & 0.59 & 529 & 768 \\
\hline Streptococcus spp. Group A & 0.36 & 0.04 & 0.07 & 0.04 & 0.09 & 1,254 & 2,424 \\
\hline Vibrio cholerae, toxigenic & $<0.01$ & $<0.01$ & $<0.01$ & $<0.01$ & $<0.01$ & 1,383 & 2,492 \\
\hline Vibrio vulnificus & $<0.01$ & 0.70 & 0.70 & 0.83 & 0.83 & $2,933,155$ & $2,935,160$ \\
\hline Vibrio parahaemolyticus & 1.02 & 0.17 & 0.24 & 0.20 & 0.29 & 1,922 & 2,829 \\
\hline Vibrio spp., other & 0.52 & 0.20 & 0.24 & 0.23 & 0.28 & 4,524 & 5,431 \\
\hline Yersinia enterocolitica & 3.09 & 1.08 & 3.49 & 1.28 & 4.13 & 4,135 & 13,355 \\
\hline \multicolumn{8}{|l|}{ Parasitic } \\
\hline$\overline{\text { Cryptosporidium spp. }}$ & 9.09 & 1.51 & 2.52 & 1.79 & 2.98 & 1,967 & 3,278 \\
\hline Cyclospora cayetanensis & 0.07 & $<0.01$ & 0.01 & 0.01 & 0.01 & 890 & 1,691 \\
\hline Giardia intestinalis & 4.47 & 0.85 & 1.58 & 1.00 & 1.87 & 2,246 & 4,174 \\
\hline Toxoplasma gondii & 2.74 & 8.51 & 9.90 & 10.07 & 11.72 & 36,730 & 42,742 \\
\hline Trichinella spp. & $<0.01$ & $<0.01$ & 0.01 & $<0.01$ & 0.01 & 8,666 & 17,086 \\
\hline \multicolumn{8}{|l|}{ Viral } \\
\hline Astrovirus & 0.49 & 0.03 & 0.06 & 0.04 & 0.07 & 765 & 1,407 \\
\hline Hepatitis A virus & 0.02 & 0.05 & 0.05 & 0.06 & 0.06 & 37,432 & 39,192 \\
\hline Norovirus & 172.77 & 7.59 & 10.79 & 8.99 & 12.77 & 520 & 739 \\
\hline Rotavirus & 0.49 & 0.03 & 0.05 & 0.04 & 0.06 & 752 & 1,290 \\
\hline Sapovirus & 0.49 & 0.03 & 0.05 & 0.03 & 0.06 & 644 & 1,191 \\
\hline Known & & 52.30 & 116.55 & 61.91 & 137.95 & 1,873 & 4,173 \\
\hline Unknown & $1,214.46$ & 89.09 & 134.04 & 105.45 & 158.65 & 868 & 1,306 \\
\hline Total & & 141.39 & 250.58 & 167.35 & 296.59 & 1,083 & 1,920 \\
\hline
\end{tabular}

${ }^{1}$ Incidence per 10,000 residents. 
TABLE A43. Tennessee Cost per Case of Foodborne Illness (by pathogen, \$2013)

\begin{tabular}{|c|c|c|c|c|c|c|c|}
\hline \multirow[b]{2}{*}{ Disease or Agent } & \multirow{2}{*}{$\begin{array}{l}\text { Illness } \\
\text { Incidence }^{1}\end{array}$} & \multicolumn{2}{|c|}{$\begin{array}{l}\text { Total Cost } \\
\text { (\$million) }\end{array}$} & \multicolumn{2}{|c|}{$\begin{array}{l}\text { Cost per } \\
\text { Resident }\end{array}$} & \multicolumn{2}{|c|}{$\begin{array}{c}\text { Cost } \\
\text { per Case }\end{array}$} \\
\hline & & Basic & Enhanced & Basic & Enhanced & Basic 1 & Enhanced \\
\hline \multicolumn{8}{|l|}{ Bacterial } \\
\hline$\overline{\text { Bacillus cereus }}$ & 2.01 & 0.20 & 0.31 & 0.03 & 0.05 & 151 & 239 \\
\hline Brucella spp. & 0.01 & 0.11 & 0.15 & 0.02 & 0.02 & 15,860 & 21,304 \\
\hline Campylobacter spp. & 26.73 & 29.50 & 150.39 & 4.54 & 23.15 & 1,699 & 8,661 \\
\hline Clostridium botulinum & $<0.01$ & 1.42 & 1.81 & 0.22 & 0.28 & $1,247,518$ & $1,591,352$ \\
\hline Clostridium perfringens & 30.56 & 7.17 & 9.39 & 1.10 & 1.45 & 361 & 473 \\
\hline STEC 0157:H7 & 2.01 & 12.30 & 13.05 & 1.89 & 2.01 & 9,422 & 9,999 \\
\hline STEC non-0157 & 3.59 & 1.86 & 3.27 & 0.29 & 0.50 & 797 & 1,404 \\
\hline ETEC & 0.57 & 0.28 & 0.50 & 0.04 & 0.08 & 757 & 1,364 \\
\hline Other diarrheogenic E. coli, & 0.38 & 0.19 & 0.34 & 0.03 & 0.05 & 757 & 1,366 \\
\hline Listeria monocytogenes & 0.04 & 27.78 & 28.06 & 4.28 & 4.32 & $1,182,846$ & $1,194,853$ \\
\hline Salmonella, spp., Nontyphoidal & 29.71 & 76.87 & 222.24 & 11.83 & 34.21 & 3,983 & 11,514 \\
\hline S. enterica serotype Typhi & 0.01 & 0.04 & 0.11 & 0.01 & 0.02 & 3,865 & 11,939 \\
\hline Shigella, spp & 4.39 & 5.08 & 29.12 & 0.78 & 4.48 & 1,780 & 10,206 \\
\hline Staphylococcus aureus & 7.63 & 2.47 & 3.47 & 0.38 & 0.53 & 499 & 701 \\
\hline Streptococcus spp. Group A & 0.36 & 0.27 & 0.50 & 0.04 & 0.08 & 1,175 & 2,164 \\
\hline Vibrio cholerae, toxigenic & $<0.01$ & $<0.01$ & $<0.01$ & $<0.01$ & $<0.01$ & 1,354 & 2,291 \\
\hline Vibrio vulnificus & $<0.01$ & 3.00 & 3.00 & 0.46 & 0.46 & $2,583,056$ & $2,584,765$ \\
\hline Vibrio parahaemolyticus & 0.65 & 0.74 & 1.06 & 0.11 & 0.16 & 1,760 & 2,527 \\
\hline Vibrio spp., other & 0.33 & 0.86 & 1.02 & 0.13 & 0.16 & 4,039 & 4,805 \\
\hline Yersinia enterocolitica & 3.09 & 7.54 & 23.62 & 1.16 & 3.64 & 3,755 & 11,773 \\
\hline \multicolumn{8}{|l|}{ Parasitic } \\
\hline$\overline{\text { Cryptosporidium spp. }}$ & 0.86 & 1.02 & 1.64 & 0.16 & 0.25 & 1,826 & 2,934 \\
\hline Cyclospora cayetanensis & 0.17 & 0.09 & 0.17 & 0.01 & 0.03 & 839 & 1,515 \\
\hline Giardia intestinalis & 1.26 & 1.72 & 3.05 & 0.26 & 0.47 & 2,103 & 3,733 \\
\hline Toxoplasma gondii & 2.74 & 59.79 & 68.91 & 9.20 & 10.61 & 33,568 & 38,685 \\
\hline Trichinella spp. & $<0.01$ & 0.03 & 0.05 & $<0.01$ & 0.01 & 8,298 & 15,431 \\
\hline \multicolumn{8}{|l|}{ Viral } \\
\hline$\overline{\text { Astrovirus }}$ & 0.49 & 0.23 & 0.41 & 0.04 & 0.06 & 737 & 1,280 \\
\hline Hepatitis A virus & 0.05 & 0.99 & 1.03 & 0.15 & 0.16 & 33,297 & 34,787 \\
\hline Norovirus & 172.77 & 54.91 & 75.65 & 8.45 & 11.65 & 489 & 674 \\
\hline Rotavirus & 0.49 & 0.24 & 0.38 & 0.04 & 0.06 & 755 & 1,209 \\
\hline Sapovirus & 0.49 & 0.20 & 0.34 & 0.03 & 0.05 & 617 & 1,079 \\
\hline Known & & 296.88 & 643.07 & 45.70 & 98.99 & 1,569 & 3,398 \\
\hline Unknown & $1,214.46$ & 636.43 & 928.51 & 97.97 & 142.94 & 807 & 1,177 \\
\hline Total & & 933.32 & $1,571.57$ & 143.68 & 241.93 & 954 & 1,607 \\
\hline
\end{tabular}

${ }^{1}$ Incidence per 10,000 residents. 
TABLE A44. Texas Cost per Case of Foodborne Illness (by pathogen, \$2013)

\begin{tabular}{|c|c|c|c|c|c|c|c|}
\hline \multirow[b]{2}{*}{ Disease or Agent } & \multirow{2}{*}{$\begin{array}{l}\text { Illness } \\
\text { Incidence }^{1}\end{array}$} & \multicolumn{2}{|c|}{$\begin{array}{l}\text { Total Cost } \\
\text { (\$million) }\end{array}$} & \multicolumn{2}{|c|}{$\begin{array}{l}\text { Cost per } \\
\text { Resident }\end{array}$} & \multicolumn{2}{|c|}{$\begin{array}{c}\text { Cost } \\
\text { per Case }\end{array}$} \\
\hline & & Basic & Enhanced & Basic & Enhanced & Basic 1 & Enhanced \\
\hline \multicolumn{8}{|l|}{ Bacterial } \\
\hline$\overline{\text { Bacillus cereus }}$ & 2.01 & 0.90 & 1.47 & 0.03 & 0.06 & 169 & 277 \\
\hline Brucella spp. & 0.06 & 3.05 & 4.13 & 0.12 & 0.16 & 18,688 & 25,309 \\
\hline Campylobacter spp. & 26.73 & 140.60 & 731.50 & 5.32 & 27.66 & 1,989 & 10,347 \\
\hline Clostridium botulinum & $<0.01$ & 6.89 & 8.80 & 0.26 & 0.33 & $1,489,275$ & $1,901,903$ \\
\hline Clostridium perfringens & 30.56 & 33.92 & 44.96 & 1.28 & 1.70 & 420 & 556 \\
\hline STEC O157:H7 & 1.20 & 35.58 & 37.82 & 1.35 & 1.43 & 11,218 & 11,923 \\
\hline STEC non-0157 & 2.14 & 5.19 & 9.39 & 0.20 & 0.35 & 916 & 1,657 \\
\hline ETEC & 0.57 & 1.30 & 2.41 & 0.05 & 0.09 & 869 & 1,611 \\
\hline Other diarrheogenic E. coli, & 0.38 & 0.87 & 1.62 & 0.03 & 0.06 & 869 & 1,613 \\
\hline Listeria monocytogenes & 0.03 & 114.76 & 116.03 & 4.34 & 4.39 & $1,413,287$ & $1,429,017$ \\
\hline Salmonella, spp., Nontyphoidal & 31.82 & 395.93 & $1,157.22$ & 14.97 & 43.75 & 4,704 & 13,750 \\
\hline S. enterica serotype Typhi & 0.05 & 0.58 & 1.84 & 0.02 & 0.07 & 4,472 & 14,177 \\
\hline Shigella, spp & 7.98 & 43.78 & 257.35 & 1.66 & 9.73 & 2,074 & 12,192 \\
\hline Staphylococcus aureus & 7.63 & 11.67 & 16.64 & 0.44 & 0.63 & 579 & 825 \\
\hline Streptococcus spp. Group A & 0.36 & 1.27 & 2.40 & 0.05 & 0.09 & 1,353 & 2,560 \\
\hline Vibrio cholerae, toxigenic & $<0.01$ & 0.01 & 0.02 & $<0.01$ & $<0.01$ & 1,559 & 2,703 \\
\hline Vibrio vulnificus & $<0.01$ & 24.07 & 24.09 & 0.91 & 0.91 & $3,092,718$ & $3,094,795$ \\
\hline Vibrio parahaemolyticus & 1.06 & 5.80 & 8.43 & 0.22 & 0.32 & 2,063 & 2,999 \\
\hline Vibrio spp., other & 0.54 & 6.82 & 8.15 & 0.26 & 0.31 & 4,792 & 5,728 \\
\hline Yersinia enterocolitica & 3.09 & 36.12 & 114.88 & 1.37 & 4.34 & 4,421 & 14,060 \\
\hline \multicolumn{8}{|l|}{ Parasitic } \\
\hline$\overline{\text { Cryptosporidium spp. }}$ & 1.34 & 7.52 & 12.31 & 0.28 & 0.47 & 2,127 & 3,481 \\
\hline Cyclospora cayetanensis & 0.20 & 0.50 & 0.93 & 0.02 & 0.04 & 964 & 1,790 \\
\hline Giardia intestinalis & 2.12 & 13.64 & 24.78 & 0.52 & 0.94 & 2,435 & 4,425 \\
\hline Toxoplasma gondii & 2.74 & 289.33 & 334.47 & 10.94 & 12.65 & 39,894 & 46,119 \\
\hline Trichinella spp. & $<0.01$ & 0.13 & 0.24 & $<0.01$ & 0.01 & 9,588 & 18,287 \\
\hline \multicolumn{8}{|l|}{ Viral } \\
\hline$\overline{\text { Astrovirus }}$ & 0.49 & 1.09 & 1.95 & 0.04 & 0.07 & 848 & 1,511 \\
\hline Hepatitis A virus & 0.06 & 5.87 & 6.14 & 0.22 & 0.23 & 39,750 & 41,568 \\
\hline Norovirus & 172.77 & 259.81 & 362.96 & 9.82 & 13.72 & 569 & 794 \\
\hline Rotavirus & 0.49 & 1.12 & 1.84 & 0.04 & 0.07 & 868 & 1,423 \\
\hline Sapovirus & 0.49 & 0.91 & 1.64 & 0.03 & 0.06 & 708 & 1,273 \\
\hline Known & & $1,449.03$ & $3,296.43$ & 54.79 & 124.64 & 1,845 & 4,198 \\
\hline Unknown & $1,214.46$ & $3,019.98$ & $4,472.19$ & 114.18 & 169.09 & 940 & 1,392 \\
\hline Total & & $4,469.01$ & $7,768.62$ & 168.97 & 293.73 & 1,118 & 1,943 \\
\hline
\end{tabular}

${ }^{1}$ Incidence per 10,000 residents. 
TABLE A45. Utah Cost per Case of Foodborne Illness (by pathogen, \$2013)

\begin{tabular}{|c|c|c|c|c|c|c|c|}
\hline \multirow[b]{2}{*}{ Disease or Agent } & \multirow{2}{*}{$\begin{array}{c}\text { Illness } \\
\text { Incidence }^{1}\end{array}$} & \multicolumn{2}{|c|}{$\begin{array}{l}\text { Total Cost } \\
\text { (\$million) }\end{array}$} & \multicolumn{2}{|c|}{$\begin{array}{l}\text { Cost per } \\
\text { Resident }\end{array}$} & \multicolumn{2}{|c|}{$\begin{array}{c}\text { Cost } \\
\text { per Case }\end{array}$} \\
\hline & & Basic & Enhanced & Basic & Enhanced & Basic 1 & Enhanced \\
\hline \multicolumn{8}{|l|}{ Bacterial } \\
\hline$\overline{\text { Bacillus cereus }}$ & 2.01 & 0.10 & 0.17 & 0.03 & 0.06 & 167 & 295 \\
\hline Brucella spp. & 0.02 & 0.13 & 0.18 & 0.05 & 0.06 & 19,036 & 26,792 \\
\hline Campylobacter spp. & 26.73 & 15.74 & 88.73 & 5.43 & 30.59 & 2,030 & 11,443 \\
\hline Clostridium botulinum & $<0.01$ & 0.82 & 1.06 & 0.28 & 0.36 & $1,615,590$ & $2,079,766$ \\
\hline Clostridium perfringens & 30.56 & 3.92 & 5.36 & 1.35 & 1.85 & 443 & 605 \\
\hline STEC O157:H7 & 4.44 & 15.61 & 16.70 & 5.38 & 5.76 & 12,121 & 12,962 \\
\hline STEC non-0157 & 7.93 & 2.06 & 4.08 & 0.71 & 1.41 & 894 & 1,773 \\
\hline ETEC & 0.57 & 0.14 & 0.29 & 0.05 & 0.10 & 858 & 1,737 \\
\hline Other diarrheogenic E. coli, & 0.38 & 0.09 & 0.19 & 0.03 & 0.07 & 858 & 1,739 \\
\hline Listeria monocytogenes & 0.02 & 8.46 & 8.58 & 2.92 & 2.96 & $1,548,869$ & $1,571,185$ \\
\hline Salmonella, spp., Nontyphoidal & 21.27 & 30.47 & 93.41 & 10.50 & 32.20 & 4,939 & 15,140 \\
\hline S. enterica serotype Typhi & 0.02 & 0.03 & 0.10 & 0.01 & 0.03 & 3,841 & 14,816 \\
\hline Shigella, spp & 1.16 & 0.70 & 4.53 & 0.24 & 1.56 & 2,091 & 13,492 \\
\hline Staphylococcus aureus & 7.63 & 1.30 & 1.94 & 0.45 & 0.67 & 586 & 878 \\
\hline Streptococcus spp. Group A & 0.36 & 0.14 & 0.29 & 0.05 & 0.10 & 1,341 & 2,773 \\
\hline Vibrio cholerae, toxigenic & $<0.01$ & $<0.01$ & $<0.01$ & $<0.01$ & $<0.01$ & 1,491 & 2,848 \\
\hline Vibrio vulnificus & $<0.01$ & 0.26 & 0.26 & 0.09 & 0.09 & $3,440,376$ & $3,442,807$ \\
\hline Vibrio parahaemolyticus & 0.09 & 0.06 & 0.09 & 0.02 & 0.03 & 2,151 & 3,261 \\
\hline Vibrio spp., other & 0.05 & 0.07 & 0.09 & 0.02 & 0.03 & 5,204 & 6,314 \\
\hline Yersinia enterocolitica & 3.09 & 4.18 & 13.96 & 1.44 & 4.81 & 4,667 & 15,574 \\
\hline \multicolumn{8}{|l|}{ Parasitic } \\
\hline$\overline{\text { Cryptosporidium spp. }}$ & 6.29 & 3.95 & 6.87 & 1.36 & 2.37 & 2,165 & 3,769 \\
\hline Cyclospora cayetanensis & $<0.01$ & $<0.01$ & $<0.01$ & $<0.01$ & $<0.01$ & 951 & 1,931 \\
\hline Giardia intestinalis & 4.35 & 3.07 & 6.05 & 1.06 & 2.08 & 2,429 & 4,788 \\
\hline Toxoplasma gondii & 2.74 & 33.84 & 39.64 & 11.66 & 13.66 & 42,537 & 49,833 \\
\hline Trichinella spp. & $<0.01$ & 0.01 & 0.03 & $<0.01$ & 0.01 & 9,328 & 19,604 \\
\hline \multicolumn{8}{|l|}{ Viral } \\
\hline$\overline{\text { Astrovirus }}$ & 0.49 & 0.12 & 0.23 & 0.04 & 0.08 & 821 & 1,607 \\
\hline Hepatitis A virus & 0.03 & 0.35 & 0.37 & 0.12 & 0.13 & 43,693 & 45,843 \\
\hline Norovirus & 172.77 & 29.01 & 42.44 & 10.00 & 14.63 & 579 & 847 \\
\hline Rotavirus & 0.49 & 0.12 & 0.21 & 0.04 & 0.07 & 813 & 1,472 \\
\hline Sapovirus & 0.49 & 0.10 & 0.19 & 0.03 & 0.07 & 690 & 1,360 \\
\hline Known & & 154.85 & 336.02 & 53.38 & 115.84 & 1,816 & 3,940 \\
\hline Unknown & $1,214.46$ & 339.92 & 528.74 & 117.18 & 182.27 & 965 & 1,501 \\
\hline Total & & 494.77 & 864.77 & 170.56 & 298.11 & 1,131 & 1,976 \\
\hline
\end{tabular}

${ }^{1}$ Incidence per 10,000 residents. 
TABLE A46. Vermont Cost per Case of Foodborne Illness (by pathogen, \$2013)

\begin{tabular}{|c|c|c|c|c|c|c|c|}
\hline \multirow[b]{2}{*}{ Disease or Agent } & \multirow{2}{*}{$\begin{array}{l}\text { Illness } \\
\text { Incidence }^{1}\end{array}$} & \multicolumn{2}{|c|}{$\begin{array}{l}\text { Total Cost } \\
\text { (\$million) }\end{array}$} & \multicolumn{2}{|c|}{$\begin{array}{l}\text { Cost per } \\
\text { Resident }\end{array}$} & \multicolumn{2}{|c|}{$\begin{array}{c}\text { Cost } \\
\text { per Case }\end{array}$} \\
\hline & & Basic & Enhanced & Basic & Enhanced & Basic 1 & Enhanced \\
\hline \multicolumn{8}{|l|}{ Bacterial } \\
\hline$\overline{\text { Bacillus cereus }}$ & 2.01 & 0.02 & 0.04 & 0.04 & 0.06 & 188 & 297 \\
\hline Brucella spp. & $<0.01$ & $<0.01$ & $<0.01$ & $<0.01$ & $<0.01$ & 19,314 & 26,097 \\
\hline Campylobacter spp. & 26.73 & 3.56 & 18.42 & 5.68 & 29.40 & 2,125 & 10,998 \\
\hline Clostridium botulinum & $<0.01$ & 0.17 & 0.22 & 0.27 & 0.35 & $1,546,136$ & $1,984,568$ \\
\hline Clostridium perfringens & 30.56 & 0.88 & 1.14 & 1.40 & 1.82 & 459 & 597 \\
\hline STEC O157:H7 & 4.11 & 3.02 & 3.20 & 4.81 & 5.11 & 11,723 & 12,434 \\
\hline STEC non-0157 & 7.33 & 0.48 & 0.82 & 0.76 & 1.31 & 1,035 & 1,786 \\
\hline ETEC & 0.57 & 0.04 & 0.06 & 0.06 & 0.10 & 1,003 & 1,753 \\
\hline Other diarrheogenic E. coli, & 0.38 & 0.02 & 0.04 & 0.04 & 0.07 & 1,002 & 1,755 \\
\hline Listeria monocytogenes & 0.06 & 5.67 & 5.72 & 9.05 & 9.13 & $1,483,928$ & $1,496,874$ \\
\hline Salmonella, spp., Nontyphoidal & 27.40 & 8.54 & 25.01 & 13.63 & 39.91 & 4,973 & 14,564 \\
\hline S. enterica serotype Typhi & 0.01 & $<0.01$ & 0.01 & $<0.01$ & 0.01 & 3,974 & 14,240 \\
\hline Shigella, spp & 0.67 & 0.09 & 0.54 & 0.15 & 0.87 & 2,266 & 13,002 \\
\hline Staphylococcus aureus & 7.63 & 0.30 & 0.42 & 0.47 & 0.66 & 621 & 870 \\
\hline Streptococcus spp. Group A & 0.36 & 0.04 & 0.06 & 0.06 & 0.10 & 1,577 & 2,800 \\
\hline Vibrio cholerae, toxigenic & $<0.01$ & $<0.01$ & $<0.01$ & $<0.01$ & $<0.01$ & 1,700 & 2,858 \\
\hline Vibrio vulnificus & $<0.01$ & 0.19 & 0.19 & 0.30 & 0.30 & $3,281,605$ & $3,283,736$ \\
\hline Vibrio parahaemolyticus & 0.33 & 0.05 & 0.07 & 0.08 & 0.11 & 2,282 & 3,230 \\
\hline Vibrio spp., other & 0.17 & 0.05 & 0.06 & 0.09 & 0.10 & 5,195 & 6,143 \\
\hline Yersinia enterocolitica & 3.09 & 0.94 & 2.92 & 1.51 & 4.65 & 4,878 & 15,069 \\
\hline \multicolumn{8}{|l|}{ Parasitic } \\
\hline$\overline{\text { Cryptosporidium spp. }}$ & 6.76 & 1.01 & 1.59 & 1.62 & 2.54 & 2,395 & 3,766 \\
\hline Cyclospora cayetanensis & $<0.01$ & $<0.01$ & $<0.01$ & $<0.01$ & $<0.01$ & 1,112 & 1,949 \\
\hline Giardia intestinalis & 10.23 & 1.80 & 3.09 & 2.87 & 4.93 & 2,802 & 4,818 \\
\hline Toxoplasma gondii & 2.74 & 7.16 & 8.25 & 11.42 & 13.17 & 41,651 & 48,025 \\
\hline Trichinella spp. & $<0.01$ & $<0.01$ & 0.01 & 0.01 & 0.01 & 10,854 & 19,698 \\
\hline \multicolumn{8}{|l|}{ Viral } \\
\hline$\overline{\text { Astrovirus }}$ & 0.49 & 0.03 & 0.05 & 0.05 & 0.08 & 946 & 1,617 \\
\hline Hepatitis A virus & 0.03 & 0.08 & 0.08 & 0.13 & 0.13 & 42,075 & 43,921 \\
\hline Norovirus & 172.77 & 6.59 & 9.06 & 10.51 & 14.46 & 609 & 837 \\
\hline Rotavirus & 0.49 & 0.03 & 0.04 & 0.04 & 0.07 & 909 & 1,471 \\
\hline Sapovirus & 0.49 & 0.02 & 0.04 & 0.04 & 0.07 & 798 & 1,369 \\
\hline Known & & 40.77 & 81.16 & 65.07 & 129.51 & 2,131 & 4,241 \\
\hline Unknown & $1,214.46$ & 78.47 & 113.33 & 125.22 & 180.85 & 1,031 & 1,489 \\
\hline Total & & 119.24 & 194.48 & 190.29 & 310.36 & 1,252 & 2,042 \\
\hline
\end{tabular}

${ }^{1}$ Incidence per 10,000 residents. 
TABLE A47. Virginia Cost per Case of Foodborne Illness (by pathogen, \$2013)

\begin{tabular}{|c|c|c|c|c|c|c|c|}
\hline \multirow[b]{2}{*}{ Disease or Agent } & \multirow{2}{*}{$\begin{array}{l}\text { Illness } \\
\text { Incidence }^{1}\end{array}$} & \multicolumn{2}{|c|}{$\begin{array}{l}\text { Total Cost } \\
\text { (\$million) }\end{array}$} & \multicolumn{2}{|c|}{$\begin{array}{l}\text { Cost per } \\
\text { Resident }\end{array}$} & \multicolumn{2}{|c|}{$\begin{array}{l}\text { Cost } \\
\text { per Case }\end{array}$} \\
\hline & & Basic & Enhanced & Basic & Enhanced & Basic 1 & Enhanced \\
\hline \multicolumn{8}{|l|}{ Bacterial } \\
\hline$\overline{\text { Bacillus cereus }}$ & 2.01 & 0.32 & 0.54 & 0.04 & 0.07 & 194 & 329 \\
\hline Brucella spp. & 0.01 & 0.13 & 0.19 & 0.02 & 0.02 & 21,714 & 29,972 \\
\hline Campylobacter spp. & 26.73 & 51.63 & 279.88 & 6.25 & 33.88 & 2,338 & 12,676 \\
\hline Clostridium botulinum & $<0.01$ & 2.59 & 3.33 & 0.31 & 0.40 & $1,791,327$ & $2,301,543$ \\
\hline Clostridium perfringens & 30.56 & 12.67 & 16.99 & 1.53 & 2.06 & 502 & 673 \\
\hline STEC O157:H7 & 2.12 & 23.57 & 25.11 & 2.85 & 3.04 & 13,488 & 14,371 \\
\hline STEC non-0157 & 3.78 & 3.35 & 6.24 & 0.41 & 0.76 & 1,074 & 2,001 \\
\hline ETEC & 0.57 & 0.48 & 0.92 & 0.06 & 0.11 & 1,034 & 1,961 \\
\hline Other diarrheogenic E. coli, & 0.38 & 0.32 & 0.61 & 0.04 & 0.07 & 1,034 & 1,963 \\
\hline Listeria monocytogenes & 0.04 & 58.43 & 59.12 & 7.07 & 7.16 & $1,716,126$ & $1,736,645$ \\
\hline Salmonella, spp., Nontyphoidal & 30.58 & 141.34 & 424.06 & 17.11 & 51.34 & 5,595 & 16,785 \\
\hline S. enterica serotype Typhi & 0.08 & 0.31 & 1.13 & 0.04 & 0.14 & 4,494 & 16,508 \\
\hline Shigella, spp & 2.43 & 4.91 & 30.04 & 0.59 & 3.64 & 2,445 & 14,960 \\
\hline Staphylococcus aureus & 7.63 & 4.25 & 6.19 & 0.51 & 0.75 & 675 & 983 \\
\hline Streptococcus spp. Group A & 0.36 & 0.48 & 0.92 & 0.06 & 0.11 & 1,622 & 3,132 \\
\hline Vibrio cholerae, toxigenic & $<0.01$ & 0.01 & 0.01 & $<0.01$ & $<0.01$ & 1,786 & 3,217 \\
\hline Vibrio vulnificus & $<0.01$ & 14.61 & 14.62 & 1.77 & 1.77 & $3,799,765$ & $3,802,356$ \\
\hline Vibrio parahaemolyticus & 1.68 & 3.45 & 5.07 & 0.42 & 0.61 & 2,485 & 3,656 \\
\hline Vibrio spp., other & 0.85 & 4.12 & 4.94 & 0.50 & 0.60 & 5,856 & 7,026 \\
\hline Yersinia enterocolitica & 3.09 & 13.68 & 44.13 & 1.66 & 5.34 & 5,362 & 17,295 \\
\hline \multicolumn{8}{|l|}{ Parasitic } \\
\hline$\overline{\text { Cryptosporidium spp. }}$ & 0.88 & 1.85 & 3.07 & 0.22 & 0.37 & 2,552 & 4,244 \\
\hline Cyclospora cayetanensis & 0.11 & 0.10 & 0.20 & 0.01 & 0.02 & 1,146 & 2,180 \\
\hline Giardia intestinalis & 1.96 & 4.73 & 8.77 & 0.57 & 1.06 & 2,919 & 5,408 \\
\hline Toxoplasma gondii & 2.74 & 107.93 & 125.52 & 13.07 & 15.20 & 47,649 & 55,414 \\
\hline Trichinella spp. & $<0.01$ & 0.05 & 0.09 & 0.01 & 0.01 & 11,286 & 22,156 \\
\hline \multicolumn{8}{|l|}{ Viral } \\
\hline$\overline{\text { Astrovirus }}$ & 0.49 & 0.40 & 0.73 & 0.05 & 0.09 & 986 & 1,815 \\
\hline Hepatitis A virus & 0.04 & 1.64 & 1.71 & 0.20 & 0.21 & 48,470 & 50,743 \\
\hline Norovirus & 172.77 & 94.89 & 135.19 & 11.49 & 16.37 & 665 & 947 \\
\hline Rotavirus & 0.49 & 0.39 & 0.67 & 0.05 & 0.08 & 968 & 1,662 \\
\hline Sapovirus & 0.49 & 0.33 & 0.62 & 0.04 & 0.07 & 829 & 1,534 \\
\hline Known & & 552.95 & $1,200.62$ & 66.94 & 145.35 & 2,286 & 4,963 \\
\hline Unknown & $1,214.46$ & $1,121.25$ & $1,688.43$ & 135.74 & 204.40 & 1,118 & 1,683 \\
\hline Total & & $1,674.20$ & $2,889.05$ & 202.68 & 349.75 & 1,345 & 2,320 \\
\hline
\end{tabular}

${ }^{1}$ Incidence per 10,000 residents. 
TABLE A48. Washington Cost per Case of Foodborne Illness (by pathogen, \$2013)

\begin{tabular}{|c|c|c|c|c|c|c|c|}
\hline \multirow[b]{2}{*}{ Disease or Agent } & \multirow{2}{*}{$\begin{array}{l}\text { Illness } \\
\text { Incidence }^{1}\end{array}$} & \multicolumn{2}{|c|}{$\begin{array}{l}\text { Total Cost } \\
\text { (\$million) }\end{array}$} & \multicolumn{2}{|c|}{$\begin{array}{l}\text { Cost per } \\
\text { Resident }\end{array}$} & \multicolumn{2}{|c|}{$\begin{array}{c}\text { Cost } \\
\text { per Case }\end{array}$} \\
\hline & & Basic & Enhanced & Basic & Enhanced & Basic 1 & Enhanced \\
\hline \multicolumn{8}{|l|}{ Bacterial } \\
\hline$\overline{\text { Bacillus cereus }}$ & 2.01 & 0.27 & 0.45 & 0.04 & 0.06 & 192 & 320 \\
\hline Brucella spp. & 0.01 & 0.13 & 0.18 & 0.02 & 0.03 & 20,877 & 28,747 \\
\hline Campylobacter spp. & 26.73 & 42.23 & 227.53 & 6.06 & 32.64 & 2,266 & 12,210 \\
\hline Clostridium botulinum & $<0.01$ & 2.10 & 2.70 & 0.30 & 0.39 & $1,718,293$ & $2,209,194$ \\
\hline Clostridium perfringens & 30.56 & 10.44 & 13.90 & 1.50 & 1.99 & 490 & 652 \\
\hline STEC O157:H7 & 3.37 & 30.47 & 32.44 & 4.37 & 4.65 & 12,963 & 13,801 \\
\hline STEC non-0157 & 6.02 & 4.44 & 8.14 & 0.64 & 1.17 & 1,058 & 1,939 \\
\hline ETEC & 0.57 & 0.40 & 0.75 & 0.06 & 0.11 & 1,022 & 1,903 \\
\hline Other diarrheogenic E. coli, & 0.38 & 0.27 & 0.50 & 0.04 & 0.07 & 1,022 & 1,905 \\
\hline Listeria monocytogenes & 0.06 & 64.26 & 64.98 & 9.22 & 9.32 & $1,649,263$ & $1,667,880$ \\
\hline Salmonella, spp., Nontyphoidal & 21.84 & 82.21 & 246.08 & 11.79 & 35.30 & 5,399 & 16,160 \\
\hline S. enterica serotype Typhi & 0.06 & 0.19 & 0.71 & 0.03 & 0.10 & 4,213 & 15,759 \\
\hline Shigella, spp & 1.61 & 2.67 & 16.15 & 0.38 & 2.32 & 2,383 & 14,420 \\
\hline Staphylococcus aureus & 7.63 & 3.49 & 5.05 & 0.50 & 0.72 & 657 & 949 \\
\hline Streptococcus spp. Group A & 0.36 & 0.40 & 0.75 & 0.06 & 0.11 & 1,605 & 3,040 \\
\hline Vibrio cholerae, toxigenic & 0.01 & 0.01 & 0.01 & $<0.01$ & $<0.01$ & 1,746 & 3,106 \\
\hline Vibrio vulnificus & 0.01 & 19.00 & 19.01 & 2.73 & 2.73 & $3,656,955$ & $3,659,425$ \\
\hline Vibrio parahaemolyticus & 2.69 & 4.55 & 6.63 & 0.65 & 0.95 & 2,424 & 3,537 \\
\hline Vibrio spp., other & 1.36 & 5.39 & 6.45 & 0.77 & 0.92 & 5,671 & 6,783 \\
\hline Yersinia enterocolitica & 3.09 & 11.24 & 35.93 & 1.61 & 5.15 & 5,219 & 16,686 \\
\hline \multicolumn{8}{|l|}{ Parasitic } \\
\hline$\overline{\text { Cryptosporidium spp. }}$ & 1.09 & 1.89 & 3.11 & 0.27 & 0.45 & 2,500 & 4,109 \\
\hline Cyclospora cayetanensis & 0.24 & 0.19 & 0.36 & 0.03 & 0.05 & 1,133 & 2,115 \\
\hline Giardia intestinalis & 2.44 & 4.89 & 8.92 & 0.70 & 1.28 & 2,877 & 5,242 \\
\hline Toxoplasma gondii & 2.74 & 87.56 & 101.70 & 12.56 & 14.59 & 45,803 & 53,202 \\
\hline Trichinella spp. & $<0.01$ & 0.04 & 0.07 & 0.01 & 0.01 & 11,096 & 21,436 \\
\hline \multicolumn{8}{|l|}{ Viral } \\
\hline$\overline{\text { Astrovirus }}$ & 0.49 & 0.33 & 0.60 & 0.05 & 0.09 & 968 & 1,756 \\
\hline Hepatitis A virus & 0.03 & 1.10 & 1.15 & 0.16 & 0.17 & 46,661 & 48,822 \\
\hline Norovirus & 172.77 & 77.83 & 110.14 & 11.16 & 15.80 & 646 & 914 \\
\hline Rotavirus & 0.49 & 0.32 & 0.54 & 0.05 & 0.08 & 939 & 1,599 \\
\hline Sapovirus & 0.49 & 0.28 & 0.51 & 0.04 & 0.07 & 816 & 1,486 \\
\hline Known & & 458.57 & 915.43 & 65.78 & 131.31 & 2,275 & 4,542 \\
\hline Unknown & $1,214.46$ & 922.82 & $1,377.73$ & 132.37 & 197.63 & 1,090 & 1,627 \\
\hline Total & & $1,381.39$ & $2,293.15$ & 198.15 & 328.94 & 1,318 & 2,188 \\
\hline
\end{tabular}

${ }^{1}$ Incidence per 10,000 residents. 
TABLE A49. West Virginia Cost per Case of Foodborne Illness (by pathogen, \$2013)

\begin{tabular}{|c|c|c|c|c|c|c|c|}
\hline \multirow[b]{2}{*}{ Disease or Agent } & \multirow{2}{*}{$\begin{array}{c}\text { Illness } \\
\text { Incidence }^{1} \\
\end{array}$} & \multicolumn{2}{|c|}{$\begin{array}{l}\text { Total Cost } \\
\text { (\$million) }\end{array}$} & \multicolumn{2}{|c|}{$\begin{array}{l}\text { Cost per } \\
\text { Resident }\end{array}$} & \multicolumn{2}{|c|}{$\begin{array}{c}\text { Cost } \\
\text { per Case }\end{array}$} \\
\hline & & Basic & Enhanced & Basic & Enhanced & Basic 1 & Enhanced \\
\hline \multicolumn{8}{|l|}{ Bacterial } \\
\hline$\overline{\text { Bacillus cereus }}$ & 2.01 & 0.05 & 0.09 & 0.03 & 0.05 & 136 & 233 \\
\hline Brucella spp. & $<0.01$ & 0.01 & 0.01 & 0.01 & 0.01 & 14,536 & 20,397 \\
\hline Campylobacter spp. & 26.73 & 7.71 & 42.95 & 4.16 & 23.16 & 1,555 & 8,666 \\
\hline Clostridium botulinum & $<0.01$ & 0.40 & 0.51 & 0.21 & 0.28 & $1,226,014$ & $1,576,681$ \\
\hline Clostridium perfringens & 30.56 & 1.95 & 2.65 & 1.05 & 1.43 & 345 & 467 \\
\hline STEC 0157:H7 & 1.26 & 2.14 & 2.29 & 1.16 & 1.24 & 9,214 & 9,849 \\
\hline STEC non-0157 & 2.24 & 0.29 & 0.56 & 0.15 & 0.30 & 688 & 1,353 \\
\hline ETEC & 0.57 & 0.07 & 0.14 & 0.04 & 0.07 & 659 & 1,323 \\
\hline Other diarrheogenic E. coli, & 0.38 & 0.05 & 0.09 & 0.02 & 0.05 & 659 & 1,325 \\
\hline Listeria monocytogenes & 0.06 & 13.67 & 13.87 & 7.37 & 7.48 & $1,173,495$ & $1,190,372$ \\
\hline Salmonella, spp., Nontyphoidal & 23.14 & 16.15 & 49.22 & 8.71 & 26.54 & 3,763 & 11,469 \\
\hline S. enterica serotype Typhi & $<0.01$ & $<0.01$ & 0.01 & $<0.01$ & 0.01 & 3,039 & 11,330 \\
\hline Shigella, spp & 1.37 & 0.41 & 2.60 & 0.22 & 1.40 & 1,598 & 10,211 \\
\hline Staphylococcus aureus & 7.63 & 0.64 & 0.96 & 0.35 & 0.52 & 456 & 676 \\
\hline Streptococcus spp. Group A & 0.36 & 0.07 & 0.14 & 0.04 & 0.07 & 1,023 & 2,104 \\
\hline Vibrio cholerae, toxigenic & $<0.01$ & $<0.01$ & $<0.01$ & $<0.01$ & $<0.01$ & 1,151 & 2,177 \\
\hline Vibrio vulnificus & $<0.01$ & 1.37 & 1.37 & 0.74 & 0.74 & $2,601,355$ & $2,603,192$ \\
\hline Vibrio parahaemolyticus & 1.02 & 0.31 & 0.47 & 0.17 & 0.25 & 1,637 & 2,476 \\
\hline Vibrio spp., other & 0.52 & 0.38 & 0.46 & 0.20 & 0.25 & 3,944 & 4,782 \\
\hline Yersinia enterocolitica & 3.09 & 2.03 & 6.75 & 1.09 & 3.64 & 3,538 & 11,777 \\
\hline \multicolumn{8}{|l|}{ Parasitic } \\
\hline$\overline{\text { Cryptosporidium spp. }}$ & 0.71 & 0.22 & 0.38 & 0.12 & 0.20 & 1,644 & 2,857 \\
\hline Cyclospora cayetanensis & $<0.01$ & $<0.01$ & $<0.01$ & $<0.01$ & $<0.01$ & 730 & 1,471 \\
\hline Giardia intestinalis & 1.16 & 0.40 & 0.78 & 0.21 & 0.42 & 1,843 & 3,626 \\
\hline Toxoplasma gondii & 2.74 & 16.43 & 19.24 & 8.86 & 10.37 & 32,317 & 37,830 \\
\hline Trichinella spp. & $<0.01$ & 0.01 & 0.01 & $<0.01$ & 0.01 & 7,093 & 14,858 \\
\hline \multicolumn{8}{|l|}{ Viral } \\
\hline$\overline{\text { Astrovirus }}$ & 0.49 & 0.06 & 0.11 & 0.03 & 0.06 & 633 & 1,227 \\
\hline Hepatitis A virus & 0.03 & 0.16 & 0.17 & 0.09 & 0.09 & 33,106 & 34,731 \\
\hline Norovirus & 172.77 & 14.38 & 20.87 & 7.76 & 11.25 & 449 & 651 \\
\hline Rotavirus & 0.49 & 0.06 & 0.10 & 0.03 & 0.06 & 634 & 1,132 \\
\hline Sapovirus & 0.49 & 0.05 & 0.09 & 0.03 & 0.05 & 533 & 1,039 \\
\hline Known & & 79.46 & 166.89 & 42.85 & 90.00 & 1,531 & 3,216 \\
\hline Unknown & $1,214.46$ & 166.73 & 257.93 & 89.91 & 139.10 & 740 & 1,145 \\
\hline Total & & 246.18 & 424.83 & 132.76 & 229.10 & 888 & 1,533 \\
\hline
\end{tabular}

${ }^{1}$ Incidence per 10,000 residents. 
TABLE A50. Wisconsin Cost per Case of Foodborne Illness (by pathogen, \$2013)

\begin{tabular}{|c|c|c|c|c|c|c|c|}
\hline \multirow[b]{2}{*}{ Disease or Agent } & \multirow{2}{*}{$\begin{array}{l}\text { Illness } \\
\text { Incidence }^{1}\end{array}$} & \multicolumn{2}{|c|}{$\begin{array}{l}\text { Total Cost } \\
\text { (\$million) }\end{array}$} & \multicolumn{2}{|c|}{$\begin{array}{l}\text { Cost per } \\
\text { Resident }\end{array}$} & \multicolumn{2}{|c|}{$\begin{array}{c}\text { Cost } \\
\text { per Case }\end{array}$} \\
\hline & & Basic & Enhanced & Basic & Enhanced & Basic 1 & Enhanced \\
\hline \multicolumn{8}{|l|}{ Bacterial } \\
\hline$\overline{\text { Bacillus cereus }}$ & 2.01 & 0.20 & 0.32 & 0.03 & 0.06 & 174 & 282 \\
\hline Brucella spp. & 0.02 & 0.24 & 0.33 & 0.04 & 0.06 & 18,612 & 25,301 \\
\hline Campylobacter spp. & 26.73 & 30.85 & 161.69 & 5.37 & 28.16 & 2,010 & 10,533 \\
\hline Clostridium botulinum & $<0.01$ & 1.51 & 1.93 & 0.26 & 0.34 & $1,497,557$ & $1,918,446$ \\
\hline Clostridium perfringens & 30.56 & 7.55 & 9.96 & 1.31 & 1.73 & 430 & 568 \\
\hline STEC O157:H7 & 4.82 & 31.27 & 33.23 & 5.44 & 5.79 & 11,306 & 12,015 \\
\hline STEC non-0157 & 8.60 & 4.66 & 8.34 & 0.81 & 1.45 & 943 & 1,690 \\
\hline ETEC & 0.57 & 0.29 & 0.54 & 0.05 & 0.09 & 905 & 1,651 \\
\hline Other diarrheogenic E. coli, & 0.38 & 0.20 & 0.36 & 0.03 & 0.06 & 904 & 1,653 \\
\hline Listeria monocytogenes & 0.05 & 38.52 & 38.93 & 6.71 & 6.78 & $1,429,673$ & $1,444,751$ \\
\hline Salmonella, spp., Nontyphoidal & 32.28 & 87.99 & 258.92 & 15.32 & 45.09 & 4,747 & 13,969 \\
\hline S. enterica serotype Typhi & 0.04 & 0.09 & 0.32 & 0.02 & 0.06 & 4,111 & 13,999 \\
\hline Shigella, spp & 3.65 & 4.42 & 26.03 & 0.77 & 4.53 & 2,113 & 12,429 \\
\hline Staphylococcus aureus & 7.63 & 2.56 & 3.65 & 0.45 & 0.64 & 585 & 833 \\
\hline Streptococcus spp. Group A & 0.36 & 0.29 & 0.54 & 0.05 & 0.09 & 1,415 & 2,631 \\
\hline Vibrio cholerae, toxigenic & $<0.01$ & $<0.01$ & $<0.01$ & $<0.01$ & $<0.01$ & 1,577 & 2,729 \\
\hline Vibrio vulnificus & $<0.01$ & 2.01 & 2.01 & 0.35 & 0.35 & $3,148,286$ & $3,150,385$ \\
\hline Vibrio parahaemolyticus & 0.40 & 0.49 & 0.71 & 0.09 & 0.12 & 2,120 & 3,064 \\
\hline Vibrio spp., other & 0.20 & 0.57 & 0.68 & 0.10 & 0.12 & 4,908 & 5,850 \\
\hline Yersinia enterocolitica & 3.09 & 8.06 & 25.48 & 1.40 & 4.44 & 4,546 & 14,365 \\
\hline \multicolumn{8}{|l|}{ Parasitic } \\
\hline$\overline{\text { Cryptosporidium spp. }}$ & 9.24 & 11.65 & 18.88 & 2.03 & 3.29 & 2,197 & 3,560 \\
\hline Cyclospora cayetanensis & 0.10 & 0.06 & 0.10 & 0.01 & 0.02 & 1,003 & 1,835 \\
\hline Giardia intestinalis & 3.95 & 5.75 & 10.30 & 1.00 & 1.79 & 2,534 & 4,538 \\
\hline Toxoplasma gondii & 2.74 & 63.18 & 73.08 & 11.00 & 12.73 & 40,123 & 46,411 \\
\hline Trichinella spp. & $<0.01$ & 0.03 & 0.05 & $<0.01$ & 0.01 & 9,876 & 18,648 \\
\hline \multicolumn{8}{|l|}{ Viral } \\
\hline$\overline{\text { Astrovirus }}$ & 0.49 & 0.24 & 0.43 & 0.04 & 0.07 & 867 & 1,535 \\
\hline Hepatitis A virus & 0.04 & 0.90 & 0.94 & 0.16 & 0.16 & 40,363 & 42,195 \\
\hline Norovirus & 172.77 & 57.04 & 79.60 & 9.93 & 13.86 & 575 & 802 \\
\hline Rotavirus & 0.49 & 0.24 & 0.40 & 0.04 & 0.07 & 862 & 1,421 \\
\hline Sapovirus & 0.49 & 0.20 & 0.36 & 0.04 & 0.06 & 728 & 1,297 \\
\hline Known & & 361.08 & 758.13 & 62.88 & 132.02 & 2,017 & 4,236 \\
\hline Unknown & $1,214.46$ & 670.44 & 988.08 & 116.75 & 172.06 & 961 & 1,417 \\
\hline Total & & $1,031.53$ & $1,746.21$ & 179.62 & 304.07 & 1,177 & 1,992 \\
\hline
\end{tabular}

${ }^{1}$ Incidence per 10,000 residents. 
TABLE A51. Wyoming Cost per Case of Foodborne Illness (by pathogen, \$2013)

\begin{tabular}{|c|c|c|c|c|c|c|c|}
\hline \multirow[b]{2}{*}{ Disease or Agent } & \multirow{2}{*}{$\begin{array}{c}\text { Illness } \\
\text { Incidence }^{1} \\
\end{array}$} & \multicolumn{2}{|c|}{$\begin{array}{l}\text { Total Cost } \\
\text { (\$million) }\end{array}$} & \multicolumn{2}{|c|}{$\begin{array}{l}\text { Cost per } \\
\text { Resident }\end{array}$} & \multicolumn{2}{|c|}{$\begin{array}{c}\text { Cost } \\
\text { per Case }\end{array}$} \\
\hline & & Basic & Enhanced & Basic & Enhanced & Basic 1 & Enhanced \\
\hline \multicolumn{8}{|l|}{ Bacterial } \\
\hline$\overline{\text { Bacillus cereus }}$ & 2.01 & 0.02 & 0.04 & 0.04 & 0.06 & 180 & 300 \\
\hline Brucella spp. & 0.07 & 0.08 & 0.11 & 0.14 & 0.19 & 19,525 & 26,871 \\
\hline Campylobacter spp. & 26.73 & 3.28 & 17.66 & 5.64 & 30.31 & 2,108 & 11,338 \\
\hline Clostridium botulinum & $<0.01$ & 0.16 & 0.21 & 0.28 & 0.36 & $1,602,854$ & $2,058,427$ \\
\hline Clostridium perfringens & 30.56 & 0.81 & 1.08 & 1.39 & 1.86 & 456 & 607 \\
\hline STEC 0157:H7 & 4.02 & 2.83 & 3.01 & 4.85 & 5.17 & 12,084 & 12,868 \\
\hline STEC non-0157 & 7.17 & 0.41 & 0.75 & 0.70 & 1.29 & 975 & 1,799 \\
\hline ETEC & 0.57 & 0.03 & 0.06 & 0.05 & 0.10 & 938 & 1,762 \\
\hline Other diarrheogenic E. coli, & 0.38 & 0.02 & 0.04 & 0.04 & 0.07 & 938 & 1,764 \\
\hline Listeria monocytogenes & 0.04 & 3.63 & 3.68 & 6.23 & 6.31 & $1,534,861$ & $1,552,770$ \\
\hline Salmonella, spp., Nontyphoidal & 27.93 & 8.18 & 24.44 & 14.04 & 41.95 & 5,026 & 15,016 \\
\hline S. enterica serotype Typhi & $<0.01$ & $<0.01$ & $<0.01$ & $<0.01$ & $<0.01$ & 4,091 & 14,813 \\
\hline Shigella, spp & 1.93 & 0.25 & 1.50 & 0.43 & 2.58 & 2,207 & 13,380 \\
\hline Staphylococcus aureus & 7.63 & 0.27 & 0.39 & 0.47 & 0.68 & 612 & 886 \\
\hline Streptococcus spp. Group A & 0.36 & 0.03 & 0.06 & 0.05 & 0.10 & 1,469 & 2,811 \\
\hline Vibrio cholerae, toxigenic & $<0.01$ & $<0.01$ & $<0.01$ & $<0.01$ & $<0.01$ & 1,621 & 2,893 \\
\hline Vibrio vulnificus & $<0.01$ & 0.06 & 0.06 & 0.11 & 0.11 & $3,395,447$ & $3,397,752$ \\
\hline Vibrio parahaemolyticus & 0.12 & 0.02 & 0.02 & 0.03 & 0.04 & 2,238 & 3,279 \\
\hline Vibrio spp., other & 0.06 & 0.02 & 0.02 & 0.03 & 0.04 & 5,249 & 6,289 \\
\hline Yersinia enterocolitica & 3.09 & 0.87 & 2.78 & 1.49 & 4.78 & 4,817 & 15,467 \\
\hline \multicolumn{8}{|l|}{ Parasitic } \\
\hline$\overline{\text { Cryptosporidium spp. }}$ & 3.73 & 0.50 & 0.83 & 0.86 & 1.42 & 2,301 & 3,805 \\
\hline Cyclospora cayetanensis & $<0.01$ & $<0.01$ & $<0.01$ & $<0.01$ & $<0.01$ & 1,040 & 1,959 \\
\hline Giardia intestinalis & 2.47 & 0.38 & 0.70 & 0.65 & 1.20 & 2,637 & 4,848 \\
\hline Toxoplasma gondii & 2.74 & 6.82 & 7.93 & 11.71 & 13.60 & 42,700 & 49,607 \\
\hline Trichinella spp. & $<0.01$ & $<0.01$ & 0.01 & 0.01 & 0.01 & 10,204 & 19,866 \\
\hline \multicolumn{8}{|l|}{ Viral } \\
\hline$\overline{\text { Astrovirus }}$ & 0.49 & 0.03 & 0.05 & 0.04 & 0.08 & 895 & 1,632 \\
\hline Hepatitis A virus & 0.02 & 0.04 & 0.05 & 0.08 & 0.08 & 43,365 & 45,385 \\
\hline Norovirus & 172.77 & 6.07 & 8.59 & 10.41 & 14.74 & 603 & 853 \\
\hline Rotavirus & 0.49 & 0.03 & 0.04 & 0.04 & 0.07 & 881 & 1,497 \\
\hline Sapovirus & 0.49 & 0.02 & 0.04 & 0.04 & 0.07 & 753 & 1,380 \\
\hline Known & & 34.86 & 74.14 & 59.84 & 127.25 & 2,023 & 4,301 \\
\hline Unknown & $1,214.46$ & 71.45 & 107.00 & 122.63 & 183.64 & 1,010 & 1,512 \\
\hline Total & & 106.32 & 181.14 & 182.47 & 310.89 & 1,208 & 2,058 \\
\hline
\end{tabular}

${ }^{1}$ Incidence per 10,000 residents. 